\title{
A review of MRI findings in schizophrenia
}

\section{Citation}

Shenton, Martha E., Chandlee C. Dickey, Melissa Frumin, and Robert W. McCarley. 2001. "A Review of MRI Findings in Schizophrenia." Schizophrenia Research 49 (1-2) (April): 1-52. doi:10.1016/s0920-9964(01)00163-3.

\section{Published Version}

doi:10.1016/s0920-9964(01)00163-3

\section{Permanent link}

http://nrs.harvard.edu/urn-3:HUL.InstRepos:28520163

\section{Terms of Use}

This article was downloaded from Harvard University's DASH repository, and is made available under the terms and conditions applicable to Other Posted Material, as set forth at http:// nrs.harvard.edu/urn-3:HUL.InstRepos:dash.current.terms-of-use\#LAA

\section{Share Your Story}

The Harvard community has made this article openly available.

Please share how this access benefits you. Submit a story.

Accessibility 


\title{
A review of MRI findings in schizophrenia
}

\author{
Martha E. Shenton ${ }^{\star}$, Chandlee C. Dickey, Melissa Frumin, and Robert W. McCarley ${ }^{1}$ \\ Clinical Neuroscience Division, Laboratory of Neuroscience, Department of Psychiatry, Harvard \\ Medical School, Brockton, MA 02301, USA
}

\section{Abstract}

After more than 100 years of research, the neuropathology of schizophrenia remains unknown and this is despite the fact that both Kraepelin (1919/1971: Kraepelin,E., 1919/1971. Dementia praecox. Churchill Livingston Inc., New York) and Bleuler (1911/1950: Bleuler, E., 1911/1950. Dementia praecox or the group of schizophrenias. International Universities Press, New York), who first described 'dementia praecox' and the 'schizophrenias', were convinced that schizophrenia would ultimately be linked to an organic brain disorder. Alzheimer (1897: Alzheimer, A., 1897. Beitrage zur pathologischen anatomie der hirnrinde und zur anatomischen grundlage einiger psychosen. Monatsschrift fur Psychiarie und Neurologie. 2, 82-120) was the first to investigate the neuropathology of schizophrenia, though he went on to study more tractable brain diseases. The results of subsequent neuropathological studies were disappointing because of conflicting findings. Research interest thus waned and did not flourish again until 1976, following the pivotal computer assisted tomography (CT) finding of lateral ventricular enlargement in schizophrenia by Johnstone and colleagues. Since that time significant progress has been made in brain imaging, particularly with the advent of magnetic resonance imaging (MRI), beginning with the first MRI study of schizophrenia by Smith and coworkers in 1984 (Smith, R.C., Calderon, M., Ravichandran, G.K., et al. (1984). Nuclear magnetic resonance in schizophrenia: A preliminary study. Psychiatry Res. 12, 137-147). MR in vivo imaging of the brain now confirms brain abnormalities in schizophrenia.

The 193 peer reviewed MRI studies reported in the current review span the period from 1988 to August, 2000. This 12 year period has witnessed a burgeoning of MRI studies and has led to more definitive findings of brain abnormalities in schizophrenia than any other time period in the history of schizophrenia research. Such progress in defining the neuropathology of schizophrenia is largely due to advances in in vivo MRI techniques. These advances have now led to the identification of a number of brain abnormalities in schizophrenia. Some of these abnormalities confirm earlier postmortem findings, and most are small and subtle, rather than large, thus necessitating more advanced and accurate measurement tools. These findings include ventricular enlargement ( $80 \%$ of studies reviewed) and third ventricle enlargement (73\% of studies reviewed). There is also preferential involvement of medial temporal lobe structures ( $74 \%$ of studies reviewed), which include the amygdala, hippocampus, and parahippocampal gyrus, and neocortical temporal lobe regions (superior temporal gyrus) (100\% of studies reviewed). When gray and white matter of superior temporal gyrus was combined, $67 \%$ of studies reported abnormalities. There was also moderate evidence for frontal lobe abnormalities (59\% of studies reviewed), particularly prefrontal gray matter and orbitofrontal regions. Similarly, there was moderate evidence for parietal lobe abnormalities (60\% of studies reviewed), particularly of the inferior parietal lobule which includes both supramarginal and angular gyri. Additionally, there was strong to moderate evidence for subcortical abnormalities (i.e. cavum septi pellucidi-92\% of studies reviewed, basal ganglia- $68 \%$ of studies reviewed, corpus callosum - $63 \%$ of studies reviewed, and thalamus - $42 \%$ of studies reviewed), but more equivocal evidence for cerebellar abnormalities ( $31 \%$ of studies reviewed).

(C) 2001 Elsevier Science Ltd All rights reserved.

*Corresponding author. 1Co-corresponding author. martha_shenton@ @ hms.harvard.edu (M.E. Shenton PhD). 
The timing of such abnormalities has not yet been determined, although many are evident when a patient first becomes symptomatic. There is, however, also evidence that a subset of brain abnormalities may change over the course of the illness. The most parsimonious explanation is that some brain abnormalities are neurodevelopmental in origin but unfold later in development, thus setting the stage for the development of the symptoms of schizophrenia. Or there may be additional factors, such as stress or neurotoxicity, that occur during adolescence or early adulthood and are necessary for the development of schizophrenia, and may be associated with neurodegenerative changes. Importantly, as several different brain regions are involved in the neuropathology of schizophrenia, new models need to be developed and tested that explain neural circuitry abnormalities effecting brain regions not necessarily structurally proximal to each other but nonetheless functionally interrelated.

Future studies will likely benefit from: (1) studying more homogeneous patient groups so that the relationship between MRI findings and clinical symptoms become more meaningful; (2) studying at risk populations such as family members of patients diagnosed with schizophrenia and subjects diagnosed with schizotypal personality disorder in order to define which abnormalities are specific to schizophrenia spectrum disorders, which are the result of epiphenomena such as medication effects and chronic institutionalization, and which are needed for the development of frank psychosis; (3) examining shape differences not detectable from measuring volume alone; (4) applying newer methods such as diffusion tensor imaging to investigate abnormalities in brain connectivity and white matter fiber tracts; and, (5) using methods that analyze brain function (fMRI) and structure simultaneously.

\section{Keywords}

Schizophrenia; Magnetic resonance imaging; MRI; Psychosis; First episode schizophrenia

\section{Introduction}

Schizophrenia is a disabling mental disorder that affects close to $1 \%$ of the general population. Although the underlying pathology remains unknown, both Kraepelin (1919/1971) and Bleuler (1911/1950), who first described 'dementia praecox' and the 'schizophrenias', believed that brain abnormalities would ultimately be linked to the etiology of schizophrenia. This conviction was fueled by important inroads being made, during this same time period, into the neuropathology of Alzheimer's disease, Huntington's Chorea, Pick's disease, tertiary syphilis and some forms of epilepsy (see reviews in Benes, 1995; Bogerts et al., 1993a, 1999; Chua and McKenna, 1995; Harrison, 1999; Heckers, 1997).

In the late nineteenth and early twentieth centuries, efforts to identify post-mortem brain abnormalities, however, led to disappointing and frequently conflicting findings largely due to both the crude measurement tools available and to the expectation of finding large abnormalities when in fact such abnormalities are small and subtle (e.g. Alzheimer, 1897; Crichton-Browne, 1879; Haug, 1962; Hecker, 1871; Jacobi and Winkler, 1928; Kahlbaum, 1874; Southard 1910, 1915). Later, more methodologically controlled studies often led to negative findings (e.g. Dunlap, 1924; Rowland and Mettler, 1949). Consequently, progress as well as interest in the neuropathology of schizophrenia waned until the mid-1970s. And, while some researchers continued to study the brain and its functions in order to understand schizophrenia (e.g. Kety, 1959; MacLean, 1952; Stevens, 1973; Torrey and Peterson, 1974), the general consensus, as stated by Plum (1972), was that 'schizophrenia is the graveyard of neuropathologists'. 
Research investigating brain abnormalities in schizophrenia thus came to a near standstill and was not rekindled until the first computer assisted tomography (CT) study of schizophrenia (Johnstone et al., 1976), which confirmed earlier pneumonencephalography findings of enlarged lateral ventricles (e.g. Haug, 1962; Jacobi and Winkler, 1928). This one study, coupled with new post-mortem findings of Scheibel and Kovelman $(1979,1981)$, led to renewed interest and to a proliferation of CT, and later magnetic resonance imaging (MRI) studies of schizophrenia (see reviews by Buckley, 1998; Gur and Pearlson, 1993; Henn and Braus, 1999; Lawrie and Abukmeil, 1998; McCarley et al., 1999b; Nelson et al., 1998; Pearlson and Marsh, 1993, 1999; Pfefferbaum et al., 1990; Pfefferbaum and Zipursky, 1991; Rauch and Renshaw, 1995; Raz and Raz, 1990; Seidman, 1983; Shelton and Weinberger, 1986; Shenton, 1996; Shenton, 1996; Shenton et al., 1997, 2001; Weight and Bigler, 1998; Yurgelun-Todd and Renshaw, 1999), as well as to more methodologically rigorous post-mortem neurochemical and cellular studies (e.g. Benes, 1995; Bogerts et al., 1985, 1993a; Brown et al., 1986; Stevens, 1973).

These newer post-mortem findings reported limbic and temporal lobe abnormalities, including the amygdala-hippocampal complex and parahippocampal gyrus, and an increase in the temporal horn portion of the lateral ventricles, a region of cerebrospinal fluid (CSF) surrounding these structures (e.g. Benes et al., 1991; Bogerts, 1984; Bogerts et al., 1985; Brown et al., 1986; Colter et al., 1987; Crow et al., 1989; Falkai and Bogerts, 1986; Falkai et al., 1988; Jakob and Beckmann, 1989; Jeste and Lohr, 1989; Kovelman and Scheibel, 1984). Additionally, many of these findings were lateralized to the left side of the brain, leading to the speculation that schizophrenia may be an anomaly of cerebral development (e.g. Crow et al., 1989; Crow, 1990a,b, 1997, 1998). Other post-mortem findings reported smaller brains in schizophrenia (e.g. Brown et al., 1986), abnormalities in the cingulate gyrus (e.g. Benes and Bird, 1987; Benes et al., 1992), as well as abnormalities in the basal ganglia (e.g. Bogerts et al., 1985).

Beginning with the first MRI study of schizophrenia in 1984 by Smith and coworkers (1984), researchers were given a new and unique opportunity to evaluate specific brain regions, in vivo, in schizophrenia. (Parenthetically, CT technology, though adequate for visualizing lateral ventricles, did not allow for careful delineation of gray matter, which MRI affords.) In fact MRI studies conducted over the past 12 years, from 1988 to 2000, now provide some of the most compelling evidence for brain abnormalities in schizophrenia. These studies, discussed below, have shown enlarged lateral ventricles and specific gray matter volume reductions that are especially prominent in the superior temporal gyrus and in medial temporal lobe brain regions (amygdala, hippocampus, and parahippocampal gyrus), thus showing a convergence with the post-mortem findings. Frontal and parietal lobe volume reductions have also been reported, though less consistently, as have increased size of cortical sulci. Our own research has focused on temporal lobe structures as we think these brain regions are critically important to understanding the neuropathology of schizophrenia. We do not suggest, however, that the temporal lobe is the only brain region evincing brain abnormalities in schizophrenia. Instead, we recognize that brain regions within the temporal lobe are highly interconnected with other brain regions, including the frontal lobe (e.g. Fuster, 1989; Goldman-Rakic et al., 1984; Pandya and Seltzer, 1982; Pandya et al., 1981; Selemon et al., 1995; Vogt and Pandya, 1987; Vogt et al., 1987), and that normal brain function depends upon such interconnectivity. There is also evidence from both post-mortem and MRI findings to suggest that at least some of these brain abnormalities may originate from neurodevelopmental anomalies (e.g. Akbarian et al., 1993a,b; Benes, 1989; Heyman and Murray, 1992; Jakob and Beckmann, 1986, ${ }^{1989}$; Kikinis et al., 1994; Murray and Lewis, 1987: see also reviews in McCarley et al., 1999b; Shenton et al., 1992, ${ }^{1997}$, 2001; Weinberger, 1986, 1987, 1996). 
Below, we provide an integration and synthesis of MRI findings in schizophrenia. We propose that schizophrenia is best viewed as a brain disorder, with clinical symptoms, cognitive distortions, and course of illness largely determined by neuropathological substrates, with environmental factors playing a contributory role.

\section{Scope of the review}

This review builds upon our earlier review (Shenton et al., 1997) and its recent update (McCarley et al., 1999b). It includes more than 193 MRI findings published between 1988 and August, $2000 .^{2}$ The year 1988 was selected because it coincides with major improvements in both MRI hardware and software. We note that by selecting this cut-off, we exclude the early seminal study of Andreasen and coworkers (1986), as well as others.

The MRI findings included in the review are summarized in Table 1 which lists the findings by first author and year (e.g. Andreasen et al., 1990) for each brain region. The percent positive and negative findings for each region of interest (ROI) are also included. Here, as in the text, we count data sets only once. Thus MRI studies reporting data from the same subjects, but using different analyses, as for example a study describing the clinical correlates of previously reported MRI findings, were counted only once (e.g. Bilder et al., 1995;Goldberg et al., 1994;Nestor et al., 1993;O'Donnell et al., 1993; Young et al., 1991). The only exception made was for two studies, using the same subjects, which examined prefrontal cortex in one study, followed by a more refined parcellation of prefrontal cortex in the second study (e.g. Gur et al., 1998b,2000b;Wible et al., 1995,1997). Here we treated the parcellation data as a separate measure from the whole prefrontal lobe data. Additionally, in follow up studies of first episode patients, we included only new brain findings in Table 1 and did not include in the tally findings reported previously (e.g. DeLisi et al., 1991,1992,1997).

In addition to the summary table (Table 1), we include a second table (Table 2) which lists the studies alphabetically and which includes subject sample size. A third table (Table 3) provides more detailed information for each of the medial temporal lobe regions. Finally, we include a fourth (Table 4) of first episode studies, and a fifth table (Table 5) that provides information specific to follow up studies. We chose a tabular presentation of MRI findings because our goal was, first, to include the largest number of studies reported in the literature, second, to present it in an easily readable format (Table 1-Table 5), and third, to provide a summary of the most compelling and consistent findings.

A possible alternative would have been to provide a meta-analysis that weights each study based on subject N and effect size (e.g. Glass et al., 1981; Gøtzsche 2000; Hunter and Schmidt 1990; Petitti, 1994; Rosenthal and Rubin, 1979, 1982, 1986; Wright et al., 2000). We chose not to use this approach for several reasons. First, information needed to compute effect size was not always available in individual studies and would, therefore, have necessitated including only a small subset of studies. As we wanted to provide a broad review of the literature, a metaanalysis approach was therefore rejected. Second, MR scanner technology has changed rapidly over the past decade, and studies are therefore not comparable. Thus to weight all studies equally seemed premature given the state of the field at the present time. Third, the methods and extent of detailed information to define ROIs varies tremendously over studies, again suggesting that the information is not easily comparable. Fourth, there is a large difference in moderator variables across studies (i.e. gender, chronicity, age of onset, medication, parental socio-economic status, etc.), once again calling into question the direct comparability of one

\footnotetext{
${ }^{2}$ Note, for cerebellum, cavum septi pellucidi, and corpus callosum findings we include studies prior to 1988 as the methodology for evaluating these brain regions did not change as dramatically as it did for other brain regions (e.g. prior to and after 1988 one midsagittal slice was primarily used to measure the corpus callosum).
} 
study with another. And, finally, meta-analysis is beset with difficulties in estimating the number of negative findings that do no get published, i.e. the 'file drawer' problem (Rosenthal, 1987). We thus concluded that meta-analysis is not appropriate for a review of this broad scope, which covers more than a decade of published MRI findings in schizophrenia. ${ }^{3}$

For heuristic purposes, we group the studies by region of interest. We begin with whole brain and ventricular studies, followed by a review of temporal, frontal, parietal, and occipital findings. This is then followed by other brain region findings, including the cerebellum, basal ganglia, thalamus, corpus callosum, and septi pellucidi studies. We then review MRI morphometric findings in first episode schizophrenia and in longitudinal studies. We focus on first episode patients because they are free of confounds such as long term effects of neuroleptic medications and illness chronicity. This group of patients is also important because they afford an opportunity to examine changes over time to determine whether or not abnormalities are extant at the time of the first episode, thus lending more credence to the theory that schizophrenia has a neurodevelopmental etiology. We conclude with a synthesis of MRI findings and discuss the direction of future imaging studies that we think will lead to a further understanding and clarification of the specific brain regions and functions that are disrupted in schizophrenia and schizophrenia related disorders.

\section{Evidence for structural brain abnormalities in schizophrenia}

\subsection{Whole brain volume and ventricle findings}

3.1.1. Whole brain volume-As early as 1801 with Pinel's work (Pinel, 1801), and later Kretchmer's (1925), there has been an interest in brain/cranium size in mental illness. Initially, this interest was based on the presumed association between brain size and mental illness, socioeconomic status, IQ, and cognitive deficits. More recently, some researchers have hypothesized that smaller brain size may be related to perinatal complications or to neurodevelopmental abnormalities, or both, though the interpretation of these findings remains unclear (see for example Andreasen et al., 1986; letters to the editor by Pearlson et al., 1991, and by Zipursky et al., 1991; see also meta-analysis of post-mortem, MRI, and CT studies by Ward et al., 1996).

Whole brain volumes are also computed to control for brain/head size when investigating smaller, specific brain regions. For example, if smaller hippocampi are identified in one subject relative to another, it is important to determine whether or not the smaller size is due to smaller overall brain size or to disproportionately smaller hippocampi, independent of brain size. Methods to measure brain size have included measures of intracranial cavity contents (gray matter, white matter, and CSF), as well as measures of gray and white matter that include or exclude the cerebellum. Additionally, given the large individual variation in head/brain size, investigators have sought an appropriate correction factor, believing that such variation needs

\footnotetext{
${ }^{3}$ We chose, nonetheless, to exclude studies that: (1) did not appear in peer reviewed journals (study N not tallied); (2) had 10 or fewer subjects in the main subject groups (e.g. Degreef et al., 1991; Kegeles et al., 2000; Kulynych et al., 1997; Levitt et al., 1994; Torres et al., 1997); (3) did not include a control group (e.g. Corson et al., 1999b; Jeste et al., 1998; Levitan et al., 1999; Maher et al., 1995, 1998; Nair et al., 1997; Scheller-Gilkey and Lewine, 1999; Seidman et al., 1994; Waldo et al., 1994; Wassink et al., 1999); (4) focused primarily upon relatives of patients with schizophrenia (e.g. Honer et al., 1994; Seidman et al., 1997, 1999); (5) relied upon relaxation times, qualitative ratings rather than quantitative measures such as volume, or used only a small number of slices to evaluate brain regions of interest (e.g. Aylward et al., 1994; Dasari et al., 1999; DeMyer et al., 1988; Friedman et al., 1999; Galderisi et al., 2000; Lewine et al., 1995; Lieberman et al., 1992, 1993; Nasrallah et al., 1997; Pfefferbaum et al., 1999; Sharma et al., 1997; Symonds et al., 1999; Williamson et al., 1991, 1992); (6) focused primarily on children or adolescents with schizophrenia (e.g. Friedman et al., 1999; Jacobsen et al., 1996, 1997, 1998; Nicolson and Rapoport, 1999; Nopoulos et al., 1998a; Rapoport et al., 1997, 1999) or (7) used unusual analyses such as a gyrification index (Kulynych et al., 1997), nonlinear deformations applied to schizophrenia (e.g. Gaser et al., 1999), cumulative anatomical risk factors (Leonard et al., 1999), or other measures not easily grouped together (e.g. Bartley et al., 1993;Bartzokis et al., 1996; Buckley et al., 1999; Galderisi et al., 1999; Guerguerian and Lewine, 1998; Kawasaki et al., 1997; Nopoulos et al., 1998b; Tiihonen et al., 1998). The latter studies are, however, discussed when appropriate. (The $n=50$ studies listed here are not included in the tally in Table 1.)
} 
to be accounted for particularly when evaluating smaller brain ROIs (e.g. Arndt et al., 1991; Flaum et al., 1994; Mathalon et al., 1993).

From our review of 50 MRI studies of whole brain volume, we note that only $11(22 \%)$ report differences between patients with schizophrenia and control subjects, whereas $39(78 \%)$ report negative findings (Table 1). There is, nonetheless, some evidence to suggest that small reductions in brain size (i.e. small effect size), may be evident in schizophrenia. For example, Ward and coworkers (1996) concluded that there are small yet statistically significant reductions in brain size and ICC in schizophrenia (effect size approximately $0.18-0.20$ ). The clinical importance of these findings, however, is unknown, although Jacobsen and coworkers (1996), who reported smaller brain volume in patients with childhood schizophrenia, suggest that brain volume reduction might be related to more 'severe genetic and/or environmental neurodevelopmental insult, leading to earlier onset'. These latter findings suggest that whole brain volume reduction, while not generally observed in schizophrenia, may be evident in a subset of cases, and thus it may be too early to conclude that small brain volume differences, or small effect sizes, are inconsequential.

In summary, most MRI studies do not report statistically significant differences in brain size between patients with schizophrenia and normal controls. There is, however, enormous individual variation in head/brain size in the general population and confounds such as age, gender, socioeconomic status, and possible nutritional deficits need to be more carefully considered. These confounds, in addition to MRI methodological problems, reviewed above, could easily have obscured small but important differences. Further research is thus needed before definitive conclusions can be drawn concerning the importance and meaning of small reductions in brain size in a subset of patients diagnosed with schizophrenia.

\subsubsection{Ventricles}

3.1.2.1. Lateral ventricles: Initially, ventricular enlargement was measured by creating casts of the ventricles from post-mortem brains. The first in vivo studies were conducted using invasive pneumonence-phalography techniques, followed many years later with more noninvasive CT studies (see introduction for references). Shelton and Weinberger (1986) reviewed CT findings in schizophrenia and found that over $75 \%$ of these studies report enlarged lateral ventricles. Enlarged lateral ventricles are, however, not specific to schizophrenia as they occur in many disorders, including Alzheimer's disease, hydrocephalus, and Huntington's Chorea. Chemotherapy agents and corticosteroids may also cause enlarged lateral ventricles.

Nonetheless, lateral ventricular enlargement may indicate tissue loss in surrounding brain regions or it may indicate a failure in development, and for these reasons such findings are of great interest to schizophrenia researchers.

In our review of 55 MRI studies, 44 (80\%) studies report enlarged lateral ventricles, thus making it one of the most robust MRI findings in the literature (Table 1). Moreover, even studies not reporting lateral ventricle enlargement have reported enlargement in the temporal horn portion of the lateral ventricular system (e.g. Shenton et al., 1992-listed as a negative finding in Table 1). This enlargement was most prominent in the left side lateral ventricle.

Enlarged temporal horns of the lateral ventricles, with left-sided prominence, have also been reported in several other MRI studies (e.g. Becker et al., 1990; Bogerts et al., 1990; Dauphinais et al., 1990; Degreef et al., 1990; DeLisi et al., 1991; Johnstone et al., 1989; Kawasaki et al., 1993; Niemann et al., 2000; Roy et al., 1998; Shenton et al., 1992). These MRI findings are also consistent with several post-mortem findings which have reported both reduced volume in the amygdala-hippocampal complex and increased temporal horn volume (e.g. Bogerts et al., 1985; Brown et al., 1986; Colter et al., 1987; Crow et al., 1989; Falkai and Bogerts, 1986; Falkai et al., 1988; Jakob and Beckmann, 1989; Jeste and Lohr, 1989; Kovelman and 
Scheibel, 1984). These findings are also consistent with a post-mortem study of Alzheimer's patients and schizophrenic patients by Crow et al. (1989), which showed enlarged temporal horn region of the lateral ventricles in schizophrenic patients compared with Alzheimer patients. Moreover, Suddath and coworkers (1989) reported a correlation between reduced left temporal lobe gray matter and increased CSF volume in the left temporal horn in the ill twin of monozygotic twins discordant for schizophrenia, again emphasizing that tissue in the region surrounding temporal horn may be reduced in schizophrenia. Fig. 1 provides an illustration of the ventricular system showing the temporal horn of the lateral ventricles, as well as other parts of the ventricular system.

3.1.2.2. Third and fourth ventricles: In 33 MR studies of third ventricle, 24 (73\%) of the findings are positive, and nine (27\%) are negative (Table 1). This is in contrast to one of five (20\%) MRI studies of fourth ventricle being positive and four (80\%) studies being negative. The proximity of the third ventricle to the thalamus is likely important, as increased fluid in the third ventricle may be related to reduced thalamic volume in schizophrenia (see discussion below). Moreover, the vast interconnections between the thalamus and most other brain regions has led to the thalamus being described as the major region of abnormality in schizophrenia (see Andreasen's paper describing the 'cognitive dysmetria hypothesis' of schizophrenia which highlights the thalamus as a critical site underlying the neuropathology and clinical and cognitive dysfunctions in schizophrenia-Andreasen et al., 1999). An enlarged third ventricle may thus be suggestive of either aberrant development of the thalamus or neurodegeneration of this critical structure (see thalamic and cerebellum sections, below).

\subsection{Temporal lobe findings}

3.2.1. Introduction-Kraepelin (1919/1971) believed that delusions and auditory hallucinations were the result of temporal lobe abnormalities. Southard $(1910,1915)$ also noted abnormalities in the temporal lobe in post-mortem brains of patients diagnosed with schizophrenia. He was particularly impressed with gross neuroanatomical abnormalities in the cortex of the left temporal lobe which he, too, thought were related to the symptom of auditory hallucinations.

Until recently, however, there has been little empirical evidence to support these earlier speculations. The first MRI study to evaluate superior temporal gyrus was conducted by Barta et al. (1990). Work in our own laboratory has focused primarily on temporal lobe abnormalities, specifically the superior temporal gyrus (STG), including Heschl's gyrus and planum temporale, as well as medial temporal lobe structures. We hypothesize that the hallucinatory symptoms and cognitive deficits in schizophrenia may be associated with disturbances in auditory and language processing functions, which likely also involve brain regions important for associative and retrieval processes in memory. These processes involve interconnections between the hippocampus, amygdala, parahippocampal gyrus, and STG, as well as other neocortical brain regions (e.g. McCarley et al., 1993, 1996; Nestor et al., 1993, 1997; Niznikiewicz et al., 2000; O'Donnell et al., 1993; Shenton et al., 1992). More specifically, the hippocampus and adjacent parahippocampal gyrus and entorhinal cortex are thought to be involved in the laying down and retrieval of memory through interconnections with neocortical regions (STG perhaps for verbal memories; e.g. Squire and Zola-Morgan, 1991; Squire, 1992; see also Wible et al., 1997), while the amygdala is thought to be importantly involved in the emotional valence given to stimuli and memories, thus serving to facilitate encoding (e.g. Gloor, 1986).

Below we review the findings for whole temporal lobe, followed by medial temporal lobe (amygdala-hippocampal complex, parahippocampal gyrus) and neocortical temporal lobe structures (superior temporal gyrus [STG], including planum temporale [PT] and Heschl's 
gyrus). Fig. 2 provides a lateral view of the brain, where the three main gyri are illustrated: the STG, which lies closest to the Sylvian fissure, superior to two parallel gyri, the middle temporal gyrus and the inferior temporal gyrus. Medial temporal lobe structures run along the longitudinal or parallel axis in the medial portion of the temporal lobe and include the hippocampus and adjacent amygdala (the parahippocampal gyrus lies inferior to these structures). The PT and Heschl's gyrus lie along the surface of the STG, not visible in Fig. 2. These brain regions are discussed below, where we review more than 137 MRI studies conducted since 1988 .

3.2.2. Whole temporal lobe findings-Of $51 \mathrm{MRI}$ studies evaluating the volume of whole temporal lobe, 31 (61\%) report smaller temporal lobe volume, while 20 (39\%) report negative findings (Table 1). Methodological differences likely contribute to the conflicting findings. For example, some studies relied upon a small number of thicker slices to estimate overall temporal lobe volume (e.g. Kelsoe et al., 1988;Rossi et al., 1989a), while other studies relied upon a large number of thin slices to estimate overall temporal lobe volume, thus allowing for more accurate volume estimations (e.g. Gur et al., 1998b;Shenton et al., 1992). Other methodological differences between studies include: (1) different landmarks to define the boundaries of the temporal lobe; (2) measurement of gray matter versus gray and white matter combined; and (3) interpolations over slices with no gaps versus interpolations over slices with gaps between slices. Again, such methodological differences are relevant to all MRI studies in schizophrenia but become more problematic when evaluating brain regions where differences between groups are likely quite small.

Of note, in our 1997 review (Shenton et al., 1997), 55\% of the 31 MRI studies showed smaller temporal lobe volume in schizophrenia, while $45 \%$ of the studies reported no differences. The increase in more positive findings $(60 \%)$ is likely the result of studies using thinner slices, stronger magnets, and more uniform segmentation. It is nonetheless important to note that overall temporal lobe volume may be less informative with respect to the neuropathology of schizophrenia than volume differences in specific structures within the temporal lobe (see discussion below). Fig. 3 illustrates an outline of the temporal lobe, manually drawn on a 1.5$\mathrm{mm}$ coronal MR image (viewer's left is subject's right).

Of the studies evaluating asymmetry differences, all reported right > left temporal lobe volume in both patients and controls (Becker et al., 1990; Bilder et al., 1994; Blackwood et al., 1991; Johnstone et al., 1989; Kawasaki et al., 1993; Rossi et al., 1989a, 1990, 1991; Suddath et al., 1989; Swayze et al., 1992). These findings are consistent with right > left temporal lobe volumes from data in the normal population, as the Sylvian fissure extends further posteriorly on the left, but is steeper on the right due to the larger area of the posterior vertical ramus (e.g. Geschwind and Levitsky, 1968; LeMay and Kidd, 1978; LeMay 1986).

3.2.3. Medial temporal lobe findings-Medial temporal lobe structures include the amygdala-hippocampal complex and the parahippocampal gyrus. The impetus for much of this work comes from post-mortem studies demonstrating tissue loss in these regions, and a corresponding volume increase in the temporal horn of the lateral ventricles which surround these structures (e.g. Benes et al., 1991; Bogerts, 1984; Bogerts et al., 1985; Brown et al., 1986; Colter et al., 1987; Crow et al., 1989; Falkai and Bogerts, 1986; Falkai et al., 1988; Jeste and Lohr, 1989). Fig. 3 illustrates the spatial relationship of these structures and their proximity to the STG. The outline of the amygdala (almond shape) can be seen on the viewer's right (subject left). Below the amygdala (viewer's right), the parahippocampal gyrus is outlined.

Most MRI studies combine the amygdala and hippocampus into the amygdala-hippocampal complex because it is difficult to separate them on coronal slices (e.g. Becker et al., 1990, 1996; Bogerts et al., 1990, 1993b; Breier et al., 1992; Chua and McKenna, 1995; DeLisi et al., 
1988, ${ }^{1991}$; Hirayasu et al., 1998; Kawasaki et al., 1993; Lawrie et al., 1999; Shenton et al., 1992). There has nonetheless generally been an attempt made to delineate an anterior portion which is primarily amygdala, and a posterior portion which is primarily hippocampus. A small number of recent studies have made separate measurements of these two brain regions (e.g. Staal et al., 2000). Given that these structures have quite different functions (i.e. hippocampus with more immediate aspects of memory and the amygdala with the emotional valence given to stimuli), both of which may be implicated in schizophrenia pathology, it is important to continue to delineate these structures in future studies.

Table 1 lists 49 MRI studies that have evaluated medial temporal lobe structures, with $74 \%$ reporting positive findings and $26 \%$ reporting negative findings. These findings are consistent with post-mortem findings and are among the most robust MRI findings in schizophrenia. Table 3 lists, by author, the main findings for each study. Fig. 4 illustrates the increase of CSF in the left temporal lobe horn of the lateral ventricle, in the region of the amygdala, in a patient with schizophrenia as compared to a normal control (viewer right; see arrow).

Volume reductions in the amygdala-hippocampal complex and parahippocampal gyrus are thus present in chronic patients. Volume reductions in the amygdala-hippocampal complex are also evident in first episode patients with schizophrenia (e.g. Bogerts et al., 1990; Copolov et al., 2000; Hirayasu et al., 1998; Lawrie et al., 1999; Velakoulis et al., 1999). The specificity of these findings to schizophrenia are, however, more equivocal as reduced amygdalahippocampal complex, particularly posteriorly, has been reported to be abnormal in first psychotic episode bipolar patients (e.g. Hirayasu et al., 1998; Velakoulis et al., 1999), in chronic mood disordered patients (e.g. Altshuler et al., 1998; Drevets et al., 1992; Mayberg, 1993; see also reviews of MR studies in affective disorder by Norris et al., 1997; Steffens and Krishnan, 1998; Soares and Mann, 1997), in normal elderly persons (e.g. Golomb et al., 1993), in patients with Cushing's syndrome (e.g. Starkman et al., 1992), as well as in patients diagnosed with post traumatic stress disorder (e.g. Bremner et al., 1995; Gurvits et al., 1996). Thus, it remains to be determined whether or not hippocampal volume is a non-specific risk factor for developing psychiatric illness, is related to cognitive impairments, including memory, in schizophrenic patients, as suggested by several investigators (e.g. Goldberg et al., 1994; Nestor et al., 1993, 1997; Weinberger et al., 1992), and, or, whether such anomalies are familial and perhaps represent a marker of vulnerability, as suggested by several recent studies of family members of patients with schizophrenia (e.g. Adler et al., 1998; Callicott et al., 1998; Seidman et al., 1999). Weinberger (1999), in fact, suggests that 'genes involved in the development and maintenance of hippocampal circuitry or in the expression of molecules that mediate certain aspects of neural plasticity' in the hippocampus, may play a critical role in the genetic predisposition to schizophrenia.

The implications of bilateral versus lateralized findings are also unknown. Many post-mortem findings of medial temporal lobe structures suggest more left lateralized involvement (see references in Introduction). In a recent meta-analysis of 18 studies, Nelson and coworkers (1998) concluded that there was only a $4 \%$ bilateral volume difference between patients with schizophrenia and controls. However, in our review of 49 MRI studies, we note a large number of studies that demonstrate left-lateralized findings for the amygdala-hippocampal complex, particularly in male patients (e.g. Barta et al., 1990, 1997a; Bogerts et al., 1990, 1993b; Breier et al., 1992; DeLisi et al., 1988; Hirayasu et al., 1998; Kawasaki et al., 1993-parahippocampal gyrus only; McNeil et al., 2000; Ohnuma et al., 1997; Razi et al., 1999; Rossi et al., 1994a; Shenton et al., 1992; Stefanis et al., 1999; Velakoulis et al., 1999; Woodruff et al., 1997b).

With respect to left lateralized findings, of particular interest is the study by Stefanis and coworkers (1999) that reported reduced left hippocampal volume in patients with schizophrenia who had a history of severe pregnancy and birth complications and no familial history of 
schizophrenia. This was not true for patients with familial schizophrenia who were free from such complications. Additionally, McNeil and coworkers (2000) reported a relationship between smaller bilateral hippocampi and labor and delivery complications in the schizophrenic twin of monozygotic twins discordant for schizophrenia. They further noted a relationship between smaller left hippocampi and prolonged labor in the ill twin. These findings suggest that, at least among some patients with schizophrenia, a neurodevelopmental factor may play a critical role in the etiology of the illness.

In another twin study of monozygotic twins discordant for schizophrenia, Suddath and coworkers $(1989,1990)$ reported bilateral volume reductions in the hippocampus in the ill twin compared to the well twin. Finally, Velakoulis and coworkers (1999) noted bilateral hippocampal volume reduction in both chronic and first episode patients. However, when the first episode patients were evaluated separately from the chronic patients, the left hippocampus was smaller in both the schizophrenic and affective groups. Additionally, smaller right hippocampal volume was correlated with increased age and longer duration of illness in chronic patients, suggesting that bilateral reductions may be associated with poorer outcome and neurodegeneration.

These findings suggest that a neurodevelopmental abnormality, possibly associated with complications in utero or at birth, may contribute to hippocampal abnormalities in schizophrenia. This explanation gains further support from findings suggesting that the hippocampus and subiculum are adversely affected by both pre- and perinatal hypoxia. Much of this work comes from animal studies (e.g. McEwen and Magarinos, 1997; Mizoguchi et al., 1992; Uno et al., 1989; Watanabe et al., 1992). For example, studies of placental insufficiency in the guinea pig, induced by unilateral uterine artery ligation, have shown a $26 \%$ hippocampal volume reduction compared to control animals, further suggesting that complications during pregnancy may be a predisposing factor for hippocampal damage (Copolov et al., 2000). Such findings hark back to Mednick and McNeil's (1968) hypothesis that pregnancy complications resulting from hypoxia in the developing fetus represent a vulnerability factor that predispose individuals to developing schizophrenia (see also discussion of 'two-hit' model below in Section 4 Neurodevelopmental versus Neurodegenerative Processes: Evidence from First Episode and Longitudinal Studies, 4.1 the Issues).

In summary, findings of medial temporal lobe volume reductions in schizophrenia, particularly of the amygdala-hippocampal complex, suggest that at least a subgroup of patients diagnosed with schizophrenia may have experienced excitotoxic damage to the hippocampus either in utero, at birth, or later. Moreover, while excitotoxicity, steroid toxicity (e.g. related to adult and prenatal stress), and hypoxia may lead to neuronal damage in the hippocampus, genetic factors may also be contributory. Further research is needed to examine the relationship between birth history and MRI findings of reduced hippocampal volume. It would also be of interest to determine whether or not such abnormalities are related to other pre- and perinatal abnormalities. One study by Kwon et al. (1998) suggests such a relationship. These investigators reported a correlation between hippocampal volume reduction and enlarged cavum septi pellucidi in male patients with chronic schizophrenia (see section below on cavum septi pellucidi abnormalities). Further, given the lateralized findings in first episode patients (see above), it would be of interest to study patients longitudinally to determine whether or not bilateral neurodegenerative processes are evident in patients who have a more chronic course. By determining the timing of brain changes, neuroprotective agents might be developed to prevent further neurodegenerative processes. This would seem important given recent findings suggesting plasticity and reversal of hippocampal damage in humans (e.g. Eriksson et al., 1998). 
3.2.4. Superior temporal gyrus (STG) findings-The superior temporal gyrus (STG) is the temporal gyrus that is just ventral to the Sylvian fissure (see Fig. 2). Along the superior surface of the STG is Heschl's gyrus, which contains primary auditory cortex. More posteriorly, and on the left, is part of Wernicke's area (Brodman's area 41 and 42), which includes the planum temporale (PT), a brain region thought to be a neurological substrate of language (e.g. Penfield and Roberts, 1959;Penfield and Perot, 1963;Wernicke, 1874). Of particular interest, disordered thinking has been elicited in electrical stimulation studies of the posterior portion of STG in patients undergoing neurosurgery for epilepsy (e.g. Haglund et al., 1992). Studies of electrical stimulation to more anterior portions of STG have resulted in complex auditory hallucinations and verbal memories (Penfield and Roberts, 1959). These findings are similar to the hallmark symptoms of schizophrenia which include verbal memory deficits, disordered thinking, and auditory hallucinations, thus making this brain region of particular interest to schizophrenia researchers.

Of 15 MRI studies that evaluated STG gray and white matter volume combined, 10 (67\%) report STG volume reductions in schizophrenia (Table 1). Of the 12 MRI studies that evaluated just STG gray matter volume, all $12(100 \%)$ report volume reduction (see also Pearlson 1997a for a review). These findings underscore the importance of evaluating STG gray matter separately.

The first two MRI studies of STG reported left STG volume reductions, thus confirming Southard's $(1910,1915)$ early anecdotal findings of 'suprasylvian atrophy' and a 'withering away' of left STG in post-mortem brains of schizophrenia. In the first study, Barta and coworkers (1990) reported an 11\% left STG volume reduction that was correlated, anteriorly, with auditory hallucinations. The second study, from our laboratory (Shenton et al., 1992), reported a $15 \%$ left STG volume reduction that was correlated, posteriorly, with increased thought disorder. [Parenthetically, the latter correlation with thought disorder has been confirmed in several other studies (e.g. Barta et al., 1997a; Holinger et al., 1999; Marsh et al., 1997; Menon et al., 1995; Vita et al., 1995).]

More recently, Hirayasu et al. (1998) reported STG gray matter volume reduction in first episode patients with schizophrenia compared with controls, but not in first episode psychotic bipolar patients. Velakoulis et al. (1999) reported similar findings. Moreover, Dickey et al. (1999) reported STG gray matter reduction in untreated and unmedicated subjects from the community diagnosed with schizotypal personality disorder. These findings suggest the specificity of STG abnormalities to schizophrenia and schizophrenia spectrum disorders. The exception to these findings is a study by Pearlson and coworkers (1997b) which reported smaller left amygdala and right anterior STG in bipolar patients, but not in schizophrenic patients. However, patients with schizophrenia could still be differentiated from bipolar patients by differences in posterior STG posterior asymmetry and by smaller left anterior STG and right amygdala.

There is also some suggestion that in early stages of the disorder, left STG volume reductions may be reversible (Keshavan et al., 1998b). This finding is based on a 1 year follow-up of only 11 patients with schizophrenia treated with neuroleptics, although if confirmed in a larger sample, it would strongly suggest that pharmacological treatment interventions may be critical to halting and perhaps reversing such brain anomalies.

With respect to correlations with other brain regions, it is interesting to note that volume reduction in the hippocampus, amygdala, parahippocampal gyrus and STG is highly intercorrelated (e.g. Shenton et al., 1992), suggesting that regions that are functionally interrelated also evince volume reductions. Wible and coworkers (1995) showed correlations between left prefrontal gray matter and left amygdala-hippocampal complex, left 
parahippocampal gyrus, and left STG. Moreover, Nestor et al. (1993) observed an association between poor performance on verbal memory, abstraction, and categorization, and volume reduction in both the parahippocampal gyrus and posterior STG. These cognitive deficits are consistent with the function of these brain regions and their role in associative links in memory, particularly verbal memory. Nestor et al. (1997) interpreted these findings as indicative of a dysfunctional semantic system in schizophrenia.

Additionally, Flaum et al. (1995) reported that positive psychotic symptoms were correlated with whole STG volume reduction. Finally, Holinger et al. (1999) reported a right STG volume reduction in left-handed male patients compared to left-handed male controls that was associated with increased formal thought disorder. These findings are thus consonant with studies showing functional abnormalities in P300 in schizophrenia (e.g. McCarley et al., 1993), with positron emission tomography (PET) studies (see review in Pearlson, 1997a), with attentional processing deficits (e.g. Posner et al., 1988), and with the theory that abnormal asymmetries in the brain represent a genetic/neurodevelopmental abnormality in schizophrenia (e.g. Crow et al., 1989; Crow, 1990b). Such cerebral anomalies likely set the stage for disruptions in functions subserving memory and associations involving language and speech, particularly in the left hemisphere (e.g. Shenton et al., 1992; Wible et al., 1997).

3.2.5. Planum temporale (PT) findings-Findings from STG studies in schizophrenia have led to more focused evaluations of the PT, a brain region critical for language and speech processing (e.g. Galaburda et al., 1978, 1987; Galaburda and Sanides, 1980; Geschwind and Levitsky, 1968). There is also a well documented left greater than right asymmetry in PT in two thirds of normal brains. As this asymmetry is evident at between 29 and 31 weeks gestation, abnormalities in PT asymmetry may be indicative of a disruption in hemisphere lateralization in neurodevelopment (Chi et al., 1977).

Shapleske et al. (1999) provide a meta-analysis of 21 MRI studies of PT in normals and seven MRI studies of PT in patients with schizophrenia. These investigators concluded that even with the different methods for measurement, there is a left asymmetry in normals that is much reduced in patients with schizophrenia. They concluded that this difference was due primarily to the relatively larger right PT in patients with schizophrenia compared to control subjects. Our own review of 10 MRI PT studies in schizophrenia suggests that of six (60\%) studies reporting PT abnormalities in schizophrenia, five reported a reversal of left greater than right PT asymmetry (Barta et al., 1997a; Hirayasu et al., 2000; Kwon et al., 1999; Petty et al., 1995; Rossi et al., 1992), and one reported less asymmetry anteriorly and more asymmetry posteriorly in patients with schizophrenia compared to controls (DeLisi et al., 1994). In addition, volume reduction in left PT has also been reported (e.g. Barta et al., 1997a; Hirayasu et al., 2000; Kwon et al., 1999). Additionally, Kwon et al. (1999) reported a correlation between left PT volume reduction and higher scores on the Suspiciousness/Persecution subscale of the Positive and Negative Symptom Scale (PANSS; Kay et al., 1986). PT asymmetry has also been associated with formal thought disorder (e.g. Petty et al., 1995; Rossi et al., 1994b).

In summary, PT findings in schizophrenia are important as they are likely related to disturbances in language and thought. These findings would likely be more consistent if the measurements (e.g. surface and volume) and the neuroanatomical landmarks for defining this brain region were more uniform. Despite these methodological limitations, it is clear that schizophrenia is likely a disorder with marked abnormalities in the left hemisphere, particularly in the left temporal lobe and in regions such as the PT which are important for language processing and are also left lateralized. Crow has postulated the 'lateralization hypothesis of schizophrenia' (Crow et al., 1989), where he emphasizes abnormal neural development of brain lateralization in the etiology of schizophrenia. Crow further notes that the left hemisphere may be more vulnerable to insult or damage because it develops later than the right hemisphere (see 
also Geschwind and Galaburda, 1985). It is not known, however, whether such disturbances result from genetic or exogenous insults that occur during fetal development.

Pearlson and coworkers (1996) further suggest that PT abnormalities in schizophrenia are related to heteromodal association cortex abnormalities, which they view as the primary site for neuroanatomical disturbances in schizophrenia. These regions include posterior portions of STG, dorsolateral prefrontal cortex, and the inferior parietal lobule. Finally, PT abnormalities are present at first episode (e.g. Hirayasu et al., 2000), but are not present in first psychotic episode bipolar patients. Thus far PT abnormalities have not been reported in any other psychiatric disorders although such abnormalities are reported in individuals with dyslexia, who show a somewhat different pattern of abnormalities. Future studies are needed which use more standardized methods in order to determine whether or not particular PT abnormalities are specific to schizophrenia.

\subsection{Frontal lobe}

The prefrontal cortex is one of the mostly highly complex and evolved neocortical regions of the human brain, comprising close to $30 \%$ of neocortex in humans, with both afferent and efferent connections to all other areas of cortex, as well as to limbic and basal ganglia structures (Fuster, 1989; Goldman-Rakic et al., 1984; Pandya and Seltzer, 1982). This brain region serves an important modulatory role in all aspects of human functioning (see also Zakzanis and Heinrichs, 1999).

Interest in frontal lobe abnormalities in schizophrenia is generated from observations of cognitive and behavioral deficits that are associated with measures of frontal lobe damage (e.g. Wisconsin Card Sorting Task, eye tracking abnormalities, spatial working memory deficits, PET and fMRI functional measures showing hypo and hyperfrontality - see review in Wible et al., 1995, 1997, see also Andreasen et al., 1992; Goldberg et al., 1987; Weinberger et al., 1992). Converging findings from post-mortem studies of schizophrenia also support the presence of prefrontal lobe abnormalities in schizophrenia (e.g. Benes et al., 1991; GoldmanRakic and Selemon, 1997; Selemon et al., 1998). Fig. 5 illustrates a three-dimensional surface reconstruction of the prefrontal cortex and its subdivision into frontal, middle, and inferior gyri, juxtaposed with a coronal $1.5-\mathrm{mm}$ slice.

Structural MRI findings of frontal lobe abnormalities in schizophrenia are equivocal. In our review of 50 MRI studies, 30 (60\%) reported positive findings, while $20(40 \%)$ reported negative findings (Table 1). It is noteworthy that most of these studies measured the frontal lobe as one structure, despite the fact that the frontal cortex is highly differentiated functionally and that different subregions within the frontal lobe have quite different and specific brain functions (e.g. Fuster, 1989). Thus, if investigators are attempting to discern small differences in specific subregions within the frontal lobe, measurement of the entire frontal lobe will likely obscure any small, local abnormalities.

The first study to measure the whole prefrontal cortex, using thin 1.5 -mm slices, was conducted in our laboratory by Wible and coworkers (1995). We found no differences between patients with schizophrenia and controls, although left prefrontal gray matter volume was highly correlated with volume reductions in the left amygdala-hippocampal complex, left STG, and left parahippocampal complex in the schizophrenia group only. Moreover, there was a correlation between patients evincing more negative symptoms and left prefrontal volume reduction. These findings suggest that differences in the prefrontal cortex may be too small to detect, but which are nonetheless correlated with reductions in areas of the left temporal lobe that are neuroanatomically and functionally related, as well as with symptoms thought to be associated with frontal lobe functioning. 
Breier et al. (1992) also noted correlations between prefrontal and temporal lobe volume.

Additionally, their measure of right prefrontal white matter volume was correlated with right amygdala-hippocampus volume, which they interpreted as supporting the hypothesis of abnormal limbic-cortical connections in schizophrenia. Further, Weinberger et al. (1992) reported an association between left hippocampal volume reduction in the affected twin of monozygotic twins discordant for schizophrenia and decreased cerebral blood flow in the dorsolateral prefrontal cortex during the Wisconsin Card Sorting Task. These findings further support direct and indirect connections between prefrontal and limbic structures in the brain, which may be abnormal in schizophrenia.

Finally, we note that small, subtle differences in the whole prefrontal lobe may be just at the threshold for MRI detection, and hence different subject samples or methodology may obscure detecting such differences. Moreover, Selemon and coworkers (1998) found only a small (8\%) reduction in prefrontal cortical thickness in schizophrenia, a reduction that was not statistically significant, although abnormalities in cell density were present. A reduction of $8 \%$, however, may not be detected using MRI, again suggesting that when the differences are small, more care is needed in defining homogeneous subject populations and using more uniform methods.

Very few studies, however, and only the most recent, have evaluated subregions within the frontal lobe. Buchanan et al. (1998) reported volume reductions in prefrontal white matter in patients with schizophrenia as well as right and left inferior gyri volume reductions. Goldstein et al. (1999) reported between 7 and $15 \%$ volume reduction in the middle frontal, middle, medial, and right sided fronto-orbital subregions in schizophrenia. Gur et al. (2000b) studied male and female patients with schizophrenia, and matched controls, and reported reduced prefrontal gray matter volume in dorsolateral regions of $9 \%$ in men and $11 \%$ in women. Dorsomedial volume reduction was evident only in male patients, and orbitofrontal volume reduction was evident only in female patients. Additionally, a larger dorsal cortex was correlated in the patient group with better performance on abstraction and attention measures whereas smaller volume in orbito-frontal regions in female patients was correlated with poorer premorbid functioning, more negative symptoms, and depression. Baaré et al. (1999), however, reported no differences between controls and schizophrenics in parcellated prefrontal regions, although these investigators noted a correlation between left and right prefrontal gray matter volume reduction and decreased performance on tests of verbal recall, visual memory, and semantic fluency. Further, reduced orbitofrontal volume was correlated with more negative symptoms $(r=-0.76)$. These findings, taken together, suggest that parcellating the frontal cortex into subregions is important not only for detecting volume differences but also for examining the association between reduced prefrontal volume and cognitive and clinical deficits.

\subsection{Parietal and occipital lobes}

The parietal lobe has received very little attention in schizophrenia research despite the fact that it is a brain region important to processes that are disturbed in schizophrenia such as language (e.g. Mesulam, 1990, 1998), spatial working memory (e.g. Park and Holzman, 1992), and attention (e.g. Nuechterlein and Dawson, 1984). This paucity of attention is further highlighted by the fact that there have been only 15 MRI studies that have investigated the parietal lobe. This is in contrast to the more than 137 studies of temporal lobe structures (see Table 1). The parietal lobe is also part of heteromodal association cortex, a highly organized and interconnected neocortical brain system that is highly lateralized and includes the superior posterior section of the temporal lobe, the dorsolateral prefrontal cortex, Broca's area, and the inferior parietal lobule (IPL) (Mesulam, 1990, 1998). Pearlson, in fact, views heteromodal association cortex abnormalities as the primary deficit in schizophrenia (Pearlson et al., 1996). 
The parietal lobe is comprised of post-central gyrus, superior parietal gyrus, and inferior parietal lobule (IPL), with the latter further subdivided into supramarginal and angular gyri (Brodmann's areas 40 and 39 respectively). Of note, both supramarginal gyrus and angular gyrus are described as part of a semantic-lexical network that supports 'word meanings' represented by a 'grid of connectivity' that constitutes a 'final common pathway for the chunking of words into thought' (Mesulam, 1990). The role of the IPL in language comprehension, particularly the angular gyrus, has also been confirmed by fMRI and positron emission studies (e.g. Binder, 1997; Frackowiak, 1994; Howard et al., 1992). Further, the semantic-lexical network proposed by Mesulam includes both the IPL and posterior portions of the STG. Additionally the IPL, like the PT, exhibits marked lateral asymmetry (e.g. Eidelberg and Galaburda, 1984; Galaburda and Geschwind, 1980). The presence of left greater than right asymmetry is important for normal language development [i.e. abnormal development in these regions is associated with autism (Hier et al., 1978, 1979) as well as other language disorders (Rosenberger and Hier, 1980)]. Finally, the relevance of the supramarginal gyrus and angular gyrus to schizophrenia stems not only from their functions as part of heteromodal association cortex, but also from their reciprocal connections to both prefrontal (e.g. Cavada and Goldman-Rakic, 1989) and temporal lobe brain regions (Seltzer and Pandya, 1984).

In our review of MRI parietal lobe findings in schizophrenia, of 15 studies, nine $(60 \%)$ have report abnormalities while six $(41 \%)$ have not (Table 1$)$. Methods of measurement, however, have varied tremendously, asymmetry has not always been assessed, nor has the parietal lobe generally been subdivided into functional subdivisions. For example, Egan et al. (1994) used only a $1-\mathrm{cm}$ slice to measure the whole parietal lobe, and two other studies measured the parietal lobe combined with other brain regions (e.g. Harvey et al., 1993;Zipursky et al., 1994).

Several recent studies have focused on subdivisions within the parietal lobe. For example, Goldstein and coworkers (1999) evaluated subdivisions within the parietal lobe and reported volume reductions in the supramarginal gyrus in patients with schizophrenia, in addition to prefrontal volume reductions including cingulate gyrus. Schlaepfer and coworkers (1994) reported dorsolateral prefrontal cortex, IPL, and STG gray matter volume reductions in schizophrenia.

Niznikiewicz and coworkers (2000), from our laboratory, measured the component parts of the parietal lobe including the post-central gyrus, the superior parietal lobule, and the IPL, including both the supramarginal and angular gyri. The angular gyrus was highly lateralized in controls, but showed a reversal of the normal left greater than right angular gyrus in male patients with schizophrenia compared to male controls. There were also correlations between IPL and neuroanatomically connected cortical regions of the prefrontal cortex (superior and inferior frontal gyrus and orbital gyrus) and of the temporal cortex (anterior STG, amygdala, and hippocampus), further supporting the notion that heteromodal associative cortex, and highly interrelated brain regions important for language functioning and integrating multimodal stimuli, might be preferentially affected in schizophrenia.

Frederikse and coworkers (2000) also evaluated the IPL in both male and female patients with schizophrenia and controls, and reported a reversal of the normal left greater than right asymmetry in male patients as well as a gray matter volume reduction. No such differences were observed in female patients with schizophrenia compared to female control subjects.

These findings suggest that structures belonging to the inferior parietal lobule, and which involve semantic-lexical networks, may help us to understand more fully the neural substrates of language and thought disorder in schizophrenia which are likely related to these highly lateralized brain regions. Future research will benefit from the selection of homogeneous 
patient groups, the examination of gender differences, and the careful parcellation and evaluation of subdivisions within the parietal lobe.

Of the nine MRI studies of the occipital lobe, four (44\%) have reported volume reductions between patients with schizophrenia and normal controls, while five (56\%) do not report volume differences (Table 1). As subdivisions within the occipital lobe have not been evaluated, it is not known whether regions within the occipital lobe are abnormal in schizophrenia. The evidence to date suggests that the occipital lobe is not critical to the neuropathology of schizophrenia.

\subsection{Other brain regions}

3.5.1. Cerebellum-Shelton and Weinberger (1986) suggest that about $10 \%$ of CT scan studies reported cerebellar atrophy in schizophrenia. The cerebellum, however, is difficult to visualize with CT technology. With the advent of MRI, measuring the cerebellum became easier, although few studies have focused on this brain region in schizophrenia. Recent evidence, however, suggests that this brain region may play a critical role in higher cognitive functioning and may be implicated in the neuropathology of schizophrenia (e.g. Wassink et al., 1999). Schmahmann (1996), in fact, describes the cerebellum's contribution to cognitive processing, and he highlights the connectivity between the cerebellar hemispheres and cortical association areas which subserve cognition, as well as the connectivity between the cerebellar vermis and limbic structures, including the hippocampus and amygdala. As cortical association areas and limbic structures have figured prominently in studies of schizophrenia, the cerebellum becomes an important brain region to investigate.

In our review of 13 MRI studies of the cerebellum in schizophrenia, four (31\%) report positive findings, while nine (69\%) report negative findings (Table 1). Of the negative findings, Nopoulos and coworkers (1999), while not reporting overall cerebellar volume reduction, did report volume reduction in the anterior lobe of the vermis. In another study reporting negative findings, Rossi and coworkers (1993) showed a decrease in vermal-to-brain ratio in male patients with schizophrenia compared to female patients with schizophrenia.

In the first study of gray and white matter of the whole cerebellum and vermis, Levitt, from our laboratory (Levitt et al., 1999), reported an increase in vermis volume in chronic male schizophrenic patients as well as an increase in white matter volume that was correlated with positive symptoms, thought disorder, and impaired verbal memory. [Parenthetically, smaller cerebellar volume predicted more negative and positive symptoms and poorer psychosocial outcome at follow up of 7 years in a study reported by Wassink et al. (1999).] Similarly, Seidman and coworkers (2000) reported no significant differences in cerebellar gray matter volume in schizophrenics, but did report a significant increase in cerebellar white matter, a finding they are investigating further.

An increase in white matter may represent a neurodevelopmental anomaly or it may be a medication effect, as there are reports of axonal sprouting in rats given neuroleptic medications (e.g. Benes et al., 1983). In the Levitt et al. (1999) study, however, increases in white matter volume were not correlated with indirect measures of neuroleptic medication exposure. Finally, Levitt et al. (1999) found trend level left greater than right cerebellum hemisphere in patients with schizophrenia, which was not found in the controls. This finding suggests that the right hemisphere of the cerebellum, where language and memory activate the inferior portion, and the crossed cerebellar cerebral cortical connections, make the left greater than right cerebellum in schizophrenia consistent with the greater left hemisphere cerebrum abnormalities in schizophrenia (see previous references in temporal lobe section). 
The cortical-cerebellar-thalamic-cortical-circuit (CCTCC) involves a feedback loop that allows for the smooth coordination of both motor and cognitive functioning (e.g. Schmahmann, 1996). Andreasen and coworkers (1999) have proposed a model of schizophrenia that involves a disturbance of the CCTCC. These investigators view the cerebellar portion of this circuit as a 'metron' that guides the 'fine-tuning' of both motor and cognitive functioning. A dysfunction in the CCTCC leads to 'cognitive dysmetria', or to a lack of coordination in the processing and retrieval of cognitive information, leading to, and underlying, the cognitive impairments in schizophrenia.

Middleton and Strick (2000) describe several loops involving cerebellum, basal ganglia and cortical brain regions, which are important to both motor and cognitive functions. They further note that an appreciation and reappraisal of these connections may reveal important new behavioral and cognitive findings. Further studies are thus needed to evaluate the role of the cerebellum in schizophrenia, particularly given the small number of studies to date and still fewer studies which have attempted to parcellate the cerebellum into functional subdivisions.

\subsubsection{Subcortical structures}

3.5.2.1. Basal ganglia: The basal ganglia structures (caudate, putamen, and globus pallidus) have become an important focus of research in schizophrenia primarily because of: (1) the extensive dopaminergic inputs into the striatum (caudate, putamen, and nucleus accumbens); (2) the therapeutic efficacy of neuroleptic medications acting on dopamine receptors; and (3) the importance of these structures in cognitive, sensory, and motor processing (see Keshavan et al., 1998a for a recent concise review). Of note, the first post-mortem study of these structures in schizophrenia reported no abnormalities (Bogerts et al., 1985), although a later study by Heckers et al. (1991) reported bilateral volume increases of $9 \%$ in the striatum and $14 \%$ in the globus pallidus.

There have been 25 MRI studies of basal ganglia structures in schizophrenia. Seventeen (68\%) report positive findings and eight (32\%) report negative findings (Table 1). Most of the positive findings report increases in volume, with the exceptions being: (1) Mion et al. (1991) reported decreased volume in the caudate in patients with tardive dyskinesia but not in patients without tardive dyskinesia; (2) DeLisi et al. (1991) reported trend decreases in the caudate and lenticular nuclei; and (3) Rossi et al. (1994a) reported trend decreases in the caudate and lenticular nuclei in male patients.

Prior neuroleptic exposure is an important factor in findings of increased volume in basal ganglia structures. For example, Chakos and coworkers (1994) evaluated first-episode patients and observed a 5.7\% increase in caudate size from baseline to follow up scan 18 months later. These investigators also noted that earlier age of onset and higher neuroleptic dosage predicted larger caudate at follow up. This finding suggests that an increase in basal ganglia volume may be a result of neuroleptic medication. Work by Keshavan et al. (1994) confirms this finding as these investigators reported increased caudate in first-episode patients from baseline MRI scan to follow up 6 and 24 months later.

The effect of atypical neuroleptics on the size of the caudate, with diminished effects on D2 receptors and increased affinity for 5-HT2 receptors, has also been studied. Chakos et al. (1995) switched some patients to atypical neuroleptics, imaged them again 1 year later, and demonstrated a decrease in caudate volume. These findings suggest that increased volume of basal ganglia structures may be a function of conventional neuroleptic medications whereas atypical neuroleptics do not exert the same effect.

In a later study by Keshavan et al. (1998a), caudate volume, but not putamen volume, was bilaterally reduced in newly diagnosed psychotic patients. Reduction in caudate volume in drug 
naive patients is of interest because it suggests that such volume reduction may be related to the pathophysiology of schizophrenia and not a medication effect. Our laboratory has also recently reported smaller caudate in a group of neuroleptic naive subjects with related schizotypal personality disorder (Levitt et al., 2000). Additionally, Shihabuddin et al. (1998) have shown decreased caudate volume in never medicated patients and increased caudate volume in previously medicated patients. Corson et al. (1999a) have also shown decreased caudate volume in first episode, neuroleptic naive, patients with schizophrenia. Finally, Gur and coworkers (1998a) evaluated basal ganglia structures in neuroleptically naive and previously treated patients and reported no differences in the volume of basal ganglia structures between the neuroleptically naive group and controls, although higher putamen volume was associated with more positive symptoms. In contrast, the previously medicated patients showed increased volumes in the putamen and globus pallidus, which is consistent with an earlier report from our group, in which Hokama et al. (1995) reported increased size of the caudate, putamen, and globus pallidus in medicated male schizophrenic patients. Of note, patients treated with atypical neuroleptics did not show an increase in the volumes of basal ganglia structures (Gur et al., 1998a).

Thus the increases in volume in basal ganglia structures may reflect the effects of some neuroleptic medications. Decreases in volume in some studies of first episode and neuroleptic naive schizophrenics, however, suggest that abnormalities may be extant prior to the introduction of neuroleptic medications. Further, reduced caudate volume has also been reported in depression (e.g. Krishnan et al., 1992), and thus the issue of the specificity of basal ganglia abnormalities to schizophrenia warrants further investigation. Finally, Seidman and coworkers (1997) reported smaller right putamen in a sample of six sisters of schizophrenic patients, suggesting that some never psychotic and never medicated relatives of schizophrenic patients may show abnormalities in basal ganglia structures. These findings, taken together, suggest that basal ganglia structures, medication effects, and the functions of these structures should be investigated further using state-of-the-art neuroimaging techniques that include both structural and functional measures.

3.5.2.2. Thalamus: The thalamus, comprised of several nuclei, is a major relay station in the brain which modulates input from many cortical areas, as well as from the reticular activating system and the limbic system (e.g. Fuster, 1989). The thalamus is also involved in attention and information processing and serves as a 'filter' for gating the input of sensory signals (e.g. Fuster, 1989; Jones, 1985). These functions evolve from reciprocal connections between the ventral anterior and dorsomedial nuclei of the thalamus and the prefrontal cortex, and between the associational thalamo-cortico-thalamic loop of the orbito-frontal and dorsolateral prefrontal cortices. Andreasen et al. (1994b) postulate its critical role in schizophrenia (see above discussion under cerebellum), and several post-mortem findings have reported abnormalities in thalamic nuclei (e.g. Pakkenberg, 1987).

Measurement of thalamic nuclei on MRI scans is, however, difficult as this brain region fades from gray to white matter with ghost like edges, even with thin $1.5-\mathrm{mm}$ slices. It was for this reason, in fact, that Andreasen et al. were reluctant to highlight their early findings of thalamic abnormalities in schizophrenia, particularly given that the reliability for measuring this brain structure was lower than for other brain regions (e.g. Andreasen et al., 1990, 1994b; Flaum et al., 1995). Using a novel method of image averaging, Andreasen et al. (1994b) reported reduced signal intensity in the thalamus, particularly in the lateral region. This group has also published a new method for visualizing subthalamic nuclei using inversion recovery imaging (Magnotta et al., 2000). This new pulse sequence may make it possible to measure the thalamic nuclei in a manner that was not previously possible. Such improved imaging may also result in even more positive findings for thalamic abnormalities in schizophrenia then we report today. 
In our review of $12 \mathrm{MRI}$ studies of the thalamus, five (42\%) report decreased thalami and seven (58\%) report no differences between patients with schizophrenia and control subjects (Table 1). Of the negative findings, Corey-Bloom and coworkers (1995) reported a correlation between early onset patients and smaller thalamus, although there were no differences observed when the patients were compared to controls. This finding is of interest as Jeste et al. (1998) have also reported an association between early onset schizophrenia and poorer performance in learning, abstraction and cognitive flexibility, and smaller thalamic volumes (this study did not include a control group). In our laboratory, while reporting no volume differences between controls and patients, we did report a correlation between smaller thalamic volumes and smaller prefrontal white matter in the patient group (Portas et al., 1998).

Snyder et al. (1998) found an absence of the adhesio interthalamica, or massa intermedia, and third ventricle enlargement in first episode schizophrenia. As the borders of the thalamus fuse to create this midline structure between the 13th and 14th week of gestation, these investigators concluded that the absence of the adhesio interthalamica and third ventricle enlargement were neurodevelopmental in origin. Meisenzahl et al. (2000), however, did not report this abnormality in patients with schizophrenia compared with controls, although they noted that patients without adhesio interthalamica evinced more negative symptoms than patients with adhesio interthalamica. As these are the only studies reported in the literature, further research is needed to evaluate this midline structure.

In a study of neuroleptic naive patients with schizophrenia, Gur and coworkers (1998a) reported smaller thalamic volumes compared to controls (non-significant trend level of $P=0.08$ ). Moreover, larger thalamic and putamen volumes correlated with a greater number of positive symptoms. Additionally, in those patients previously treated with both atypical and typical neuroleptics, higher neuroleptic dosage was correlated with larger thalamic volumes. Finally, in two studies of relatives of patients with schizophrenia, thalamic volumes were significantly smaller in the relatives compared with controls (left thalamus only for the Seidman et al., 1997 study; Staal et al., 1998). These findings suggest that the thalamus may be implicated in the neuropathology of schizophrenia. Further studies are needed, however, which evaluate subnuclei within the thalamus using imaging techniques that allow for a better visualization of this brain structure, such as proposed by Magnotta and coworkers (2000).

3.5.2.3. Corpus callosum: The corpus callosum is a midline brain structure comprised of white matter fiber tracts that connect the two hemispheres. Gruzelier (1991) has speculated that the information processing deficits observed in schizophrenia are related to defective interhemispheric communication which is largely mediated by the corpus callosum. One of the first studies of the corpus callosum in schizophrenia was a post-mortem study by Rosenthal and Bigelow (1972) that showed a thicker corpus callosum in patients with schizophrenia compared with controls (see Raine et al., 1990 for a review of early studies).

In 27 MRI studies of the corpus callosum (CC), 17 (63\%) report positive findings and $10(37 \%)$ report negative findings (Table 1). We suspect that the large variation in methods might contribute to inconsistent findings. More specifically, most studies use a single midsagittal slice to measure the whole corpus callosum, while other studies parcellate the slice into presumed functional subdivisions. With only one slice to examine, the data are more vulnerable to errors in the alignment of the head in the MR scanner. Slice thickness, the selection of the 'best midsagittal slice', and gender dimorphism in both shape and size further contribute to possible sources of error (e.g. Hoff et al., 1994). More recent studies examining shape (e.g. DeQuardo et al., 1996;Downhill et al., 2000;Frumin et al., 1998) may help to clarify further the role of corpus callosum abnormalities in schizophrenia. 
3.5.2.4. Cavum septi pellucidim: The septum pellucidum is a triangular shaped membrane that separates the two frontal horns of the lateral ventricles. Developmental abnormalities in the formation of structures bordering the septum pellucidum (i.e. the corpus callosum and hippocampus) are thought to be reflected in a space, or 'cavum', in this membrane (e.g. Rakic and Yakovlev, 1968).

One of the first reports of cavum septi pellucidi (CSP) abnormalities and psychosis was a report by Lewis and Mezey (1985). This was followed by the first MRI study of CSP by Mathew and coworkers (1985b). There are now 12 MRI studies in the literature of which $11(92 \%)$ report positive findings and one (8\%) reports negative findings, thus making it one of the most robust MRI findings in the literature (Table 1). These findings are most commonly based on counting the number of slices in which CSP is observed (e.g. Kwon et al., 1998; Nopoulos et al., 1996, 1997). Large CSP in schizophrenic patients has ranged from 15\% of patients to $45 \%$ (e.g. Degreef et al., 1992b,c; DeLisi et al., 1993; Jurjus et al., 1993; Kwon et al., 1998; Nopoulos et al., 1996; Scott et al., 1993). Additionally, large CSP has been reported in first episode schizophrenics (e.g. Degreef et al., 1992c; DeLisi et al., 1993; Kwon et al., 1998). Moreover, large CSP has been correlated with a family history of schizophrenia in schizophrenic patients (Uematsu and Kaiya, 1988), as well as with left temporal lobe volume reduction in male schizophrenics (Nopoulos et al., 1996), and with hippocampal volume reduction in chronic male schizophrenics (Kwon et al., 1998). Kwon et al. (1998) also reported large CSP in first psychotic episode bipolar patients and in schizotypal personality disorder. This suggests that while CSP abnormalities are evident in schizophrenia, they are also present in other psychiatric disorders and, therefore, are not specific to schizophrenia.

Of note, Degreef et al. (1992a,b), Jurjus et al. (1993), Nopoulos et al. (1996, 1997), and Kwon et al. (1998) all reported large CSP in male patients with schizophrenia, suggesting the importance of gender, particularly in evaluating possible prenatal neurodevelopmental abnormalities, which tend to show a greater prevalence in males (e.g. Shaw and Alvord, 1969). Nopoulos and coworkers $(1996,1997)$, in fact, suggest that the pattern of abnormalities involving large CSP and left temporal lobe volume reductions in male schizophrenics, may reflect regional, localized tissue reduction. They further speculate that an asymmetry in the development of the cerebral hemispheres, which creates 'diverging growth vectors', may disrupt the normal fusion process of the septum pellucidi (i.e. 'lateralized temporal lobe dysgenesis').

In summary, MRI findings of CSP are among the most robust in the literature and suggest that this neurodevelopmental anomaly is relevant to the neuropathology of schizophrenia for at least a subgroup of individuals diagnosed with this disorder.

3.5.3. Olfactory bulbs-The olfactory system is of interest to schizophrenia researchers because it receives input from several brain regions thought to be implicated in the neuropathology of schizophrenia, including ventromedial temporal lobe, basal forebrain, and the prefrontal cortex. The olfactory bulbs are unique in that there is a single synapse between peripheral olfactory receptors and primary olfactory cortex, thus representing a direct link between the brain and the outside world. There is also some suggestion that it is more influenced by neurodevelopmental factors and also resistant to progressive changes (e.g. see review in Turetsky et al., 2000). Turetsky and coworkers (2000) conducted the first MRI study of olfactory bulb volume in schizophrenia and reported a $23 \%$ bilateral volume reduction compared with controls. They also noted an association between olfactory sensitivity and olfactory bulb volume in control subjects that was not observed in the patients. As this is the first study to evaluate olfactory bulbs, and as 3-mm slices were used, this finding needs to be replicated. 


\section{Neurodevelopmental and neurodegenerative abnormalities: first episode and longitudinal studies}

\subsection{The issues}

Previously, we focused on answering the questions: (1) 'Are there brain abnormalities in schizophrenia?' (2) 'If so, which regions are affected?' and finally, (3) 'Are brain abnormalities related to cognitive and clinical symptoms observed in schizophrenia?' Another set of important questions include: 'Are the brain abnormalities observed due to events that occurred pre- or perinatally (i.e. have a neurodevelopmental origin), are they progressive (neurodegenerative), or are they a combination of both?'

That some structural brain abnormalities may be due to neurodevelopmental anomalies does not explain why the onset of schizophrenia generally occurs in late adolescence or early adulthood. One explanation might be that brain abnormalities that occur in late adolescence or early adulthood are related to neurodevelopmental abnormalities, but simply unfold over the course of development. Feinberg (1982), for example, posits such an anomaly, which results in aberrant synaptic pruning during adolescence and early adulthood. A potential model for such phenomena is also supported by animal studies. More specifically, rat pups with hippocampi lesioned early in development show delayed aberrant behavior occurring during adolescence (Lipska et al., 1993, 1995, 1998). These findings suggest that a neurodevelopmental lesion in a critical area, such as the hippocampus, may have delayed manifestations.

Alternatively, though not mutually exclusive, some researchers suggest that a 'two-hit model', often described in medicine, may be operative in schizophrenia (McCarley et al., 1991, 1996; Mednick and McNeil, 1968; Meehl, 1962). Such a model was proposed by Mednick and McNeil (1968) who noted the importance of a genetic component that was necessary but not sufficient for the development of schizophrenia. These investigators believed that another risk factor such as hypoxia during child birth, with possible hippocampal damage, was required.

Several research investigators have focused on glutamate, the major excitatory neurotransmitter in the central nervous system, as playing an important role in the pathogenesis of schizophrenia (e.g. Coyle 1996; McCarley et al., 1991; Olney, 1989, 1990; Olney and Farber, 1995; Robinson and Coyle, 1987; Tsai and Coyle, 1995). More specifically, abnormal Excitatory-Amino-Acid (EAA) transmission is the likely mechanism for abnormalities in neurodevelopment which are secondary to a disruption of EAA-mediated neural guide mechanisms (i.e. 'first-hit'), and may also result in ongoing, use dependent excitoxic cell damage or death (Coyle, 1996; Coyle and Puttfarcken, 1993; McCarley et al., 1991, 1999a; Komuro and Rakic, 1993, 1998; Olney, 1989, 1990). Thus both developmental and excitoxic aspects of EAA neurotransmission abnormalities could be explanatory mechanisms for the gray matter reductions reported in MRI and post-mortem studies (see also Grunze et al., 1996). Such toxic actions may also exert their effects in an age-dependent fashion, for example, in late adolescence, when there is myelination of frontal glutamate pathways (Benes, 1989). Whether or not specific brain regions are more susceptible to such excitoxicity warrants further investigation.

Currently, two strategies have been used in MRI studies to address questions concerning neurodevelopmental versus neurodegenerative brain abnormalities. The first is to evaluate the brain early in the course of the illness, at first episode or first hospitalization, prior to neuroleptic exposure and/or the stress of having a serious chronic illness. This approach is predicated on the belief that studying first episode patients obviates confounds such as medication, chronicity of illness, and progressive changes. Research interest in childhood schizophrenia (Frazier et 
al., 1996, 1997; Rapoport et al., 1997; Yeo et al., 1997) and adolescent schizophrenia (Dasari et al., 1999; James et al., 1999; Friedman et al., 1999) is also increasing. While these groups are not representative of the schizophrenia population and therefore may not be generalizable, they nonetheless offer important insights into the course of the illness and in change in brain morphology.

The second strategy is to evaluate changes in structural brain morphometry over time. The general assumption is that changes over time are indicative of neurodegeneration, although such changes might also reflect neurodevelopmental anomalies. These studies are difficult to conduct and have many confounds, including: (1) patient drop out, possibly leading to a systematic error of more or less severely ill subjects being studied; (2) the time interval to identify progressive changes is not known as some brain regions may change at different rates than others (DeLisi et al., 1997; Gur et al., 1998b); (3) little is known about the effect of normal aging on brain morphology; and (4) psychotropic medications can effect brain structures. With respect to the latter, as previously noted, typical neuroleptics have often resulted in an increase in basal ganglia structures, and atypical neuroleptics, with effects on multiple

neurotransmitters, may also change the morphology of brain regions. Thus such caveats need to be kept in mind in reviewing the current longitudinal studies.

Below, we highlight findings first from 124 first episode MRI studies, listed by brain region finding, followed by a review of 15 longitudinal, or follow up, studies (see Table 4 and Table $5)$.

\subsection{Evidence from first episode patients}

Results of studies with first episode patients are quite similar to those reported for chronic patients (Table 4). Specifically, findings for whole brain volume reduction are primarily negative (seven out of eight studies), with the exception of one study of adolescent with schizophrenia (James et al., 1999). Additionally, similar to findings for chronic patients, enlarged lateral ventricles are among the most robust findings, with 15 studies reporting positive findings and four studies reporting negative findings (see Table 4; note Lawrie et al., 1999 showed increased third ventricle only). Several investigators have also reported enlarged left temporal horn of the lateral ventricles (e.g. Bogerts et al., 1990;Degreef et al., 1992a;James et al., 1999), again similar to what has been reported in chronic patients and in post-mortem studies. Clinical correlations have also been reported between enlarged lateral ventricles and poor premorbid functioning (DeLisi et al., 1998), and between enlarged lateral ventricles and increased positive and negative symptoms (Degreef et al., 1992a). Finally, Snyder et al. (1998) reported an association between the absence of adhesio interthalamica, a medial adhesion between the two thalami, and enlarged third ventricle in first episode patients.

With respect to temporal lobe findings, 11 MRI studies have investigated whole temporal lobe volume, five of which report positive findings and six report negative findings (Table 4). When just medial temporal lobe structures are evaluated, the findings are more positive, with five studies reporting differences between schizophrenic patients and controls and one reporting no differences (DeLisi et al., 1991). In studies examining the amygdala and hippocampus separately, eight out of ten studies report hippocampal volume reduction but only one out of five studies report amygdala volume reduction and that is in male schizophrenic patients, only (Gur et al., 2000a;). Additionally, Bilder et al. (1995) reported a correlation between anterior hippocampus volume reduction and neuropsychological measures considered to reflect frontal lobe function. This finding suggests the importance of fronto-temporal connections in the neuropathology of schizophrenia. However, these findings do not appear to be specific to first episode patients diagnosed with schizophrenia, as two studies report hippocampal volume reductions in first episode bipolar patients (e.g. Hirayasu et al., 1998;Velakoulis et al., 1999). In reviewing STG findings, however, Hirayasu et al. (1998) reported left STG volume reduction 
in first psychotic episode schizophrenics that was not evident in first psychotic episode bipolar patients. Keshavan et al. (1998b) also reported reduced STG volume which reversed over time following psychotropic medications (Table 4).

For MRI studies of the whole frontal lobe, seven out often studies showed abnormalities (Table 4). Bilder et al. $(1994,1999)$ also reported asymmetry abnormalities in prefrontal cortex, and one study reported volume reduction in the cingulate (Ohnuma et al., 1997), while another study of subgenual cingulate did not (Hirayasu et al., 1999). Additionally, Szeszko et al. (1999) reported right > left orbitofrontal regions with the ratio of right orbitofrontal to dorsolateral volume being correlated with severity of delusions. Gur et al. (2000b) also observed gray matter volume reduction in dorsolateral areas, in dorsomedial areas (males only), and in orbital frontal regions (females only). These prefrontal and orbitofrontal asymmetry findings also favor a neurodevelopmental origin as the sulco-gyral patterns are established in utero.

The corpus callosum, CSP, basal ganglia, thalamus adhesio interthalamica and cerebellum have also been investigated in first episode schizophrenia (Table 4). Three out of four corpus callosum studies report abnormalities, seven out of 10 basal ganglia studies report abnormalities (though these are complicated by the medication status of the patient), three out of three studies of CSP report abnormalities, and one out of two studies report thalamic or cerebellar abnormalities. Finally one study of the adhesio thalamic reports abnormalities in first episode schizophrenic patients (Table 4). MRI findings thus demonstrate that brain abnormalities are present at first episode of illness, and that the brain regions involved are the same brain regions observed in more chronic patients.

\subsection{Evidence from longitudinal studies}

In reviewing 15 follow up studies, DeLisi and coworkers (e.g. 1992, 1995, 1997) have conducted the most extensive work in this area as part of the Stony Brook First Episode Study (Table 5). In their earliest reports (DeLisi et al., 1991, 1992), no differences in ventricular size were noted between first episode patients and controls, although change in ventricular size was inversely correlated with duration of hospitalization (Table 5). As the subject sample increased, subsequent studies reported enlarged lateral ventricles (e.g. DeLisi et al., 1995,1997).

Interestingly, the rate of change in the left ventricle was greater in the patient group. Patients with the smallest ventricles at baseline had the greatest change in ventricle size, and subjects with larger ventricles at baseline had the worse premorbid social adjustment (DeLisi et al., 1998). These findings were interpreted as indicating that pathologic changes had occurred prior to the onset of psychosis. Finally, Nair and coworkers (1997) report that patients who showed larger ventricles over time and differed from controls at follow up had a more severe illness and prodromal phase than patients who had larger ventricles than controls, though not statistically significantly so (Table 5). These findings also suggest that ventricle size is not static but rather there appears to be an early enlargement with later stabilization at the larger size. These findings are also consistent with early CT findings of enlarged lateral ventricles which were associated with poorer prognosis (e.g. Shelton and Weinberger, 1986). In reviewing temporal lobe findings (Table 5), we note that DeLisi and coworkers (1997) report no changes over 4 years in the amygdala-hippocampal complex or in temporal lobe volume (DeLisi et al., 1992, 1995). Of particular interest, Gur and coworkers (1998a) report temporal lobe volume changes in both schizophrenics and controls. Keshavan et al. (1998b) evaluated the STG at baseline and then again 1 year later and observed a reversal of the STG volume with neuroleptic treatment (Table 5). As only 11 subjects were included in this part of the study, it will be important to confirm these results in future studies.

Gur and coworkers (1998b) report temporal and frontal lobe volume reduction over time, though the percent difference is quite small (e.g. $4.2 \%$ for left frontal and $2.8 \%$ for right frontal). 
Other follow up studies have evaluated basal ganglia structures where increases and decreases in the volume of these structures is complicated by the confound of medication (see previous discussions).

Finally, we conclude this section with a comment on one series of childhood schizophrenia studies that deserve special mention. Rapoport and colleagues (e.g. Jacobson et al., 1996; Rapoport et al., 1997, 1999) have followed a cohort of severely ill children with onset of psychosis before age 12 (Table 5). At a 4 year follow up, these investigators reported that normal controls showed a decrease in cortical gray matter, particularly in frontal and parietal regions (Rapoport et al., 1999). In contrast, the children with schizophrenia showed a marked decrease in frontal areas, greater than controls, as well as a decrease in temporal lobe gray matter. These findings again suggest the importance of fronto-temporal brain regions in the pathophysiology of schizophrenia and also highlight the importance of following normal populations over time to discern brain volume changes.

\subsection{Conclusion}

In conclusion, there appear to be progressive changes in the frontal lobes and possibly in the parietal lobes, superior temporal gyrus, and lateral ventricles. Basal ganglia changes seem to be more directly related to type and duration of neuroleptic treatment. Amygdala-hippocampal volume reduction appears not to change over time. In contrast, STG volume reduction does appear to change over time. More work is, however, needed to confirm these important studies, particularly in the temporal lobe region, as findings suggest that treatment intervention may possibly retard the progression of this devastating disease.

\section{Summary of MRI findings and future directions for research}

Our understanding of the neuropathology of schizophrenia has increased dramatically over the past decade. MRI findings now confirm structural brain abnormalities in schizophrenia. These findings have widened the scope of both clinical and basic science research and have led to an important research focus on the neurobiology of this disorder. MRI structural findings in schizophrenia include: (1) ventricular enlargement; (2) medial temporal lobe involvement (amygdala, hippocampus and parahippocampal gyrus); (3) STG involvement; (4) parietal lobe involvement (particularly the inferior parietal lobule and its subdivision into angular and supramarginal gyrus); as well as, (5) subcortical brain region involvement, including the cerebellum, basal ganglia, corpus callosum, thalamus, and CSP. The pattern and number of abnormalities are consistent with a disturbance of connectivity within and between brain regions, most likely neurodevelopmental in origin.

Several theories have been proposed in an attempt to understand the involvement of such a large number of abnormal brain regions in schizophrenia, many of which are likely highly functionally related. Andreasen and coworkers (1994a,b, 1999), for example, suggest that the 'cognitive dysmetria' of schizophrenia can be explained by abnormalities in the thalamus and its connections with the cortex and cerebellum. Buchsbaum and colleagues (1990) have focused on abnormalities in the frontal lobes, basal ganglia and temporal lobe connections. In contrast, Weinberger and coworkers (1992; Weinberger, 1987, 1995) describe schizophrenia as a neurodevelopmental encephalopathy and they propose a 'disconnection model' to explain how alterations in temporal lobe structures might interrupt connections between the temporolimbic and prefrontal regions, and vice a versa. This model has been extended to basic science studies where these investigators have reported the effect of neonatal lesions on medial temporal lobe structures and their disruption of prefrontal cortical brain regions (Saunders et al., 1998). 
Feinberg (1982) proposes that neurodevelopmental abnormalities in schizophrenia result from errors in synaptic pruning that occur at the onset of this disorder, during adolescence and early adulthood. Crow (1990a,b, 1997, 1998) also invokes a neurodevelopmental explanation for schizophrenia but has focused on temporal lobe brain regions that are highly lateralized and important for language production. Our laboratory has also focused on temporal lobe abnormalities as being key to understanding the neuropathology of schizophrenia and we highlight damage to an interconnected neural network that is functionally important for language and associative links in memory as a fundamental defect in schizophrenia (e.g. Shenton et al., 1992, 1997; McCarley et al., 1996, 1999a,b; Nestor et al., 1997). And, finally, Pearlson et al. (1996) highlights heteromodal association areas of the brain as being fundamental to the neuropathology of schizophrenia.

All of these theories have evolved from earlier theories of brain abnormalities in schizophrenia, though confirmation and then refinement was not possible until the application of in vivo neuroimaging techniques. This technology, in fact, has led to the most important discoveries of brain abnormalities in the history of research in schizophrenia. Future research studies will include characterizing basic mechanisms using molecular biology techniques and their application to post-mortem brain tissue, as well as animal models of lesions and their effect on interconnected brain regions. Such studies will likely advance our knowledge of the neural circuitry of the brain. Additionally, clinical studies will need to identify more homogeneous subject groups, evaluate early prenatal and birth history, and follow patients longitudinally from first onset of illness, throughout the life stages, in order to better inform our understanding of neurodevelopmental abnormalities and neurodegenerative changes in the brain.

Future research studies will also need to investigate brain abnormalities in high risk individuals such as family members of patients diagnosed with schizophrenia, as such investigations will likely further our understanding of the genetics of schizophrenia and perhaps suggest which insults or genes result in the development of schizophrenia. While some studies have been conducted in this area (e.g. Seidman et al., 1999), more are needed. Moreover, an investigation of brain abnormalities in individuals diagnosed with schizotypal personality disorder, a disorder which is genetically linked to schizophrenia, will likely be fruitful as these individuals are genetically linked to schizophrenia but the symptoms are more attenuated, and they are not psychotic (e.g. Kendler et al., 1993). And, while work in this area has begun (e.g. Dickey et al., 1999; Siever, 1994), further studies are needed. These individuals are of particular interest since they have generally not been exposed to neuroleptic medications nor have they experienced the effects of chronic hospitalization, both confounds in patients diagnosed with schizophrenia.

In terms of technical advances, the quality of in vivo images using MRI has dramatically increased over the past decade. For example, we are now able to evaluate nearly isotropic voxels in brain images (e.g. 1-mm ${ }^{3}$ ). New segmentation algorithms have also been developed which facilitate the accuracy and speed with which brains can be segmented into gray matter, white matter, and CSF. It will be important for future studies to combine structural and functional measures.

Another important advance will be in measuring brain regions of interest. Specific regions of interest are still generally drawn manually and the process is quite labor intensive.

Improvements will include techniques that utilize template driven segmentation based on techniques such as 'warping'. For example, a brain atlas, with multiple segmented brain regions, will be 'warped' into new MRI data sets in order to delineate specific regions of interest (e.g. Anderson et al., 1998; Collins et al., 1992; Evans et al., 1991; Gee et al., 1993; Iosifescu et al., 1997; Kikinis et al., 1996; Shenton et al., 1995; Tiede et al., 1993). This approach will enable the segmentation of multiple regions of interest in a large number of subjects. Moreover, 
such an approach will be critical for investigating multiple brain regions in the same subjects rather than being limited to only a small subset of ROI for a given study. Investigators will also be able to evaluate intercorrelations among brain regions. By increasing both the number of brain ROIs and the number of subjects that can be analyzed in a given study, further links may also be made between structural brain abnormalities and clinical and cognitive measures.

Other methods for investigating brain regions in MR data sets, which will be important in future studies, include the use of: (1) artificial neural networks (e.g. Magnotta et al., 1999); (2) landmark based shape analysis (e.g. Arndt et al., 1996; Bookstein, 1991, 1997a,b; Buckley et al.,1999; Casanova et al.,1990; Corson et al.,1999a; DeQuardo et al., 1996, 1999; Tibbo et al., 1998); (3) surface parametrization techniques for shape extraction (e.g. Brechbühler et al., 1995; Narr et al., 2000); (4) skeletonization techniques for extracting shape (e.g. Frumin et al., 1998; Golland et al., 1999; Golland and Grimson, 2000; Näf et al., 1996; Pizer et al., 1998); and (5) high dimensional transformations to extract shape (e.g. Csernansky et al., 1998; Haller et al., 1997). Image averaging (e.g. Andreasen et al., 1994a,b; Wolkin et al., 1998), and voxel based approaches may also be important in future studies defining brain regions (see Pearlson and Marsh, 1999 for a review of the latter approaches).

A focus on shape deformations of brain regions, as opposed to only volume measures, may also provide important information relevant to neurodevelopmental theories of schizophrenia, because such deformations may be associated with neurodevelopmental abnormalities. Support for this hypothesis comes from Van Essen (1997) who has shown that the course of development in cortical-cortical and subcortical-cortical connections determines their pattern of growth and shape.

Another area likely to receive attention in future studies is the evaluation of white matter abnormalities. Many studies have reported gray matter abnormalities in schizophrenia, but few have reported white matter changes. White matter is harder to define and to evaluate using conventional MRI as it appears uniform and homogeneous. MR brain diffusion tensor imaging (DTI), however, is a new technique that has recently been developed for use with humans which makes it possible to investigate white matter more closely. This technique has been used to evaluate changes in the brain following acute stroke (e.g. Le Bihan et al., 1986; Maier et al., 1998; Moseley et al., 1990; Warach et al., 1992). It has also been used to evaluate brain tumors (e.g. Le Bihan et al., 1986; Hajnal et al., 1991) and normal and abnormal white matter via diffusion anisotropy (Chien et al., 1990; Doran et al., 1990; Douek et al., 1991; Le Bihan, 1995; Peled et al., 1998).

With respect to white matter, MR brain diffusion tensor imaging is well suited for evaluating white matter because water diffusion is restricted by the physical characteristics of the fiber tracts. There are currently only a small number of studies of schizophrenia using this technique. Specifically, Buchsbaum and colleagues (1998) reported diminished anisotropic diffusion in the right inferior prefrontal region in six schizophrenic patients. A study by Lim et al. (1999) reported reduced anisotropy, indicative of reduced white matter integrity in schizophrenic patients compared to controls. Finally, Foong and colleagues (2000b) reported decreased anisotropy in the splenium of the corpus callosum in patients with schizophrenia. Fig. 6 shows an example of MR diffusion tensor imaging which highlights the corpus callosum fibers. These fibers appear as a dense array of tensors that indicate white matter fiber tracts.

DTI may also be combined with magnetization transfer imaging, which makes possible the indirect estimation of protons bound to myelin and cell membranes of white matter (e.g. Foong et al., 2000a). The magnetization transfer ratio (MTR), which reflects the exchange of magnetization between bound protons and free water, is thought to index myelin and axonal integrity. Thus MTR, in combination with DTI, can help to address further specific white matter 
anomalies which will likely lead to a new understanding of disrupted connectivity in schizophrenia.

Last, and perhaps the greatest recent advance in MRI technology, is functional MRI. One of the most important changes in the last few years has been to move from examining isolated brain regions to examining interconnected neural networks which are likely impaired in schizophrenia (e.g. Andreasen, 1997, 2000; Weinberger, 1996; Weinberger et al., 1996). This move has been significant with the advent of fMRI technology which affords the opportunity to evaluate both brain structure and function more closely. And indeed, many laboratories are developing fMRI technology, which is rapidly changing and evolving, and which has already led to a wealth of new information concerning brain structure and function. [See review by Weinberger et al. (1996)]. fMRI is particularly useful when there is a simultaneous focus on understanding the relationship between normal cognition and functional and neuroanatomical connections. The next decade will likely witness an explosion of new research from interdisciplinary teams of physicists, cognitive neuroscientists, neuroscientists, psychologists, and psychiatrists, which will likely lead to a greater understanding of the brain mechanisms responsible for observed structural abnormalities in schizophrenia.

\section{Acknowledgments}

The authors would like to thank Elizabeth David, Aleksandra Ciszewski, Iris A. Fischer, Sarah Toner, Sarah Corriveau, and Marie Fairbanks for their administrative and technical assistance. Additionally, we gratefully acknowledge the support of the National Institute of Mental Health (MH 50740 and MH 01110 to MES, and MH 40799 to RWM), the support of the Department of Veterans Affairs Merit Review Awards (RWM and MES), the support of a VA Psychiatry/ Neuroscience Research Fellowship Award (MF), the support of a Young Investigator Award from the National Alliance for Research in Schizophrenia and Depression (MF), and the support of a VA Career Development Award (CCD). This review is an update and extension of: M.E. Shenton, Temporal lobe structural abnormalities in schizophrenia: A selective review and presentation of new MR findings, In: S. Matthysse, D. Levy, J. Kagan, and F.M. Benes (Eds.), Psychopathology: The Evolving Science of Mental Disorders, Cambridge University Press, New York, NY, 1996, pp. 51-99; M.E. Shenton, C.G. Wible, R.W. McCarley, A review of magnetic resonance imaging studies of brain abnormalities in schizophrenia, In: K.R.R. Krishnan, P.M. Doraiswamy (Eds.), Brain Imaging in Clinical Psychiatry, Marcel Dekker Inc., New York, NY, 1997, pp. 297-380; R.W. McCarley, C.G. Wible, M. Frumin, Y. Hirayasu, J. Levitt, I.A. Fischer, M.E. Shenton, MRI Anatomy of Schizophrenia, Biological Psychiatry, 1999;45:1099-1119; and, M.E. Shenton, M. Frumin, R.W. McCarley, S. Maier, C.F. Westin, I.A. Fischer, C. Dickey, R. Kikinis, Morphometric MR Findings in Schizophrenia, In: D. Dougherty, S. Rauch, and J. Rosenbaum (Eds.), Psychiatric Neuroimaging Strategies: Research and Clinical Applications, American Psychiatric Press, In Press.

\section{References}

Adler LE, Olincy A, Waldo M, et al. Schizophrenia, sensory gating, and nicotinic receptors. Schizophr. Bull 1998;24:189-202. [PubMed: 9613620]

Akbarian S, Bunney WE Jr, Potkin SG, et al. Altered distribution of nicotinamideadenine dinucleotide phosphatedia-phorase cells in frontal lobe of schizophrenics implies disturbances of cortical development. Arch. Gen. Psychiatry 1993a;50:169-177. [PubMed: 7679891]

Akbarian S, Vinuela A, Kim JJ, et al. Distorted distribution of nicotinamideadenine dinucleotide phosphatediaphorase neurons in temporal lobe of schizophrenics implies anomalous cortical development. Arch. Gen. Psychiatry 1993b;50:178-187. [PubMed: 7679892]

Altshuler LL, Bartzokis G, Grieder T, et al. Amygdala enlargement in bipolar disorder and hippocampal reduction in schizophrenia: an MRI study demonstrating neuroanatomic specificity [letter]. Arch. Gen. Psychiatry 1998;55:663-664. [PubMed: 9672058]

Alzheimer A. Beitrage zur pathologischen anatomie der hirnrinde und zur anatomischen grundlage einiger psychosen. Monatsschrift fur Psychiarie und Neurologie 1897;2:82-120.

Anderson J, Umans C, Halle M, et al. Anatomy Browser: Java based interactive teaching tool for learning human neuro-anatomy. RSNA Electronic Journal 1998;2:50-97. http://ej.rsna.org/ej2/0050-97.fin/ index.html.

Andreasen N, Nasrallah HA, Dunn V, et al. Structural abnormalities in the frontal system in schizophrenia. A magnetic resonance imaging study. Arch. Gen. Psychiatry 1986;43:136-144. [PubMed: 3947208] 
Andreasen NC, Ehrhardt JC, Swayze VW II, et al. Magnetic resonance imaging of the brain in schizophrenia. The pathophysiologic significance of structural abnormalities. Arch. Gen. Psychiatry 1990;47:35-44. [PubMed: 2294854]

Andreasen NC, Rezai K, Alliger R, et al. Hypofrontality in neurolepticnaive patients and in patients with chronic schizophrenia. Assessment with xenon 133 singlephoton emission computed tomography and the Tower of London. Arch. Gen. Psychiatry 1992;49:943-958. [PubMed: 1360199]

Andreasen NC, Flashman L, Flaum M, et al. Regional brain abnormalities in schizophrenia measured with magnetic resonance imaging. JAMA 1994a;272:1763-1769. [PubMed: 7966925]

Andreasen NC, Arndt S, Swayze VW II, et al. Thalamic abnormalities in schizophrenia visualized through magnetic resonance image averaging . Science 1994b;266:294-298. [see comments]. [PubMed: 7939669]

Andreasen NC. Linking mind and brain in the study of mental illnesses: a project for a scientific psychopathology. Science 1997;275:1586-1593. [PubMed: 9054346]

Andreasen NC, Nopoulos P, O'Leary DS, et al. Defining the phenotype of schizophrenia: cognitive dysmetria and its neural mechanisms. Biol. Psychiatry 1999;46:908-920. [PubMed: 10509174]

Andreasen NC. Schizophrenia: the fundamental questions. Brain Res. Brain Res. Rev 2000;31:106-112. [PubMed: 10719138]

Arciniegas D, Rojas DC, Teale P, et al. The thalamus and the schizophrenia phenotype: failure to replicate reduced volume. Biol. Psychiatry 1999;45:1329-1335. [PubMed: 10349040]

Arndt S, Cohen G, Alliger RJ, et al. Problems with ratio and proportion measures of imaged cerebral structures. Psychiatry Res 1991;40:79-89. [PubMed: 1946842]

Arndt S, Rajarethinam R, Cizadlo T, et al. Landmark-based MR image registration and measurement: a reliability and validation study. J. Psychiatr. Res. Neuroimaging 1996;67:145-154.

Aylward EH, Reiss AL, Barta PE, et al. Magnetic resonance imaging measurement of posterior fossa structures in schizophrenia. Am. J. Psychiatry 1994;151:1448-1452. [PubMed: 8092338]

Baaré WF, Hulshoff Pol HE, Hijman R, et al. Volumetric analysis of frontal lobe regions in schizophrenia: relation to cognitive function and symptomatology. Biol. Psychiatry 1999;45:1597-1605. [PubMed: 10376121]

Barr WB, Ashtari M, Bilder RM, et al. Brain morphometric comparison of firstepisode schizophrenia and temporal lobe epilepsy. Br. J. Psychiatry 1997;170:515-519. [PubMed: 9330016]

Barta PE, Pearlson GD, Powers RE, et al. Auditory hallucinations and smaller superior temporal gyral volume in schizophrenia. Am. J. Psychiatry 1990;147:1457-1462. [PubMed: 2221156]

Barta PE, Pearlson GD, Brill LB II, et al. Planum temporale asymmetry reversal in schizophrenia: replication and relationship to gray matter abnormalities. Am. J. Psychiatry 1997a;154:661-667. [PubMed: 9137122]

Barta PE, Powers RE, Aylward EH, et al. Quantitative MRI volume changes in late onset schizophrenia and Alzheimer's disease compared to normal controls. Psychiatry Res 1997b;68:65-75. [PubMed: 9104754]

Bartley AJ, Jones DW, Torrey EF, et al. Sylvian fissure asymmetries in monozygotic twins: a test of laterality in schizophrenia. Biol. Psychiatry 1993;34:853-863. [PubMed: 8110912]

Bartzokis G, Nuechterlein KH, Marder SR, et al. Age at illness onset and left temporal lobe length in males with schizophrenia. Psychiatry Research: Neuroimaging 1996;67:189-201.

Becker T, Elmer K, Mechela B, et al. MRI findings in medial temporal lobe structures in schizophrenia. Eur. Neuropsychopharmacol 1990;1:83-86. [PubMed: 2136220]

Becker T, Elmer K, Schneider F, et al. Confirmation of reduced temporal limbic structure volume on magnetic resonance imaging in male patients with schizophrenia. Psychiatry Res 1996;67:135-143. [published erratum appears in Psychiatry Res 1997 May 16;74(2):1278]. [PubMed: 8876013]

Benes FM, Bird ED. An analysis of the arrangement of neurons in the cingulate cortex of schizophrenic patients. Arch. Gen. Psychiatry 1987;44:608-616. [PubMed: 3606326]

Benes FM, Paskevich PA, Domesick VB. Haloperiodol-induced plasticity of axon terminals in rat substantia nigra. Science 1983;221:969-971. [PubMed: 6879197]

Benes FM. Myelination of corticalhippocampal relays during late adolescence. Schizophr. Bull 1989;15:585-593. [PubMed: 2623440] 
Benes FM, Sorensen I, Bird ED. Reduced neuronal size in posterior hippocampus of schizophrenic patients. Schizophr. Bull 1991;17:597-608. [PubMed: 1805353]

Benes FM, Vincent SL, Alsterberg G, et al. Increased GABAa receptor binding in superficial layers of cingulate cortex in schizophrenics. J. Neurosci 1992;12:924-929. [PubMed: 1372045]

Benes F. Is there a neuroanatomic basis for schizophrenia? An old question revisited. Neuroscientist 1995;1:104-115.

Bilder RM, Wu H, Bogerts B, et al. Absence of regional hemispheric volume asymmetries in firstepisode schizophrenia. Am. J. Psychiatry 1994;151:1437-1447. [PubMed: 8092337]

Bilder RM, Bogerts B, Ashtari M, et al. Anterior hippocampal volume reductions predict frontal lobe dysfunction in first episode schizophrenia. Schizophr. Res 1995;17:47-58. [PubMed: 8541249]

Bilder RM, Wu H, Bogerts B, et al. Cerebral volume asymmetries in schizophrenia and mood disorders: a quantitative magnetic resonance imaging study. Int. J. Psychophysiol 1999;34:197-205. [PubMed: $10610044]$

Binder J. Functional magnetic resonance imaging. Language mapping. Neurosurg. Clin. N. Am 1997;8:383-392. [PubMed: 9188545]

Blackwood DH, Young AH, McQueen JK, et al. Magnetic resonance imaging in schizophrenia: altered brain morphology associated with P300 abnormalities and eye tracking dysfunction. Biol. Psychiatry 1991;30:753-769. [PubMed: 1751619]

Bleuler, E. Dementia praecox or the group of schizophrenias. New York: International Universities Press; 1911-1950.

Bogerts B. Neuropathology of schizophrenias. Fortschr. Neural. Psychiatr 1984;52:428-437.

Bogerts B, Meertz E, SchonfeldtBausch R. Basal ganglia and limbic system pathology in schizophrenia. A morphometric study of brain volume and shrinkage. Arch. Gen. Psychiatry 1985;42:784-791. [PubMed: 4015323]

Bogerts B, Ashtari M, Degreef G, et al. Reduced temporal limbic structure volumes on magnetic resonance images in first episode schizophrenia. Psychiatry Res 1990;35:1-13. [PubMed: 2367608]

Bogerts B, Falkai P, Greve B, et al. The neuropathology of schizophrenia: past and present. J. Hirnforsch 1993a;34:193-205. [PubMed: 8228181]

Bogerts B, Lieberman JA, Ashtari M, et al. Hippocampusamygdala volumes and psychopathology in chronic schizophrenia. Biol. Psychiatry 1993b;33:236-246. [PubMed: 8471676]

Bogerts B. The neuropathology of schizophrenic diseases: historical aspects and present knowledge. Eur. Arch. Psychiatry Clin. Neurosci 1999;249:2-13. [PubMed: 10654104]

Bookstein, F. Morphometric tools for landmark data: geometry and biology. Cambridge University Press: Cambridge; 1991.

Bookstein FL. Shape and information in medical images: A decade of the morphometric synthesis. Computer Vision and Image Understanding 1997a;66:97-118.

Bookstein FL. Landmark methods for forms without landmarks: Morphometrics of group differences in outline shape. Medical Image Analysis 1997b;1:225-243. [PubMed: 9873908]

Bornstein RA, Schwarzkopf SB, Olson SC, et al. Third-ventricle enlargement and neuropsychological deficit in schizophrenia. Biol. Psychiatry 1992;31:954-961. [PubMed: 1637933]

Brechbühler C, Gerig G, Kübler O. Parametrization of closed surfaces for 3-D shape description. CVGIP: Image Understanding 1995;61:154-170.

Breier A, Buchanan RW, Elkashef A, et al. Brain morphology and schizophrenia. A magnetic resonance imaging study of limbic, prefrontal cortex, and caudate structures. Arch. Gen. Psychiatry 1992;49:921-926. [see comments]. [PubMed: 1449382]

Bremner JD, Randall P, Scott TM, et al. MRI-based measurement of hippocampal volume in patients with combat-related posttraumatic stress disorder. Am. J. Psychiatry 1995;152:973-981. [PubMed: 7793467]

Brown R, Colter N, Corsellis JA, et al. Postmortem evidence of structural brain changes in schizophrenia. Differences in brain weight, temporal horn area, and parahippocampal gyrus compared with affective disorder. Arch. Gen. Psychiatry 1986;43:36-42. [PubMed: 2935114] 
Bryant NL, Buchanan RW, Vladar K, et al. Gender differences in temporal lobe structures of patients with schizophrenia: a volumetric MRI study. Am. J. Psychiatry 1999;156:603-609. [PubMed: 10200741]

Buchanan RW, Breier A, Kirkpatrick B, et al. Structural abnormalities in deficit and nondeficit schizophrenia. Am. J. Psychiatry 1993;150:59-65. [see comments]. [PubMed: 8417581]

Buchanan RW, Vladar K, Barta PE, et al. Structural evaluation of the prefrontal cortex in schizophrenia. Am. J. Psychiatry 1998;155:1049-1055. [PubMed: 9699693]

Buchsbaum MS. The frontal lobes, basal ganglia, and temporal lobes as sites for schizophrenia. Schizophr. Bull 1990;16:379-389. [PubMed: 2287929]

Buchsbaum MS, Someya T, Teng CY, et al. PET and MRI of the thalamus in nevermedicated patients with schizophrenia. Am. J. Psychiatry 1996;153:191-199. [PubMed: 8561198]

Buchsbaum MS, Yang S, Hazlett E, et al. Ventricular volume and asymmetry in schizotypal personality disorder and schizophrenia assessed with magnetic resonance imaging. Schizophr. Res 1997;27:4553. [PubMed: 9373894]

Buchsbaum MS, Tang CY, Peled S, et al. MRI white matter diffusion anisotropy and PET metabolic rate in schizophrenia. Neuroreport 1998;9:425-430. [PubMed: 9512384]

Buckley PF. Structural brain imaging in schizophrenia. Psychiatr. Clin. North Am 1998;21:77-92. [PubMed: 9551492]

Buckley PF, Dean D, Bookstein FL, et al. Threedimensional magnetic resonancebased morphometrics and ventricular dysmorphology in schizophrenia. Biol. Psychiatry 1999;45:62-67. [PubMed: 9894576]

Callicott JH, Egan MF, Bertolino A, et al. Hippocampal nacetyl aspartate in unaffected siblings of patients with schizophrenia: a possible intermediate neurobiological phenotype. Biol. Psychiatry 1998;44:941-950. [PubMed: 9821558]

Cannon TD, van Erp TG, Huttunen M, et al. Regional gray matter, white matter, and cerebrospinal fluid distributions in schizophrenic patients, their siblings, and controls. Arch. Gen. Psychiatry 1998;55:1084-1091. [PubMed: 9862551]

Carpenter, M. Core Text of Neuroanatomy. Human Neuroanatomy. Baltimore, MD: Williams and Wilkins; 1983.

Casanova MF, Zito M, Goldberg T, et al. Shape distortion of the corpus callosum of monozygotic twins discordant for schizophrenia [letter]. Schizophr. Res 1990;3:155-156. [PubMed: 2278979]

Cavada C, Goldman-Rakic PS. Posterior parietal cortex in rhesus monkeys, I: Parcellation of areas based on distinctive limbic and sensory corticocortical connections. J. Comp. Neurol 1989;287:393-421. [PubMed: 2477405]

Chakos MH, Lieberman JA, Bilder RM, et al. Increase in caudate nuclei volumes of first-episode schizophrenic patients taking antipsychotic drugs. Am. J. Psychiatry 1994;151:1430-1436. [PubMed: 7916539]

Chakos MH, Lieberman JA, Alvir J, et al. Caudate nuclei volumes in schizophrenic patients treated with typical antipsychotics or clozapine [letter]. Lancet 1995;345:456-457. [PubMed: 7853978]

Chi JG, Dooling EC, Gilles FH. Gyral development of the human brain. Ann. Neurol 1977;1:86-93. [PubMed: 560818]

Chien D, Buxton RB, Kwong KK, et al. MR diffusion imaging of the human brain. J. Comput. Assist. Tomogr 1990;14:514-520. [PubMed: 2370348]

Chua SE, McKenna PJ. Schizophrenia brain disease? A critical review of structural and functional cerebral abnormality in the disorder. Br. J. Psychiatry 1995;166:563-582. [PubMed: 7620741]

Chua SE, Sharma T, Takei N, et al. A magnetic resonance imaging study of corpus callosum size in familial schizophrenic subjects, their relatives, and normal controls. Schizophr. Res 2000;41:397403. [PubMed: 10728717]

Coffman JA, Schwarzkopf SB, Olson SC, et al. Midsagittal cerebral anatomy by magnetic resonance imaging. The importance of slice position and thickness. Schizophr. Res 1989;2:287-294. [PubMed: 2487168]

Collins, DL.; Dai, W.; Peters, TM.; Evans, AC. Model based segmentation of individual brain structures from MRI data. In: Robb, RA., editor. Proc. SPIE 1808. Chapel Hill, NC: Visualization in Biomedical Computing II; 1992. p. 10-23. 
Colombo C, Abbruzzese M, Livian S, et al. Memory functions and temporallimbic morphology in schizophrenia. Psychiatry Res 1993;50:45-56. [PubMed: 8511223]

Colombo C, Bonfanti A, Scarone S. Anatomical characteristics of the corpus callosum and clinical correlates in schizophrenia. Eur. Arch. Psychiatry Clin. Neurosci 1994;243:244-248. [PubMed: 8172939]

Colter N, Battal S, Crow TJ, et al. White matter reduction in the parahippocampal gyrus of patients with schizophrenia [letter]. Arch. Gen. Psychiatry 1987;44:1023. [PubMed: 3675129]

Copolov D, Velakoulis D, McGorry P, et al. Neurobiological findings in early phase schizophrenia. Brain Res. Brain Res. Rev 2000;31:157-165. [PubMed: 10719144]

Corey-Bloom J, Jernigan T, Archibald S, et al. Quantitative magnetic resonance imaging of the brain in latelife schizophrenia. Am. J. Psychiatry 1995;152:447-449. [PubMed: 7864275]

Corson PW, Nopoulos P, Andreasen NC, et al. Caudate size in first episode neurolepticnaive schizophrenic patients measured using an artificial neural network. Biol. Psychiatry 1999a;46:712720. [PubMed: 10472424]

Corson PW, Nopoulos P, Miller DD, et al. Change in basal ganglia volume over 2 years in patients with schizophrenia: typical versus atypical neuroleptics. Am. J. Psychiatry 1999b;156:1200-1204. [PubMed: 10450260]

Coyle JT, Puttfarcken P. Oxidative stress, glutamate, and neurodegenerative disorders. Science 1993;262:689-695. [PubMed: 7901908]

Coyle JT. The glutamatergic dysfunction hypothesis for schizophrenia. Harvard Rev. Psychiatr 1996;3:241-253.

Crichton-Browne J. On the weight of the brain and its components parts in the insane. Brain 1879;2:4267.

Crow TJ, Ball J, Bloom SR, et al. Schizophrenia as an anomaly of development of cerebral asymmetry. A postmortem study and a proposal concerning the genetic basis of the disease. Arch. Gen. Psychiatry 1989;46:1145-1150. [PubMed: 2589928]

Crow TJ. The continuum of psychosis and its genetic origins. The sixty-fifth Maudsley lecture. Br. J. Psychiatry 1990a;156:788-797. [see comments]. [PubMed: 2207509]

Crow TJ. Temporal lobe asymmetries as the key to the etiology of schizophrenia. Schizophr. Bull 1990b; 16:433-443. [PubMed: 2287933]

Crow TJ. Temporolimbic or transcallosal connections: Where is the primary lesion in schizophrenia and what is its nature? Schizophr. Bull 1997;23:521-523. [comment]. [PubMed: 9327516]

Crow TJ. Schizophrenia as a transcallosal misconnection syndrome. Schizophr. Res 1998;30:111-114. [PubMed: 9549773]

Csernansky JG, Joshi S, Wang L, et al. Hippocampal morphometry in schizophrenia by high dimensional brain mapping. Proc. Natl. Acad. Sci. USA 1998;95:11406-11411. [PubMed: 9736749]

Dasari M, Friedman L, Jesberger J, et al. A magnetic resonance imaging study of thalamic area in adolescent patients with either schizophrenia or bipolar disorder as compared to healthy controls. Psychiatry Res 1999;91:155-162. [PubMed: 10641579]

Dauphinais ID, DeLisi LE, Crow TJ, et al. Reduction in temporal lobe size in siblings with schizophrenia: a magnetic resonance imaging study. Psychiatry Res 1990;35:137-147. [PubMed: 2100805]

DeLisi LE, Dauphinais ID, Gershon ES. Perinatal complications and reduced size of brain limbic structures in familial schizophrenia. Schizophr. Bull 1988;14:185-191. [PubMed: 3201176]

DeLisi LE, Hoff AL, Schwartz JE. Brain morphology in firstepisode schizophreniclike psychotic patients: a quantitative magnetic resonance imaging study. Biol. Psychiatry 1991;29:159-175. [published erratum appears in Biol. Psychiatry 1991 Mar 1;29(5):519]. [PubMed: 1995085]

DeLisi LE, Stritzke P, Riordan H, et al. The timing of brain morphological changes in schizophrenia and their relationship to clinical outcome. Biol. Psychiatry 1992;31:241-254. [published erratum appears in Biol. Psychiatry 1992 jun 1;31(11):1172]. [PubMed: 1547298]

DeLisi LE, Hoff AL, Kushner M, et al. Increased prevalence of cavum septum pellucidum in schizophrenia. Psychiatry Res 1993;50:193-199. [PubMed: 8272454] 
DeLisi LE, Hoff AL, Neale C, et al. Asymmetries in the superior temporal lobe in male and female firstepisode schizophrenic patients: measures of the planum temporale and superior temporal gyrus by MRI. Schizophr. Res 1994;12:19-28. [PubMed: 8018582]

DeLisi LE, Tew W, Xie S, et al. A prospective followup study of brain morphology and cognition in first-episode schizophrenic patients: preliminary findings. Biol. Psychiatry 1995;38:349-360. [PubMed: 8547454]

DeLisi LE, Sakuma M, Tew W. Schizophrenia as a chronic active brain process: a study of progressive brain structural change subsequent to the onset of schizophrenia. Psychiatry Res 1997;74:129-140. [see comments]. [PubMed: 9255858]

DeLisi LE, Sakuma M, Ge S, et al. Association of brain structural change with the heterogeneous course of schizophrenia from early childhood through five years subsequent to a first hospitalization. Psychiatry Res 1998;84:75-88. [PubMed: 10710165]

DeMyer MK, Gilmor RL, Hendrie HC, et al. Magnetic resonance brain images in schizophrenic and normal subjects: influence of diagnosis and education. Schizophr. Bull 1988;14:21-37. [PubMed: 3387916]

DeQuardo JR, Bookstein FL, Green WD, et al. Spatial relationships of neuroanatomic landmarks in schizophrenia. Psychiatry Res 1996;67:81-95. [PubMed: 8797245]

DeQuardo JR, Keshavan MS, Bookstein FL, et al. Landmark based morphometric analysis of firstepisode schizophrenia. Biol. Psychiatry 1999;45:1321-1328. [PubMed: 10349039]

Degreef G, Bogerts B, Ashtari M, et al. Ventricular system morphology in first episode schizophrenia: a volumetic study of ventricular subdivisions on MRI. Schizophr. Res 1990;3:18.

Degreef G, Ashtari M, Wu HW, et al. Follow up MRI study in first episode schizophrenia. Schizophr. Res 1991;5:204-206. [PubMed: 1760397]

Degreef G, Ashtari M, Bogerts B, et al. Volumes of ventricular system subdivisions measured from magnetic resonance images in firstepisode schizophrenic patients. Arch. Gen. Psychiatry 1992a; 49:531-537. [PubMed: 1627044]

Degreef G, Lantos G, Bogerts B, et al. Abnormalities of the septum pellucidum on MR scans in firstepisode schizophrenic patients. Am. J. Neuroradiol 1992b;13:835-840. [see comments]. [PubMed: 1590179]

Degreef G, Bogerts B, Falkai P, et al. Increased prevalence of the cavum septum pellucidum in magnetic resonance scans and postmortem brains of schizophrenic patients. Psychiatry Res 1992c;45:1-13. [PubMed: 1410074]

Deicken RF, Pegues M, Amend D. Reduced hippocampal nacetylaspartate without volume loss in schizophrenia. Schizophr. Res 1999;37:217-223. [PubMed: 10403193]

Di Michele V, Rossi A, Stratta P, et al. Neuropsychological and clinical correlates of temporal lobe anatomy in schizophrenia. Acta Psychiatr. Scand 1992;85:484-488. [PubMed: 1642134]

Dickey CC, McCarley RW, Voglmaier MM, et al. Schizotypal personality disorder and MRI abnormalities of temporal lobe gray matter. Biol. Psychiatry 1999;45:1393-1402. [PubMed: 10356620]

Doran M, Hajnal JV, Van Bruggen N, et al. Normal and abnormal white matter tracts shown by MR imaging using directional diffusion weighted sequences. J. Comput. Assist. Tomogr 1990;14:865873. [PubMed: 2229559]

Douek P, Turner R, Pekar J, et al. MR color mapping of myelin fiber orientation. J. Comput. Assist. Tomogr 1991;15:923-929. [PubMed: 1939769]

Downhill JE Jr, Buchsbaum MS, Wei T, et al. Shape and size of the corpus callosum in schizophrenia and schizotypal personality disorder. Schizophr. Res 2000;42:193-208. [PubMed: 10785578]

Drevets WC, Videen T, Price JL, et al. A functional anatomical study of unipolar depression. J. Neurosci 1992;12:3628-3641. [PubMed: 1527602]

Dunlap C. Dementia praecox: Some preliminary observations on brains from carefully selected cases, and a consideration of certain sources of error. Am. J. Psychiatry 1924;80:403-421.

Egan MF, Duncan CC, Suddath RL, et al. Eventrelated potential abnormalities correlate with structural brain alterations and clinical features in patients with chronic schizophrenia. Schizophr. Res 1994;11:259-271. [PubMed: 7910755] 
Eidelberg D, Galaburda AM. Inferior parietal lobule: divergent architectonic asymmetries in the human brain. Arch. Neurol 1984;41:843-852. [PubMed: 6466160]

Elkashef AM, Buchanan RW, Gellad F, et al. Basal ganglia pathology in schizophrenia and tardive dyskinesia: an MRI quantitative study. Am. J. Psychiatry 1994;151:752-755. [PubMed: 7909412]

Eriksson PS, Perfilieva E, Bjork-Eriksson T, et al. Neurogenesis in the adult human hippocampus. Nat. Med 1998;11:1313-1317. [PubMed: 9809557]

Evans A, Marret S, Torrescorzo J, et al. MRI-PET correlation in three dimensions using a volume-ofinterest (VOI) atlas. J. Cerebral Blood Flow Metab 1991;11:A69-A78.

Falkai P, Bogerts B. Cell loss in the hippocampus of schizophrenics. Eur. Arch. Psychiatry Neurol. Sci 1986;236:154-161. [PubMed: 3803399]

Falkai P, Bogerts B, Rozumek M. Limbic pathology in schizophrenia: The entorhinal regiona morphometric study. Biol. Psychiatry 1988;24:515-521. [PubMed: 3167140]

Feinberg I. Schizophrenia: Caused by a fault in programmed synaptic elimination during adolescence? J. Psychiatr. Res 1982;17:319-334. [PubMed: 7187776]

Flaum M, Andreasen NC, Swayze VW, et al. I.Q. and brain size in schizophrenia. Psychiatr. Res 1994;53:243-257.

Flaum M, Swayze VW II, O’Leary DS, et al. Effects of diagnosis, laterality, and gender on brain morphology in schizophrenia. Am. J. Psychiatry 1995;152:704-714. [PubMed: 7726310]

Foong J, Maier M, Barker GJ, et al. In vivo investigation of white matter pathology in schizophrenia with magnetisation transfer imaging. J. Neurol. Neurosurg. Psychiatry 2000a;68:70-74. [PubMed: 10601405]

Foong J, Maier M, Clark CA, et al. Neuropathological abnormalities of the corpus callosum in schizophrenia: a diffusion tensor imaging study. J. Neurol. Neurosurg. Psychiatry 2000b;68:242244. [PubMed: 10644799]

Frackowiak RS. Functional mapping of verbal memory and language. Trends Neurosci 1994;17:109_ 115. [PubMed: 7515526]

Frangou S, Sharma T, Sigmudsson T, et al. The Maudsley Family Study. 4. Normal planum temporale asymmetry in familial schizophrenia. A volumetric MRI study. Br. J. Psychiatry 1997;170:328333. [PubMed: 9246250]

Frazier JA, Giedd JN, Hamburger SD, et al. Brain anatomic magnetic resonance imaging in childhoodonset schizophrenia. Arch. Gen. Psychiatry 1996;53:617-624. [PubMed: 8660128]

Frazier JA, Alaghband-Rad J, Jacobsen L, et al. Pubertal development and onset of psychosis in childhood onset of schizophrenia. Psychiatr. Res 1997;70:1-7.

Frederikse M, Lu A, Aylward E, et al. Sex differences in inferior parietal lobule volume in schizophrenia. Am. J. Psychiatry 2000;157:422-427. [PubMed: 10698819]

Friedman L, Findling RL, Kenny JT, et al. An MRI study of adolescent patients with either schizophrenia or bipolar disorder as compared to healthy control subjects. Biol. Psychiatry 1999;46:78-88. [published erratum appears in Biol. Psychiatry 1999 Aug 15;46(4):Follow-ing 584]. [PubMed: 10394476]

Frumin, M.; Golland, P.; McCarley, RW., et al. Shape differences in the corpus callosum in first episode schizophrenia and affective disorder. 37th Annual Meeting of the American College of Neuropsychopharmacology; Puerto Rico. 1998 Dec.

Fukuzako H, Fukazako T, Hashiguchi T, et al. Reduction in hippocampal formation volume is caused mainly by its shortening in chronic schizophrenia: assessment by MRI. Biol. Psychiatry 1996a; 39:938-945. [PubMed: 9162205]

Fukuzako T, Fukuzako H, Kodama S, et al. Cavum septum pellucidum in schizophrenia: a magnetic resonance imaging study. Psychiatry Clin. Neurosci 1996b;50:125-128. [PubMed: 9201757]

Fukuzako H, Yamada K, Kodama S, et al. Hippocampal volume asymmetry and age at illness onset in males with schizophrenia. Eur. Arch. Psychiatry Clin. Neurosci 1997;247:248-251. [PubMed: 9444493]

Fuster, JM. The Prefrontal Cortex. New York: Raven Press; 1989.

Galaburda A, Geschwind N. The human language areas and cerebral asymmetries. Rev. Med. Suisse Romande 1980;100:119-128. [PubMed: 6990448] 
Galaburda AM, Sanides F. Cytoarchitectonic organization of the human auditory cortex. J. Comp. Neurol 1980;190:597-610. [PubMed: 6771305]

Galaburda AM, Sanides F, Geschwind N. Human brain: cytoarchitectonic left-right asymmetries in the temporal speech region. Arch. Neurol 1978;35:812-817. [PubMed: 718483]

Galaburda AM, Corsiglia J, Rosen GD, et al. Planum temporale asymmetry, reappraisal since Geschwind and Levitsky. Neuropsychologia 1987;25:853.

Galderisi S, Mucci A, Mignone ML, et al. Hemispheric asymmetry and psychopathological dimensions in drug-free patients with schizophrenia. Int. J. Psychophysiol 1999;34:293-301. [PubMed: 10610053]

Galderisi S, Vita A, Rossi A, et al. Qualitative MRI findings in patients with schizophrenia: a controlled study. Psychiatry Res 2000;98:117-126. [PubMed: 10762737]

Gaser C, Volz HP, Kiebel S, et al. Detecting structural changes in whole brain based on nonlinear deformations-application to schizophrenia research. Neuroimage 1999;10:107-113. [PubMed: 10417245]

Gee JC, Reivich M, Bajcsy R. Elastically deforming 3D atlas to match anatomical brain images. J. Computer-Assisted Tomog 1993;17:225-236.

Geschwind N, Galaburda AM. Cerebral lateralization: Biological mechanisms, associations and pathology: I. A hypothesis and program for research. Arch. Neurol 1985;42:428-459. [PubMed: 3994562]

Geschwind N, Levitsky W. Human brain: left-right asymmetries in temporal speech region. Science 1968;161:186-187. [PubMed: 5657070]

Glass, G.; McGraw, B.; Smith, M. Metaanalysis in Social Research. Newbury Park, CA: Sage Publications; 1981.

Gloor, P. The role of the limbic system in perception, memory, and affect. In: Livingston, BDK., editor. The Limbic System. New York: Raven Press; 1986.

Goldberg TE, Weinberger DR, Berman KF, et al. Further evidence for dementia of the prefrontal type in schizophrenia? A controlled study of teaching the Wisconsin Card Sorting Test. Arch. Gen. Psychiatry 1987;44:1008-1014. [see comments]. [PubMed: 3675128]

Goldberg TE, Torrey EF, Berman KF, et al. Relations between neuropsychological performance and brain morphological and physiological measures in monozygotic twins discordant for schizophrenia. Psychiatry Res 1994;55:51-61. [PubMed: 8047629]

Goldman-Rakic PS, Selemon LD. Functional and anatomical aspects of prefrontal pathology in schizophrenia. Schizophr. Bull 1997;23:437-458. [PubMed: 9327508]

Goldman-Rakic PS, Selemon LD, Schwartz ML. Dual pathways connecting the dorsolateral prefrontal cortex with the hippocampal formation and parahippocampal cortex in the rhesus monkey. Neuroscience 1984;12:719-743. [PubMed: 6472617]

Goldstein JM, Goodman JM, Seidman LJ, et al. Cortical abnormalities in schizophrenia identified by structural magnetic resonance imaging. Arch. Gen. Psychiatry 1999;56:537-547. [PubMed: 10359468]

Golland P, Grimson WE. Fixed topology skeletons. Computer Vision and Pattern Recognition: IEEE Computer Society 2000:10-17.

Golland, P.; Grimson, WE.; Kikinis, R. Statistical shape analyses using fixed topology skeletons: corpus callosum study. In: Kuba, A.; Smal, M.; Todd-Polropek, A., editors. Sixteenth International Conference on Information Processing and Medical Imaging. Springer-Verlag: Visegrad, Hungary; 1999. p. 382-387.

Golomb J, de Leon MJ, Kluger A, et al. Hippocampal atrophy in normal aging: an association with recent memory impairment. Arch. Neurol 1993;50:967-973. [PubMed: 8363451]

Grunze HC, Rainnie DG, Hasselmo ME, et al. NMDA-dependent modulation of cal local circuit inhibition. J. Neurosci 1996;16:2034-2043. [PubMed: 8604048]

Gruzelier, JH. Hemispheric imbalance: syndromes of schizophrenia, premorbid personality, and neurodevelopmental influences. In: Steinhauer, SR.; Gruzelier, JH.; Zubin, J., editors. Handbook of Schizophrenia: Neuropsychology, Psychophysiology and Information Processing. Vol. vol. 5.. New York, NY: Elsevier; 1991. p. 599-650. 
Guenther W, Moser E, Petsch R, et al. Pathological cerebral blood blow and corpus callosum abnormalities in schizophrenia: Relations to EEG mapping and PET data. Psychiatry Res 1989;29:453-455. [PubMed: 2608818]

Guerguerian R, Lewine RR. Brain torque and sex differences in schizophrenia. Schizophr. Res 1998;30:175-181. [PubMed: 9549782]

Gunther W, Petsch R, Steinberg R, et al. Brain dysfunction during motor activation and corpus callosum alterations in schizophrenia measured by cerebral blood flow and magnetic resonance imaging. Biol. Psychiatry 1991;29:535-555. [PubMed: 1905162]

Gur RE, Pearlson GD. Neuroimaging in schizophrenia research. Schizophr. Bull 1993;19:337-353. [PubMed: 8322037]

Gur RE, Mozley PD, Shtasel DL, et al. Clinical subtypes of schizophrenia: Differences in brain and CSF volume. Am. J. Psychiatry 1994;151:343-350. [see comments]. [PubMed: 8109642]

Gur RE, Maany V, Mozley PD, et al. Subcortical MRI volumes in neurolepticnaive and treated patients with schizophrenia. Am. J. Psychiatry 1998a;155:1711-1717. [see comments]. [PubMed: 9842780]

Gur RE, Cowell P, Turetsky BI, et al. A followup magnetic resonance imaging study of schizophrenia. Relationship of neuroanatomical changes to clinical and neurobehavioral measures. Arch. Gen. Psychiatry 1998b;55:145-152. [PubMed: 9477928]

Gur RE, Turetsky BI, Bilker WB, et al. Reduced gray matter volume in schizophrenia. Arch. Gen. Psychiatry 1999;56:905-911. [PubMed: 10530632]

Gur RE, Turetsky BI, Cowell PE, et al. Temporolimbic volume reductions in schizophrenia. Arch. Gen. Psychiatry 2000a;57:769-775. [PubMed: 10920465]

Gur RE, Cowell PE, Latshaw A, et al. Reduced dorsal and orbital prefrontal gray matter volumes in schizophrenia. Arch. Gen. Psychiatry 2000b;57:761-768. [PubMed: 10920464]

Gurvits TV, Shenton ME, Hokama H, et al. Magnetic resonance imaging study of hippocampal volume in chronic, combat-related post-traumatic stress disorder. Biol. Psychiatry 1996;40:1091-1099. [PubMed: 8931911]

Gøtzsche PC. Why we need a broad perspective on meta-analysis: it may be crucially important for patients. [Letter]. BMJ 2000;321:585-586. [PubMed: 10977820]

Haglund MM, Ojemann GA, Hochman DW. Optical imaging of epileptiform and functional activity in human cerebral cortex. Nature 1992;358:668-671. [PubMed: 1495561]

Hajek M, Huonker R, Boehle C, et al. Abnormalities of auditory evoked magnetic fields and structural changes in the left hemisphere of male schizophrenicsa magnetoencephalographicmagnetic resonance imaging study. Biol. Psychiatry 1997;42:609-616. [PubMed: 9376457]

Hajnal JV, Doran M, Hall AS, et al. MR imaging of anisotropically restricted diffusion of water in the nervous system: Technical, anatomic, and pathologic considerations. J. Comput. Assist. Tomogr 1991;15:1-18. [PubMed: 1987175]

Haller JW, Banerjee A, Christensen GE, et al. Threedimensional hippocampal MR morphometry with highdimensional transformation of a neuroanatomic atlas. Radiology 1997;202:504-510. [PubMed: 9015081]

Harrison PJ. The neuropathology of schizophrenia: A critical review of the data and their interpretation. Brain 1999;122:593-624. [PubMed: 10219775]

Harvey I, Ron MA, Du Boulay G, et al. Reduction of cortical volume in schizophrenia on magnetic resonance imaging. Psychol. Med 1993;23:591-604. [PubMed: 8234567]

Haug J. Pneumoencephalographic studies in mental disease. Acta Psychiatr. Neurol 1962;165:11-104.

Hauser P, Dauphinais ID, Berrettini W, et al. Corpus callosum dimensions measured by magnetic resonance imaging in bipolar affective disorder and schizophrenia. Biol. Psychiatry 1989;26:659668. [PubMed: 2804188]

Havermans R, Honig A, Vuurman EF, et al. A controlled study of temporal lobe structure volumes and P300 responses in schizophrenic patients with persistent auditory hallucinations. Schizophr. Res 1999;38:151-158. [PubMed: 10463460]

Hazlett EA, Buchsbaum MS, Byne W, et al. Threedimensional analysis with MRI and pet of the size, shape, and function of the thalamus in the schizophrenia spectrum. Am. J. Psychiatry 1999;156:1190-1199. [PubMed: 10450259] 
Hecker E. Die hebephrenic. Arch. Patholiche Anat. und fur Physiol. Klinische Medicin 1871;52:394429.

Heckers S, Heinsen H, Heinsen Y, et al. Cortex, white matter, and basal ganglia in schizophrenia: a volumetric postmortem study. Biol. Psychiatry 1991;29:556-566. [PubMed: 2054430]

Heckers S. Neuropathology of schizophrenia: cortex, thalamus, basal ganglia, and neurotransmitterspecific projection systems. Schizophr. Bull 1997;23(3):403-421. [PubMed: 9327506]

Henn FA, Braus DF. Structural neuroimaging in schizophrenia. An integrative view of neuromorphology. Eur. Arch. Psychiatry Clin. Neurosci 1999;249:48-56. [PubMed: 10654109]

Heyman I, Murray RM. Schizophrenia and neurodevelopment. J. R. Coll. Physicians Lond 1992;26:143146. [PubMed: 1588520]

Hier D, LeMay M, Rosenberger P. Autism-association with reversed cerebral asymmetry. Neurology 1978;28:348-349.

Hier D, LeMay M, Rosenberger PB. Autism and unfavorable left-right asymmetries of the brain. J. Autism Dev. Disord 1979;9:153-159. [PubMed: 479099]

Hirayasu Y, Shenton ME, Salisbury DF, et al. Lower left temporal lobe MRI volumes in patients with firstepisode schizophrenia compared with psychotic patients with firstepisode affective disorder and normal subjects. Am. J. Psychiatry 1998;155:1384-1391. [PubMed: 9766770]

Hirayasu Y, Shenton ME, Salisbury DF, et al. Subgenual cingulate cortex volume in first-episode psychosis. Am. J. Psychiatry 1999;156:1091-1093. [PubMed: 10401458]

Hirayasu Y, McCarley RW, Salisbury DF, et al. Planum temporale and Hesch gyrus volume reduction in schizophrenia: A magnetic resonance imaging study of first-episode patients. Arch. Gen. Psychiatry 2000;57:692-699. [PubMed: 10891040]

Hoff AL, Riordan H, O'Donnell D, et al. Anomalous lateral sulcus asymmetry and cognitive function in first-episode schizophrenia. Schizophr. Bull 1992;18:257-272. [published erratum appears in Schizophr. Bull. 1994;20(2):248]. [PubMed: 1621072]

Hoff AL, Neal C, Kushner M, et al. Gender differences in corpus callosum size in first-episode schizophrenics. Biol. Psychiatry 1994;35:913-919. [PubMed: 8080890]

Hokama H, Shenton ME, Nestor PG, et al. Caudate, putamen, and globus pallidus volume in schizophrenia: a quantitative MRI study. Psychiatry Res 1995;61:209-229. [PubMed: 8748466]

Holinger DP, Shenton ME, Wible CG, et al. Superior temporal gyrus volume abnormalities and thought disorder in left-handed schizophrenic men. Am. J. Psychiatry 1999;156:1730-1735. [PubMed: 10553736]

Honer WG, Bassett AS, Smith GN, et al. Temporal lobe abnormalities in multigenerational families with schizophrenia. Biol. Psychiatry 1994;36:737-743. [PubMed: 7858069]

Howard D, Patterson K, Wise R, et al. The cortical localization of the lexicons: positron emission tomography evidence. Brain 1992;115:1769-1782. [PubMed: 1486460]

Hunter, J.; Schmidt, F. Methods of Metaanalysis. Newbury Park, CA: Sage Publications; 1990.

Iosifescu DV, Shenton ME, Warfield SK, et al. An automated registration algorithm for measuring MRI subcortical brain structures. Neuroimage 1997;6:13-25. [PubMed: 9245652]

Jacobi W, Winkler H. Encephalographische studien an schizophrenen. Arch. Psychiatrie 1928;84:208226.

Jacobsen LK, Giedd JN, Vaituzis AC. Temporal lobe morphology in childhoodonset schizophrenia. Am. J. Psychiatry 1996;153:355-361. [published erratum appears in Am. J. Psychiatry 1996 jun;153(6): 851]. [PubMed: 8610822]

Jacobsen LK, Giedd JN, Rajapakse JC, et al. Quantitative magnetic resonance imaging of the corpus callosum in childhood onset schizophrenia. Psychiatry Res 1997;68:77-86. [PubMed: 9104755]

Jacobsen LK, Giedd JN, Castellanos FX, et al. Progressive reduction of temporal lobe structures in childhood-onset schizophrenia. Am. J. Psychiatry 1998;155:678-685. [PubMed: 9585721]

Jakob H, Beckmann H. Prenatal developmental disturbances in the limbic allocortex in schizophrenics. J. Neural. Transm 1986;65:303-326. [PubMed: 3711886]

Jakob H, Beckmann H. Gross and histological criteria for developmental disorders in brains of schizophrenics. J. R. Soc. Med 1989;82:466-469. [PubMed: 2674429] 
James AC, Crow TJ, Renowden S, et al. Is the course of brain development in schizophrenia delayed? Evidence from onsets in adolescence. Schizophr. Res 1999;40:1-10. [PubMed: 10541001]

Jernigan TL, Zisook S, Heaton RK, et al. Magnetic resonance imaging abnormalities in lenticular nuclei and cerebral cortex in schizophrenia. Arch. Gen. Psychiatry 1991;48:881-890. [PubMed: 1929757]

Jeste DV, Lohr JB. Hippocampal pathologic findings in schizophrenia. A morphometric study. Arch. Gen. Psychiatry 1989;46:1019-1024. [PubMed: 2818139]

Jeste DV, McAdams LA, Palmer BW, et al. Relationship of neuropsychological and MRI measures to age of onset of schizophrenia. Acta Psychiatr. Scand 1998;98:156-164. [PubMed: 9718243]

Johnstone EC, Crow TJ, Frith CD, et al. Cerebral ventricular size and cognitive impairment in chronic schizophrenia. Lancet 1976;2:924-926. [PubMed: 62160]

Johnstone EC, Owens DG, Crow TJ, et al. Temporal lobe structure as determined by nuclear magnetic resonance in schizophrenia and bipolar affective disorder. J. Neurol. Neurosurg. Psychiatry 1989;52:736-741. [PubMed: 2746266]

Jones, EG. The Thalamus. New York, NY: Plenum Press; 1985.

Jurjus GJ, Nasrallah HA, Olson SC, et al. Cavum septum pellucidum in schizophrenia, affective disorder and healthy controls: A magnetic resonance imaging study. Psychol. Med 1993;23:319-322. [PubMed: 8332648]

Kahlbaum, K. Die Katatonie oder der Spannungsirresein. Berlin: Hirshwald; 1874.

Kawasaki Y, Maeda Y, Urata K, et al. A quantitative magnetic resonance imaging study of patients with schizophrenia. Eur. Arch. Psychiatry Clin. Neurosci 1993;242:268-272. [PubMed: 8499495]

Kawasaki Y, Maeda Y, Higashima M, et al. Reduced auditory P300 amplitude, medial temporal volume reduction and psychopathology in schizophrenia. Schizophr. Res 1997;26:107-115. [PubMed: 9323340]

Kay, SR.; Opler, LA.; Fizbein, A. Positive and Negative Syndrome Scale. North Tonawanda, New York: Multi-Health Systems Inc; 1986.

Kegeles LS, Shungu DC, Anjilvel S, et al. Hippocampal pathology in schizophrenia: magnetic resonance imaging and spectroscopy studies. Psychiatry Res 2000;98:163-175. [PubMed: 10821999]

Kelsoe JR Jr, Cadet JL, Pickar D, et al. Quantitative neuroanatomy in schizophrenia. A controlled magnetic resonance imaging study. Arch. Gen. Psychiatry 1988;45:533-541. [PubMed: 3377640]

Kendler KS, McGuire M, Gruenberg AM, et al. The Roscommon family study, I: methods, diagnosis of probands, and risk of schizophrenia in relatives. Arch. Gen. Psychiatry 1993;50:527-540. [PubMed: 8317947]

Keshavan MS, Bagwell WW, Haas GL, et al. Changes in caudate volume with neuroleptic treatment [letter]. Lancet 1994;344:1434. [PubMed: 7968091]

Keshavan MS, Bagwell WW, Haas GL, et al. Does caudate volume increase during follow up in firstepisode psychosis? Schizophr. Res 1995;15:87.

Keshavan MS, Rosenberg D, Sweeney JA, et al. Decreased caudate volume in neurolepticnaive psychotic patients. Am. J. Psychiatry 1998a;155:774-778. [PubMed: 9619149]

Keshavan MS, Haas GL, Kahn CE, et al. Superior temporal gyrus and the course of early schizophrenia: progressive, static, or reversible? J. Psychiatr. Res 1998b;32:161-167. [PubMed: 9793869]

Kety SS. Biochemical theories of schizophrenia. Science 1959;129:1528-1532. [PubMed: 13658985]

Kikinis R, Shenton ME, Gerig G, et al. Temporal lobe sulcogyral pattern anomalies in schizophrenia: an in vivo MR three-dimensional surface rendering study. Neurosci. Lett 1994;182:7-12. [PubMed: 7891892]

Kikinis R, Shenton ME, Iosifescu DV, et al. A digital brain atlas for surgical planning, model driven segmentation, and teaching. IEEE Transactions on Visualization and Computer Graphics 1996;2:232-241.

Kleinschmidt A, Falkai P, Huang Y, et al. In vivo morphometry of planum temporale asymmetry in firstepisode schizophrenia. Schizophr. Res 1994;12:9-18. [PubMed: 8018589]

Komuro H, Rakic P. Modulation of neuronal migration by NMDA receptors. Science 1993;260:95-97. [PubMed: 8096653]

Komuro H, Rakic P. Orchestration of neural migration by activity of ion channels, neurotransmitter receptors, and intra-cellular Ca2 + fluctuations. J. Neurobiol 1998;37:110-130. [PubMed: 9777736] 
Kovelman JA, Scheibel AB. A neurohistological correlate of schizophrenia. Biol. Psychiatry 1984;19:1601-1621. [PubMed: 6518211]

Kraepelin, E. Dementia Praecox. New York: Churchill Livingston Inc; 1919-1971.

Kretschmer, E. Physique and Character. New York: Harcourt Brace Jovanovich Publishers; 1925.

Krishnan K, McDonald WM, Escalona PR, et al. Magnetic resonance imaging of the caudate nuclei in depression: preliminary observations. Arch. Gen. Psychiatry 1992;49:553-557. [PubMed: 1627046]

Kulynych JJ, Vladar K, Fantie BD, et al. Normal asymmetry of the planum temporale in patients with schizophrenia. Three-dimensional cortical morphometry with MRI. Br. J. Psychiatry 1995;166:742-749. [PubMed: 7663822]

Kulynych JJ, Vladar K, Jones DW, et al. Superior temporal gyrus volume in schizophrenia: a study using MRI morphometry assisted by surface rendering. Am. J. Psychiatry 1996;153:50-56. [PubMed: 8540591]

Kulynych JJ, Luevano LF, Jones DW, et al. Cortical abnormality in schizophrenia: an in vivo application of the gyrification index. Biol. Psychiatry 1997;41:995-999. [PubMed: 9129779]

Kwon JS, Shenton ME, Hirayasu Y, et al. MRI study of cavum septi pellucidi in schizophrenia, affective disorder, and schizotypal personality disorder. Am. J. Psychiatry 1998;155:509-515. [PubMed: 9545997]

Kwon JS, McCarley RW, Hirayasu Y, et al. Left planum temporale volume reduction in schizophrenia. Arch. Gen. Psychiatry 1999;56:142-148. [PubMed: 10025438]

Lauriello J, Hoff A, Wieneke MH, et al. Similar extent of brain dysmorphology in severely ill women and men with schizophrenia. Am. J. Psychiatry 1997;154:819-825. [PubMed: 9167510]

Lawrie SM, Abukmeil SS. Brain abnormality in schizophrenia. A systematic and quantitative review of volumetric magnetic resonance imaging studies. Br. J. Psychiatry 1998;172:110-120. [see comments]. [PubMed: 9519062]

Lawrie SM, Whalley H, Kestelman JN, et al. Magnetic resonance imaging of brain in people at high risk of developing schizophrenia. Lancet 1999;353:30-33. [see comments]. [PubMed: 10023948]

Le Bihan D, Breton E, Lallemand D. MR imaging of intravoxel incoherent motions: Application to diffusion and perfusion in neurologic disorders. Radiology 1986;161:401-407. [PubMed: 3763909]

Le Bihan, D. Diffusion and Perfusion Magnetic Resonance Imaging. New York: Raven Press; 1995.

LeMay M, Kidd DK. Asymmetry of cerebral hemispheres on computed tomograms. J. Comput. Assist. Tomogr 1978;2:471-476. [PubMed: 708500]

LeMay M. Leftright temporal region asymmetry in infants and children [letter]. AJNR Am. J. Neuroradiol 1986;7:974. [PubMed: 3096123]

Leonard CM, Kuldau JM, Breier JI, et al. Cumulative effect of anatomical risk factors for schizophrenia: an MRI study. Biol. Psychiatry 1999;46:374-382. [PubMed: 10435203]

Levitan C, Ward PB, Catts SV. Superior temporal gyral volumes and laterality correlates of auditory hallucinations in schizophrenia. Biol. Psychiatry 1999;46:955-962. [PubMed: 10509178]

Levitt JJ, Shenton ME, McCarley RW, et al. Premorbid adjustment in schizophrenia: Implications for psychosocial and ventricular pathology. Schizophr. Res 1994;12:159-168. [PubMed: 8043526]

Levitt JJ, McCarley RW, Nestor PG, et al. Quantitative volumetric MRI study of the cerebellum and vermis in schizophrenia: clinical and cognitive correlates. Am. J. Psychiatry 1999;156:1105-1107. [PubMed: 10401463]

Levitt JJ, McCarley RW, Ciszewski AA, et al. Caudate and ventricular volume in neuroleptic-naive schizotypal personality disorder. [Abstract]. American Psychiatric Association New Research Abstracts 2000;140

Lewine RR, Gulley LR, Risch SC, et al. Sexual dimorphism, brain morphology, and schizophrenia. Schizophr. Bull 1990;16:195-203. [PubMed: 2374880]

Lewine RR, Hudgins P, Brown F, et al. Differences in qualitative brain morphology findings in schizophrenia, major depression, bipolar disorder, and normal volunteers. Schizophr. Res 1995;15:253-259. [PubMed: 7632622]

Lewis SW, Mezey GC. Clinical correlates of septum pellucidum cavities: an unusual association with psychosis. Psychol. Med 1985;15:43-54. [PubMed: 2581281] 
Lieberman J, Bogerts B, Degreef G, et al. Qualitative assessment of brain morphology in acute and chronic schizophrenia. Am. J. Psychiatry 1992;149:784-794. [PubMed: 1590495]

Lieberman JA, Jody D, Alvir JM, et al. Brain morphology, dopamine, and eyetracking abnormalities in first episode schizophrenia. Prevalence and clinical correlates. Arch. Gen. Psychiatry 1993;50:357368. [PubMed: 8489325]

Lieberman JA, Alvir JM, Koreen A, et al. Psychobiologic correlates of treatment response in schizophrenia. Neuropsychopharmacology 1996;14:135-215.

Lim KO, Tew W, Kushner M, et al. Cortical gray matter volume deficit in patients with first-episode schizophrenia. Am. J. Psychiatry 1996;153:1548-1553. [PubMed: 8942450]

Lim KO, Hedehus M, Moseley M, et al. Compromised white matter tract integrity in schizophrenia inferred from diffusion tensor imaging. Arch. Gen. Psychiatry 1999;56:367-374. [PubMed: 10197834]

Lipska B, Jaskiw G, Weinberger DR. Postpubertal emergence of hyperresponsiveness to stress and to amphetamine after neonatal excitotoxic hippocampal damage: A potential animal model of schizophrenia. Neuropsychopharmacology 1993;9:67-75. [PubMed: 8397725]

Lipska B, Swerdlow N, Geyer M, et al. Neonatal excitotoxic hippocampal damage in rats causes postpubertal changes in prepulse inhibition of startle and its disruption by apomorphine. Psychopharmacology 1995;122:35-43. [PubMed: 8711062]

Lipska B, Al-Amin HA, Weinberger DR. Excitotoxic lesions of the rat medial prefrontal cortex: effects on abnormal behaviors associated with neonatal hippocampal damage. Neuropsychopharmacology 1998;19:451-464. [PubMed: 9803421]

MacLean PD. Some psychiatric implications of physiological studies on frontotemporal portion of limbic system (visceral brain). Electroencephalogr. Clin. Neurophysiol 1952;4:407-418. [PubMed: 12998590]

Magnotta VA, Heckel D, Andreasen NC, et al. Measurement of brain structures with artificial neural networks: two and three-dimensional applications. Radiology 1999;211:781-790. [PubMed: 10352607]

Magnotta VA, Gold S, Andreasen NC, et al. Visualization of subthalamic nuclei with cortex attenuated inversion recovery MR imaging. Neuroimage 2000;11:341-346. [PubMed: 10725190]

Maher BA, Manschreck TC, Woods BT, et al. Frontal brain volume and context effects in short-term recall in schizophrenia. Biol. Psychiatry 1995;37:144-150. [PubMed: 7727622]

Maher BA, Manschreck TC, Yurgelun-Todd DA, et al. Hemispheric asymmetry of frontal and temporal gray matter and age of onset in schizophrenia. Biol. Psychiatry 1998;44:413-417. [PubMed: 9777170]

Maier SE, Gudbjartsson H, Patz S, et al. Line scan diffusion imaging: characterization in healthy subjects and stroke patients. Am. J. Roentgenol 1998;171:85-93. [PubMed: 9648769]

Marsh L, Suddath RL, Higgins N, et al. Medial temporal lobe structures in schizophrenia: relationship of size to duration of illness. Schizophr. Res 1994;11:225-238. [PubMed: 8193061]

Marsh L, Harris D, Lim KO, et al. Structural magnetic resonance imaging abnormalities in men with severe chronic schizophrenia and an early age at clinical onset. Arch. Gen. Psychiatry 1997;54:1104-1112. [PubMed: 9400346]

Marsh L, Lim KO, Hoff AL, et al. Severity of schizophrenia and magnetic resonance imaging abnormalities: a comparison of State and Veterans hospital patients. Biol. Psychiatry 1999;45:49_ 61. [PubMed: 9894575]

Mathalon DH, Sullivan EV, Rawles JM, et al. Correction for head size in brainimaging measurements. Psychiatry Res 1993;50:121-139. [see comments] [published erratum appears in Psychiatry Res, 1994 sep;55(3):179]. [PubMed: 8378488]

Mathew RJ, Partain CL. Midsagittal sections of the cerebellar vermis and fourth ventricle obtained with magnetic resonance imaging of schizophrenic patients. Am. J. Psychiatry 1985a;142:970-971. [PubMed: 4025598]

Mathew RJ, Partain CL, Prakash R, et al. A study of the septum pellucidum and corpus callosum in schizophrenia with MR imaging. Acta Psychiatr. Scand 1985b;72:414-421. [PubMed: 4091025] 
Mayberg, HS. Neuroimaging studies of depression in neurologic disease. In: Starkstein, SE.; Robinson, RG., editors. Depression in Neurological Disease. Johns Hopkins University Press; 1993. p. 186-216.

McCarley RW, Faux SF, Shenton ME, et al. Event-related potentials in schizophrenia: their biological and clinical correlates and a new model of schizophrenic pathophysiology. Schizophr. Res 1991;4:209-231. [PubMed: 2039762]

McCarley RW, Shenton ME, O’ Donnell BF, et al. Auditory P300 abnormalities and left posterior superior temporal gyrus volume reduction in schizophrenia. Arch. Gen. Psychiatry 1993;50:190-197. [PubMed: 8439239]

McCarley RW, Hsiao JK, Freedman R, et al. Neuroimaging and the cognitive neuroscience of schizophrenia. Schizophr. Bull 1996;22:703-725. [PubMed: 8938923]

McCarley RW, Niznikiewicz MA, Salisbury DF, et al. Cognitive dysfunction in schizophrenia: unifying basic research and clinical aspects. Eur. Arch. Psychiatry Clin. Neurosci 1999a;249:69-82. [PubMed: 10654112]

McCarley RW, Wible CG, Frumin M, et al. MRI anatomy of schizophrenia. Biol. Psychiatry 1999b; 45:1099-1119. [PubMed: 10331102]

McEwen BS, Magarinos AM. Stress effects on morphology and function of the hippocampus. Ann. N.Y. Acad. Sci 1997;821:271-284. [PubMed: 9238211]

McNeil TF, CantorGraae E, Weinberger DR. Relationship of obstetric complications and differences in size of brain structures in monozygotic twin pairs discordant for schizophrenia. Am. J. Psychiatry 2000;157:203-212. [PubMed: 10671388]

Mednick SA, McNeil TF. Current methodology in research on the etiology of schizophrenia: Serious difficulties which suggest the use of the high-risk-group method. Psychol. Bull 1968;70:681-693. [PubMed: 4889572]

Meehl PE. Schizotaxia, schizotypy, schizophrenia. Am. Psychologist 1962;17:827-838.

Meisenzahl EM, Frodl T, Greiner J, et al. Corpus callosum size in schizophrenia-a magnetic resonance imaging analysis. Eur. Arch. Psychiatry Clin. Neurosci 1999;249:305-312. [PubMed: 10653287]

Meisenzahl EM, Frodl T, Zetzsche T, et al. Adhesio interthalamica in male patients with schizophrenia. Am. J. Psychiatry 2000;157:823-825. [PubMed: 10784480]

Menon RR, Barta PE, Aylward EH, et al. Posterior superior temporal gyrus in schizophrenia: grey matter changes and clinical correlates. Schizophr. Res 1995;16:127-135. [PubMed: 7577766]

Mesulam M-M. Large-scale neurocognitive networks and distributed processing for attention, language, and memory. Ann. Neural 1990;28:597-613.

Mesulam M-M. From sensation to cognition. Brain 1998;121:1013-1052. [PubMed: 9648540]

Middleton FA, Strick PL. Basal ganglia and cerebellar loops: motor and cognitive circuits. Brain Research Reviews 2000;31:236-250. [PubMed: 10719151]

Mion CC, Andreasen NC, Arndt S, et al. MRI abnormalities in tardive dyskinesia. Psychiatry Res 1991;40:157-166. [PubMed: 1685788]

Mizoguchi K, Kunishita T, Chui DH, et al. Stress induces neuronal death in the hippocampus of castrated rats. Neurosci. Lett 1992;138:157-160. [PubMed: 1407656]

Moseley ME, Kucharczyk J, Mintorovitch J. Diffusion-weighted MR imaging of acute stroke: correlation with T2-weighted and magnetic susceptibility-enhanced MR imaging in cats. AJNR 1990;11:423429. [PubMed: 2161612]

Murray RM, Lewis SW. Is schizophrenia a neurodevelopmental disorder? [editorial]. Br. Med. J. (Clin. Res. Ed.) 1987;295:681-682.

Nair TR, Christensen JD, Kingsbury SJ, et al. Progression of cerebroventricular enlargement and the subtyping of schizophrenia. Psychiatry Res 1997;74:141-150. [PubMed: 9255859]

Narr KL, Thompson PM, Sharma T, et al. Mapping morphology of the corpus callosum in schizophrenia. Cereb. Cortex 2000;10:40-49. [PubMed: 10639394]

Nasrallah HA, Andreasen NC, Coffman JA, et al. A controlled magnetic resonance imaging study of corpus callosum thickness in schizophrenia. Biol. Psychiatry 1986;21:274-282. [PubMed: 3947709] 
Nasrallah HA, Schwarzkopf SB, Olson SC, et al. Gender differences in schizophrenia on MRI brain scans. Schizophr. Bull 1990;16:205-210. [PubMed: 2374881]

Nasrallah HA, Sharma S, Olson SC. The volume of the entorhinal cortex in schizophrenia: a controlled MRI study. Prog. Neuropsychopharmacol. Biol. Psychiatry 1997;21:1317-1322. [PubMed: 9460094]

Nelson MD, Saykin AJ, Flashman LA, et al. Hippocampal volume reduction in schizophrenia as assessed by magnetic resonance imaging: a meta-analytic study. Arch. Gen. Psychiatry 1998;55:433-440. [see comments]. [PubMed: 9596046]

Nestor PG, Shenton ME, McCarley RW, et al. Neuropsychological correlates of MRI temporal lobe abnormalities in schizophrenia. Am. J. Psychiatry 1993;150:1849-1855. [see comments]. [PubMed: 8238641]

Nestor PG, Kimble MO, O'Donnell BF, et al. Aberrant semantic activation in schizophrenia: a neurophysiological study. Am. J. Psychiatry 1997;154:640-646. [PubMed: 9137119]

Nicolson R, Rapoport JL. Childhood-onset schizophrenia: rare but worth studying. Biol. Psychiatry 1999;46:1418-1428. [PubMed: 10578456]

Niemann K, Hammers A, Coenen VA, et al. Evidence of a smaller left hippocampus and left temporal horn in both patients with first episode schizophrenia and normal control subjects [in process citation]. Psychiatry Res 2000;99:93-110. [PubMed: 10963985]

Niznikiewicz M, Donnino R, McCarley RW, et al. Abnormal angular gyrus asymmetry in schizophrenia. Am. J. Psychiatry 2000;157:428-437. [PubMed: 10698820]

Noga JT, Aylward E, Barta PE, et al. Cingulate gyrus in schizophrenic patients and normal volunteers. Psychiatry Res 1995;61:201-208. [PubMed: 8748465]

Nopoulos P, Torres I, Flaum M, et al. Brain morphology in first-episode schizophrenia. Am. J. Psychiatry 1995;152:1721-1723. [PubMed: 8526236]

Nopoulos P, Swayze V, Andreasen NC. Pattern of brain morphology in patients with schizophrenia and large cavum septi pellucidi. J. Neuropsychiatry Clin. Neurosci 1996;8:147-152. [PubMed: 9081549]

Nopoulos P, Swayze V, Flaum M, et al. Cavum septi pellucidi in normals and patients with schizophrenia as detected by magnetic resonance imaging. Biol. Psychiatry 1997;41:1102-1108. [see comments]. [PubMed: 9146821]

Nopoulos PC, Giedd JN, Andreasen NC, et al. Frequency and severity of enlarged cavum septi pellucidi in childhood-onset schizophrenia. Am. J. Psychiatry 1998a;155:1074-1079. [PubMed: 9699696]

Nopoulos P, Swayze V, Flaum M, et al. Incidence of ectopic gray matter in patients with schizophrenia and healthy control subjects studied with MRI. J. Neuropsychiatry Clin. Neurosci 1998b;10:351353. [PubMed: 9706544]

Nopoulos PC, Ceilley JW, Gailis EA, et al. An MRI study of cerebellar vermis morphology in patients with schizophrenia: Evidence in support of the cognitive dysmetria concept. Biol. Psychiatry 1999;46:703-711. [PubMed: 10472423]

Norris SD, Krishnan KR, Ahearn E. Structural changes in the brain of patients with bipolar affective disorder by MRI: a review of the literature. Prog. Neuropsychopharmacol. Biol. Psychiatry 1997;21:1323-1337. [PubMed: 9460095]

Nuechterlein KR, Dawson ME. Information processing and attentional functioning in the developmental course of schizophrenic disorders. Schizophr. Bull 1984;10:160-203. [PubMed: 6729409]

Näf M, Kübler O, Kikinis R, Shenton ME, et al. Characterization and recognition of 3D organ shapes in medical image analysis using skeletonization. IEEE Mathematical Methods in Biomedical Image Analysis 1996:139-150.

O'Donnell BF, Shenton ME, McCarley RW, et al. The auditory N2 component in schizophrenia: relationship to MRI temporal lobe gray matter and to other ERP abnormalities. Biol. Psychiatry 1993;34:26-40. [PubMed: 8373937]

Ohnuma T, Kimura M, Takahashi T, et al. A magnetic resonance imaging study in first-episode disorganized-type patients with schizophrenia. Psychiatry Clin. Neurosci 1997;51:9-15. [PubMed: 9076854]

Olney JW. Excitatory amino acids and neuropsychiatric disorders. Biol. Psychiatry 1989;26:505-525. [see comments]. [PubMed: 2571362] 
Olney JW. Excitotoxic amino acids and neuropsychiatric disorders. Ann. Rev. Pharmacol. Toxicology 1990;30:47-71.

Olney JW, Farber NB. Glutamate receptor dysfunction and schizophrenia. Arch. Gen. Psychiatry 1995;52:998-1007. [see comments]. [PubMed: 7492260]

Pakkenberg B. Postmortem study of chronic schizophrenic brains. Br. J. Psychiatry 1987;151:744-752. [PubMed: 3502800]

Pandya DN, Seltzer B. Association areas of the cerebral cortex. Trends in Neuroscience 1982;5:386-394.

Pandya DN, Van Hoesen GW, Mesulam MM. Efferent connections of the cingulate gyrus in the rhesus monkey. Exp. Brain Res 1981;42:319-330. [PubMed: 6165607]

Park S, Holzman PS. Schizophrenics show spatial working memory deficits. Arch. Gen. Psychiatry 1992;49:975-982. [PubMed: 1449384]

Pearlson, GD.; Marsh, L. MRI in psychiatry. In: Oldham, J.; B, R.; A, T., editors. American Psychiatric Association Press Review of Psychiatry. Washington DC: American Psychiatric Association; 1993. p. 347-381.

Pearlson GD, Barta PA, Schrami FV, et al. Brain size in schizophrenia [Letter]. Arch. Gen. Psychiatry 1991;48:181-182.

Pearlson GD, Petty RG, Ross CA, et al. Schizophrenia: a disease of heteromodal association cortex? Neuropsychopharmacology 1996;14:1-17. [PubMed: 8719025]

Pearlson GD. Superior temporal gyrus and planum temporale in schizophrenia: a selective review. Prog. Neuropsychopharmacol. Biol. Psychiatry 1997a;21:1203-1229. [PubMed: 9460087]

Pearlson GD, Marsh L. Structural brain imaging in schizophrenia: a selective review. Biol. Psychiatry 1999;46:627-649. [PubMed: 10472416]

Pearlson GD, Barta PE, Powers RE, et al. Ziskind-Somerfeld research award 1996. Medial and superior temporal gyral volumes and cerebral asymmetry in schizophrenia versus bipolar disorder. Biol. Psychiatry 1997b;41:1-14. [PubMed: 8988790]

Peled S, Gudbjartsson H, Westin CF, et al. Magnetic resonance imaging shows orientation and asymmetry of white matter fiber tracts. Brain Res 1998;780:27-33. [PubMed: 9473573]

Penfield W, Perot P. The brain's record of auditory and visual experience: a final summary and discussion. Brain 1963;86:595-696. [PubMed: 14090522]

Penfield, W.; Roberts, L. Speech and Brain Mechanisms. Princeton, NJ: Princeton University Press; 1959.

Petitti, D. Metaanalysis, Decision Analysis, and Cost Effectiveness Analysis. New York: Oxford University Press; 1994.

Petty RG, Barta PE, Pearlson GD, et al. Reversal of asymmetry of the planum temporale in schizophrenia. Am. J. Psychiatry 1995;152:715-721. [PubMed: 7726311]

Pfefferbaum A, Zipursky RB. Neuroimaging studies of schizophrenia. Schizophr. Res 1991;4:193-208. [PubMed: 2039761]

Pfefferbaum A, Lim KO, Rosenbloom M, et al. Brain magnetic resonance imaging: approaches for investigating schizophrenia. Schizophr. Bull 1990;16:453-476. [PubMed: 2287935]

Pfefferbaum A, Sullivan EV, Hedehus M, et al. Brain gray and white matter transverse relaxation time in schizophrenia. Psychiatry Res 1999;91:93-100. [PubMed: 10515464]

Pinel, P. Traite medico philosophique sur l'alienation mentale boulamania. Paris: Richard Caille et Ravier; 1801.

Pizer SM, Eberly D, Fritsch DS, et al. Zoom-invariant vision of figural shape: the mathematics of cores. Computer Vision and Image Understanding 1998;69:55-71.

Plum F. Prospects for research on schizophrenia. 3. Neurophysiology. Neuropathological findings. Neurosci. Res Program Bull 1972;10:384-388. [PubMed: 4663816]

Portas CM, Goldstein JM, Shenton ME, et al. Volumetric evaluation of the thalamus in schizophrenic male patients using magnetic resonance imaging. Biol. Psychiatry 1998;43:649-659. [PubMed: 9582998]

Posner MI, Early TS, Reiman E, et al. Asymmetries in hemispheric control of attention in schizophrenia. Arch. Gen. Psychiatry 1988;45:814-821. [see comments]. [PubMed: 3415424] 
Raine A, Harrison GN, Reynolds GP, et al. Structural and functional characteristics of the corpus callosum in schizophrenics, psychiatric controls, and normal controls. A magnetic resonance imaging and neuropsychological evaluation. Arch. Gen. Psychiatry 1990;47:1060-1064. [PubMed: 2241507]

Raine A, Lencz T, Reynolds GP, et al. An evaluation of structural and functional prefrontal deficits in schizophrenia: MRI and neuropsychological measures. Psychiatry Res 1992;45:123-137. [PubMed: 1362615]

Rajarethinam RP, DeQuardo JR, Nalepa R, et al. Superior temporal gyrus in schizophrenia: a volumetric magnetic resonance imaging study. Schizophr. Res 2000;41:303-312. [PubMed: 10708339]

Rakic P, Yakovlev PI. Development of the corpus callosum and cavum septi in man. J. Comp. Neurol 1968;132:45-72. [PubMed: 5293999]

Rapoport JL, Giedd J, Kumra S, et al. Childhoodonset schizophrenia. Progressive ventricular change during adolescence. Arch. Gen. Psychiatry 1997;54:897-903. [see comments]. [PubMed: 9337768]

Rapoport JL, Giedd JN, Blumenthal J, et al. Progressive cortical change during adolescence in childhoodonset schizophrenia. A longitudinal magnetic resonance imaging study. Arch. Gen. Psychiatry 1999;56:649-654. [PubMed: 10401513]

Rauch SL, Renshaw PF. Clinical neuroimaging in psychiatry. Harv. Rev. Psychiatry 1995;2:297-312. [PubMed: 9384916]

Raz S, Raz N. Structural brain abnormalities in the major psychoses: a quantitative review of the evidence from computerized imaging. Psychological Bulletin 1990;108:93-108. [PubMed: 2143298]

Razi K, Greene KP, Sakuma M, et al. Reduction of the parahippocampal gyrus and the hippocampus in patients with chronic schizophrenia. Br. J. Psychiatry 1999;174:512-519. [see comments]. [PubMed: 10616629]

Reite M, Sheeder J, Teale P, et al. Magnetic source imaging evidence of sex differences in cerebral lateralization in schizophrenia. Arch. Gen. Psychiatry 1997;54:433-440. [PubMed: 9152097]

Robinson MB, Coyle JT. Glutamate and related acidic excitatory neurotransmitters: from basic science to clinical application. FASEB Journal 1987;1:446-455. [PubMed: 2890549]

Rosenberger PB, Hier DB. Cerebral asymmetry and verbal intellectual deficits. Ann. Neurol 1980;8:300304. [PubMed: 7436373]

Rosenthal R, Bigelow LB. Quantitative brain measurements in chronic schizophrenia. Br. J. Psychiatry 1972;121:259-264. [PubMed: 5073779]

Rosenthal, R. Design, Analysis, and Meta-analysis. Cambridge, MA: Cambridge University Press; 1987. Judgement Studies.

Rosenthal R, Rubin DB. Comparing significance levels of independent studies. Psychol. Bull 1979;56:1163-1168.

Rosenthal R, Rubin DB. Comparing effect sizes of independent studies. Psychol. Bull 1982;92:500-504.

Rosenthal R, Rubin DB. Meta-analysis procedures for combining studies with multiple effect sizes. Psychol. Bull 1986;99:400-406.

Rossi A, Stratta P, Gallucci M, et al. Standardized magnetic resonance image intensity study in schizophrenia. Psychiatry Res 1988;25:223-231. [PubMed: 3174904]

Rossi A, Stratta P, D’Albenzio L, et al. Reduced temporal lobe area in schizophrenia by magnetic resonance imaging: preliminary evidence. Psychiatry Res 1989a;29:261-263. [PubMed: 2608770]

Rossi A, Stratta P, Gallucci M, et al. Quantification of corpus callosum and ventricles in schizophrenia with nuclear magnetic resonance imaging: a pilot study. Am. J. Psychiatry 1989b;146:99-101. [PubMed: 2912255]

Rossi A, Stratta P, D’Albenzio L, et al. Reduced temporal lobe areas in schizophrenia: preliminary evidences from a controlled multiplanar magnetic resonance imaging study. Biol. Psychiatry 1990;27:61-68. [PubMed: 2297553]

Rossi A, Stratta P, et al. Di Michele, V. Temporal lobe structure by magnetic resonance in bipolar affective disorders and schizophrenia. J. Affect. Disord 1991;21:19-22. [PubMed: 1827473]

Rossi A, Stratta P, Mattei P, et al. Planum temporale in schizophrenia: a magnetic resonance study. Schizophr. Res 1992;7:19-22. [PubMed: 1591193]

Rossi A, Stratta P, Mancini F, et al. Cerebellar vermal size in schizophrenia: a male effect. Biol. Psychiatry 1993;33:35-47. 
Rossi A, Stratta P, Mancini F, et al. Magnetic resonance imaging findings of amygdala-anterior hippocampus shrinkage in male patients with schizophrenia. Psychiatry Res 1994a;52:43-53. [PubMed: 8047621]

Rossi A, Serio A, Stratta P, et al. Planum temporale asymmetry and thought disorder in schizophrenia. Schizophr. Res 1994b;12:1-7. [PubMed: 8018581]

Rowland L, Mettler F. Cell concentration and laminar thickness of frontal cortex of psychotic patients. J. Comp. Neurol 1949;90:225.

Roy PD, Zipursky RB, SaintCyr JA, et al. Temporal horn enlargement is present in schizophrenia and bipolar disorder. Biol. Psychiatry 1998;44:418-422. [PubMed: 9777171]

Sachdev PS, Brodaty H. Midsagittal anatomy in late onset schizophrenia. Psychol. Med 1999;29:963970. [PubMed: 10473323]

Sanfilipo M, Lafargue T, Arena L, et al. Fine volumetric analysis of the cerebral ventricular system in schizophrenia: further evidence for multifocal mild to moderate enlargement. Schizophr. Bull 2000a;26:201-216. [PubMed: 10755682]

Sanfilipo M, Lafargue T, Rusinek H, et al. Volumetric measure of the frontal and temporal lobe regions in schizophrenia: relationship to negative symptoms. Arch. Gen. Psychiatry 2000b;57:471-480. [PubMed: 10807487]

Saunders RC, Kolachana BS, Bachevalier J, et al. Neonatal lesions of the medial temporal lobe disrupt prefrontal cortical regulation of striatal dopamine. Nature 1998;393:169-171. [PubMed: 9603519]

Scheibel AB, Kovelman JA. Dendritic disarray in the hippocampus of paranoid schizophrenia. Annual Meeting of the Society of Biological Psychiatry. 1979

Scheibel AB, Kovelman JA. Disorientation of the hippocampal pyramidal cell and its processes in the schizophrenic patient. Biol. Psychiatry 1981;16:101-102.

SchellerGilkey G, Lewine RR. Age at onset and sex differences in corpus callosum area in schizophrenia. Schizophr. Res 1999;40:229-235. [PubMed: 10638861]

Schlaepfer TE, Harris GJ, Tien AY, et al. Decreased regional cortical gray matter volume in schizophrenia. Am. J. Psychiatry 1994;151:842-848. [PubMed: 8184992]

Schmahmann JD. From movement to thought: Anatomic substrates of the cerebellar contribution to cognitive processing. Human Brain Mapping 1996;4:174-198.

Schwartz JM, Aylward E, Barta PE, et al. Sylvian fissure size in schizophrenia measured with the magnetic resonance imaging rating protocol of the Consortium to Establish a Registry for Alzheimer's Disease. Am. J. Psychiatry 1992;149:1195-1198. [PubMed: 1503132]

Schwarzkopf SB, Olson SC, Coffman JA, et al. Third and lateral ventricular volumes in schizophrenia: support for progressive enlargement of both structures. Psychopharmacol. Bull 1990;26:385-391. [PubMed: 2274640]

Scott TF, Price TR, George MS, et al. Midline cerebral malformations and schizophrenia. J. Neuropsychiatry Clin. Neurosci 1993;5:287-293. [PubMed: 8369638]

Seidman LJ. Schizophrenia and brain dysfunction: An integration of recent neurodiagnostic findings. Psychol. Bull 1983;94:195-238. [PubMed: 6356196]

Seidman LJ, Yurgelun-Todd D, Kremen WS, et al. Relationship of prefrontal and temporal lobe MRI measures to neuropsychological performance in chronic schizophrenia. Biol. Psychiatry 1994;35:235-246. [PubMed: 8186328]

Seidman LJ, Faraone SV, Goldstein JM, et al. Reduced subcortical brain volumes in nonpsychotic siblings of schizophrenic patients. Am. J. Med. Genetics (Neuropsychiatric Genetics) 1997;74:507-514.

Seidman LJ, Faraone SV, Goldstein JM, et al. Thalamic and amygdalahippocampal volume reductions in firstdegree relatives of patients with schizophrenia: an MRIbased morphometric analysis. Biol. Psychiatry 1999;46:941-954. [PubMed: 10509177]

Seidman LJ, Goldstein JM, Makris NN, et al. Subcortical brain abnormalities in patients with schizophrenia: an MRI morphometric study. Biol. Psychiatry 2000;47(8s):24s. [Abstract].

Selemon LD, Rajkowska G, Goldman-Rakic PS. Abnormally high neuronal density in the schizophrenic cortex. A morphometric analysis of prefrontal area 9 and occipital area 17. Arch. Gen. Psychiatry 1995;52:805-818. discussion 819-820. [PubMed: 7575100] 
Selemon LD, Rajkowska G, Goldman-Rakic PS. Elevated neuronal density in prefrontal area 46 in brains from schizophrenic patients: application of a three-dimensional, stereologic counting method. J. Comp. Neurol 1998;392:402-412. [PubMed: 9511926]

Seltzer B, Pandya DN. Further observations on parietotemporal connections in the rhesus monkey. Exp. Brain Res 1984;55:301-312. [PubMed: 6745368]

Shapleske J, Rossell SL, Woodruff PW, et al. The planum temporale: a systematic, quantitative review of its structural, functional and clinical significance. Brain Res. Brain Res. Rev 1999;29:26-49. [PubMed: 9974150]

Sharma T, DuBoulay G, Lewis S, et al. The Maudsley Family Study I: structural brain changes on magnetic resonance imaging in familial schizophrenia. Prog. Neuro-Psychopharmacol. \& Biol. Psychiatry 1997;21:1297-1315.

Shaw CM, Alvord EC Jr. Cava septi pellucidi et vergae: Their normal and pathological states. Brain 1969;92:213-223. [PubMed: 5774029]

Shelton, RC.; Weinberger, DR. X-ray computerized tomography studies in schizophrenia: a review and synthesis. In: Nasrallah, HA.; Weinberger, DR., editors. Handbook of Schizophrenia: The Neuropathology of Schizophrenia. Vol. vol. I.. New York: Elsevier Science Publishers; 1986. p. 207-225.

Shenton ME, Kikinis R, McCarley RW, et al. Application of automated MRI volumetric measurement techniques to the ventricular system in schizophrenics and normal controls. Schizophr. Res 1991;5:103-113. [PubMed: 1931803]

Shenton ME, Kikinis R, Jolesz FA, et al. Abnormalities of the left temporal lobe and thought disorder in schizophrenia. A quantitative magnetic resonance imaging study. N. Engl. J. Med 1992;327:604612. [PubMed: 1640954]

Shenton ME, Kikinis R, McCarley RW, et al. Harvard brain atlas: a teaching and visualization tool. IEEE Biomedical Visualization 1995:10-17.

Shenton, ME. Temporal lobe structural abnormalities in schizophrenia: a selective review and presentation of new MR findings. In: Matthysse, DLS.; Kagan, J.; Benes, FM., editors. Psychopathology: The Evolving Science of Mental Disorders. New York: Cambridge University Press; 1996. p. 51-99.

Shenton, ME.; Wible, CG.; McCarley, RW. A review of magnetic resonance imaging studies of brain abnormalities in schizophrenia. In: Krishnan, K.; Doraiswamy, P., editors. Brain Imaging in Clinical Psychiatry. New York: Marcel Dekker, Inc; 1997. p. 297-380.

Shenton, M.; Frumin, M.; McCarley, R., et al. Morphometric MRI studies: Findings in schizophrenia. In: Dougherty, D.; Rauch, S.; Rosen, J., et al., editors. Psychiatric Neuroimaging Strategies: Research and Clinical Applications. Washington, DC: American Psychiatric Association; 2001. (in press)

Shihabuddin L, Buchsbaum MS, Hazlett EA, et al. Dorsal striatal size, shape, and metabolic rate in nevermedicated and previously medicated schizophrenics performing a verbal learning task. Arch. Gen. Psychiatry 1998;55:235-243. [PubMed: 9510217]

Shioiri T, Oshitani Y, Kato T, et al. Prevalence of cavum septum pellucidum detected by MRI in patients with bipolar disorder, major depression and schizophrenia. Psychol. Med 1996;26:431-434. [PubMed: 8685300]

Siever LJ. Biological factors in schizotypal personality disorders. Acta Psychiatr. Scand 1994;90:45-50.

Smith RC, Calderon M, Ravichandran GK, et al. Nuclear magnetic resonance in schizophrenia: a preliminary study. Psychiatry Res 1984;12:137-147. [PubMed: 6591219]

Snyder PJ, Bogerts B, Wu H, et al. Absence of the adhesio interthalamica as a marker of early developmental neuropathology in schizophrenia: an MRI and postmortem histologic study. J. Neuroimaging 1998;8:159-163. [PubMed: 9664852]

Soares JC, Mann JJ. The anatomy of mood disordersreview of structural neuroimaging studies. Biol. Psychiatry 1997;41:86-106. [see comments]. [PubMed: 8988799]

Southard EE. A study of the dementia praecox group in the light of certain cases showing anomalies or scleroses in particular brain regions. Am. J. Insanity 1910;67:119-176.

Southard EE. On the topographic distribution of cortex lesions and anomalies in dementia praecox with some account of their functional significance. Am. J. Insanity 1915;71:603-671. 
Squire LR, Zola-Morgan S. The medial temporal lobe memory system. Science 1991;253:1380-1386. [PubMed: 1896849]

Squire LR. Memory and the hippocampus: a synthesis from findings with rats, monkeys, and humans. Psychol. Rev 1992;99:195-231. [published erratum appears in Psychol. Rev. 1992 jul;99(3):582]. [PubMed: 1594723]

Staal WG, Pulshoff Pol HE, Schnack H, et al. Partial volume decrease of the thalamus in relatives of patients with schizophrenia. Am. J. Psychiatry 1998;155:1784-1786. et al. [PubMed: 9842796]

Staal WG, Pulshoff Pol HE, Schnack H, et al. Structural brain abnormalities in patients with schizophrenia and their healthy siblings. Am. J. Psychiatry 2000;157:416-421. [PubMed: 10698818]

Starkman MN, Gebarski SS, Berent S, et al. Hippocampal formation volume, memory dysfunction, and cortisol levels in patients with Cushing's syndrome. Biol. Psychiatry 1992;32:756-765. [PubMed: 1450290]

Stefanis N, Frangou S, Yakeley J, et al. Hippocampal volume reduction in schizophrenia: effects of genetic risk and pregnancy and birth complications. Biol. Psychiatry 1999;46:697-702. [PubMed: 10472422]

Steffens DC, Krishnan KR. Structural neuroimaging and mood disorders: recent findings, implications for classification, and future directions. Biol. Psychiatry 1998;43:705-712. [PubMed: 9606523]

Stevens JR. An anatomy of schizophrenia? Arch. Gen. Psychiatry 1973;29:177-189. [PubMed: 4147475]

Stratta P, Rossi A, Gallucci M, et al. Hemispheric asymmetries and schizophrenia: a preliminary magnetic resonance imaging study. Biol. Psychiatry 1989;25:275-284. [PubMed: 2914152]

Suddath RL, Casanova MF, Goldberg TE, et al. Temporal lobe pathology in schizophrenia: a quantitative magnetic resonance imaging study. Am. J. Psychiatry 1989;146:464-472. [PubMed: 2929746]

Suddath RL, Christison GW, Torrey EF, et al. Anatomical abnormalities in the brains of monozygotic twins discordant for schizophrenia. N. Engl. J. Med 1990;322:789-794. [published erratum appears in N.Engl. J. Med. 1990 may 31;322(22):1616] [see comments]. [PubMed: 2308615]

Sullivan EV, Mathalon DH, Lim KO, et al. Patterns of regional cortical dysmorphology distinguishing schizophrenia and chronic alcoholism. Biol. Psychiatry 1998;43:118-131. [PubMed: 9474444]

Swayze VW, Andreasen NC, Alliger RJ, et al. Subcortical and temporal structures in affective disorder and schizophrenia: a magnetic resonance imaging study. Biol. Psychiatry 1992;31:221-240. [see comments]. [PubMed: 1547297]

Symonds LL, Archibald SL, Grant I, et al. Does an increase in sulcal or ventricular fluid predict where brain tissue is lost? J. Neuroimaging 1999;9:201-209. [PubMed: 10540599]

Szeszko PR, Bilder RM, Lencz T, et al. Investigation of frontal lobe subregions in first-episode schizophrenia. Psychiatry Res 1999;90:1-15. [PubMed: 10320207]

Tibbo P, Nopoulos P, Arndt S, et al. Corpus callosum shape and size in male patients with schizophrenia. Biol. Psychiatry 1998;44:405-412. [see comments]. [PubMed: 9777169]

Tiede U, Bomans M, Hohne KH, et al. A computerized three-dimensional atlas of the human skull and brain. Am. J. Neuroradiology 1993;14:551-559.

Tiihonen J, Katila H, Pekkonen E, et al. Reversal of cerebral asymmetry in schizophrenia measured with magnetoencephalography. Schizophr. Res 1998;30:209-219. [PubMed: 9589515]

Torres IJ, Flashman LA, O’Leary DS, et al. Lack of an association between delayed memory and hippocampal and temporal lobe size in patients with schizophrenia and healthy controls. Biol. Psychiatry 1997;42:1087-1096. [PubMed: 9426878]

Torrey EF, Peterson MR. Schizophrenia and the limbic system. Lancet 1974;2:942-946. [PubMed: 4138925]

Tsai G, Coyle JT. Nacetylaspartate in neuropsychiatric disorders. Prog. Neurobiol 1995;46:531-540. [PubMed: 8532851]

Tune L, Barta P, Wong D, et al. Striatal dopamine D2 receptor quantification and superior temporal gyrus: Volume determination in 14 chronic schizophrenic subjects. Psychiatry Res 1996;67:155-158. [PubMed: 8876015]

Turetsky BI, Cowell PE, Gur RC, et al. Frontal and temporal lobe brain volumes in schizophrenia. Arch. Gen. Psychiatry 1995;52:1061-1070. [PubMed: 7492258] 
Turetsky BI, Moberg PJ, Yousem DM, et al. Reduced olfactory bulb volume in patients with schizophrenia. Am. J. Psychiatry 2000;157:828-830. [PubMed: 10784482]

Uematsu M, Kaiya H. The morphology of the corpus callosum in schizophrenia. An MRI study. Schizophr. Res 1988;1:391-398.

Uematsu M, Kaiya H. Midsagittal cortical pathomorphology of schizophrenia: A magnetic resonance imaging study. Psychiatry Res 1989;30:11-20. [PubMed: 2574474]

Uno H, Tarara R, Else J, Suleman M, et al. Hippocampal damage associated with prolonged and fatal stress in primates. J. Neurosci 1989;9:1705-1711. [PubMed: 2723746]

Van Essen DCA. tension-based theory of morphogenesis and compact wiring in the central nervous system. Nature 1997;385:313-318. [PubMed: 9002514]

Velakoulis D, Pantelis C, McGorry PD, et al. Hippocampal volume in firstepisode psychoses and chronic schizophrenia: a high resolution magnetic resonance imaging study. Arch. Gen. Psychiatry 1999;56:133-141. [see comments]. [PubMed: 10025437]

Vita A, Dieci M, Giobbio GM, et al. Language and thought disorder in schizophrenia: Brain morphological correlates. Schizophr. Res 1995;15:243-251. [PubMed: 7632621]

Vogt BA, Pandya DN. Cingulate cortex of the rhesus monkey: II. Cortical afferents. J. Comp. Neurol 1987;262:271-289. [PubMed: 3624555]

Vogt BA, Pandya DN, Rosene DL. Cingulate cortex of the rhesus monkey: I. Cytoarchitecture and thalamic afferents. J. Comp. Neurol 1987;262:256-270. [PubMed: 3624554]

Waldo MC, Cawthra E, Adler LE, et al. Auditory sensory gating, hippocampal volume, and catecholamine metabolism in schizophrenics and their siblings. Schizophr. Res 1994;12:93-106. [PubMed: 8043530]

Warach S, Chien D, Li W, et al. Fast magnetic resonance diffusionweighted imaging of acute human stroke. Neurology 1992;42:1717-1723. [published erratum appears in Neurology 1992 Nov;42(11): 2192]. [PubMed: 1513459]

Ward KE, Friedman L, Wise A, Schulz SC. Meta-analysis of brain and cranial size in schizophrenia. Schizophr. Res 1996;22:197-213. [PubMed: 9000317]

Wassink TH, Andreasen NC, Nopoulos P, et al. Cerebellar morphology as a predictor of symptom and psychosocial outcome in schizophrenia. Biol. Psychiatry 1999;45:41-48. [PubMed: 9894574]

Watanabe Y, Gould E, McEwen BS. Stress induces atrophy of apical dendrites of hippocampal CA3 pyramidal neurons. Brain Res 1992;588:341-345. [PubMed: 1393587]

Weight DG, Bigler ED. Neuroimaging in psychiatry. Psychiatr. Clin. North Am 1998;21:725-759. [PubMed: 9890119]

Weinberger, DR. The pathogenesis: a neurodevelopmental theory. In: Nasrallah, HA.; Weinberger, DR., editors. Handbook of Schizophrenia: The Neuropathology of Schizophrenia. Vol. vol. I. New York: Elsevier Science Publishers; 1986. p. 397-406.

Weinberger DR. Implications of normal brain development for the pathogenesis of schizophrenia. Arch. Gen. Psychiatry 1987;44:660-669. [PubMed: 3606332]

Weinberger DR, Berman KF, Suddath R, et al. Evidence of dysfunction of a prefrontallimbic network in schizophrenia: A magnetic resonance imaging and regional cerebral blood flow study of discordant monozygotic twins. Am. J. Psychiatry 1992;149:890-897. [PubMed: 1609867]

Weinberger DR. From neuropathology to neurodevelopment. Lancet 1995;346:552-557. [PubMed: 7544856]

Weinberger DR. On the plausibility of "The Neurodevelopmental Hypothesis" of schizophrenia. Neuropsychopharmacology 1996;14:1S-11S. [PubMed: 8866738]

Weinberger DR, Mattay V, Callicott J, et al. fMRI applications in schizophrenia research. Neuroimage 1996;4:S118-S126. [PubMed: 9345536]

Weinberger DR. Cell biology of the hippocampal formation in schizophrenia. Biol. Psychiatry 1999;45:395-402. [PubMed: 10071707]

Wernicke, C. De aphasische symptomenkomplex. Breslau: Cohen and Weigart; 1874.

Whitworth AB, Honeder M, Kremser C, et al. Hippocampal volume reduction in male schizophrenic patients. Schizophr. Res 1998;31:73-81. [PubMed: 9689711] 
Wible CG, Shenton ME, Hokama H, et al. Prefrontal cortex and schizophrenia. A quantitative magnetic resonance imaging study. Arch. Gen. Psychiatry 1995;52:279-288. [PubMed: 7702444]

Wible CG, Shenton ME, Fischer LA, et al. Parcellation of the human prefrontal cortex using MRI. Psychiatry Res 1997;76:29-40. [PubMed: 9498307]

Williamson P, Pelz D, Merskey H, et al. Correlation of negative symptoms in schizophrenia with frontal lobe parameters on magnetic resonance imaging. Br. J. Psychiatry 1991;159:130-134. [PubMed: 1888960]

Williamson P, Pelz D, Merskey H, et al. Frontal, temporal, and striatal proton relaxation times in schizophrenic patients and normal comparison subjects. Am. J. Psychiatry 1992;149:549-551. [PubMed: 1554045]

Wolkin A, Rusinek H, Vaid G, et al. Structural magnetic resonance image averaging in schizophrenia. Am. J. Psychiatry 1998;155:1064-1073. [PubMed: 9699695]

Woodruff PW, Pearlson GD, Geer MJ, et al. A computerized magnetic resonance imaging study of corpus callosum morphology in schizophrenia. Psychol. Med 1993;23:45-56. [PubMed: 8475214]

Woodruff PW, Phillips ML, Rushe T, et al. Corpus callosum size and interhemispheric function in schizophrenia. Schizophr. Res 1997a;23:189-196. [PubMed: 9075296]

Woodruff PW, Wright IC, Shuriquie N, et al. Structural brain abnormalities in male schizophrenics reflect frontotemporal dissociation. Psychol. Med 1997b;27:1257-1266. [PubMed: 9403897]

Woods BT, Yurgelun-Todd D, Goldstein JM, et al. MRI brain abnormalities in chronic schizophrenia: One process or more? Biol. Psychiatry 1996;40:585-596. [PubMed: 8886291]

Wright IC, RabeHesketh S, Woodruff PW, et al. Metaanalysis of regional brain volumes in schizophrenia. Am. J. Psychiatry 2000;157:16-25. [PubMed: 10618008]

Yeo RA, Hodde-Vargas J, Hendren RL, et al. Brain abnormalities in schizophrenia-spectrum children: implications for a neurodevelopmental perspective. Psychiatry Res 1997;76:1-13. [PubMed: 9498305]

Young AH, Blackwood DH, Roxborough $\mathrm{H}$, et al. A magnetic resonance imaging study of schizophrenia: Brain structure and clinical symptoms. Br. J. Psychiatry 1991;158:158-164. [PubMed: 2012905]

Yurgelun-Todd DA, Renshaw PF. Applications of functional MR imaging to research in psychiatry. Neuroimaging Clin. N. Am 1999;9:295-308. [PubMed: 10318716]

Zakzanis KK, Heinrichs RW. Schizophrenia and the frontal brain: A quantitative review. J. Int. Neuropsychol. Soc 1999;5:556-566. [PubMed: 10561937]

Zipursky RB, Lim KO, Pfefferbaum A. Brain size in schizophrenia. Arch. Gen. Psychiatry 1991;48:179_ 180.

Zipursky RB, Lim KO, Sullivan EV, et al. Widespread cerebral gray matter volume deficits in schizophrenia. Arch. Gen. Psychiatry 1992;49:195-205. [PubMed: 1567274]

Zipursky RB, Marsh L, Lim KO, et al. Volumetric MRI assessment of temporal lobe structures in schizophrenia. Biol. Psychiatry 1994;35:501-516. [PubMed: 8038294]

Zipursky RB, Seeman MV, Bury A, et al. Deficits in gray matter volume are present in schizophrenia but not bipolar disorder. Schizophr. Res 1997;26:85-92. [PubMed: 9323337]

Zipursky RB, Lambe EK, Kapur S, et al. Cerebral gray matter volume deficits in first episode psychosis. Arch. Gen. Psychiatry 1998a;55:540-546. [see comments]. [PubMed: 9633673]

Zipursky RB, ZhangWong J, Lambe EK, et al. MRI correlates of treatment response in first episode psychosis. Schizophr. Res 1998b;30:81-90. [PubMed: 9542791] 


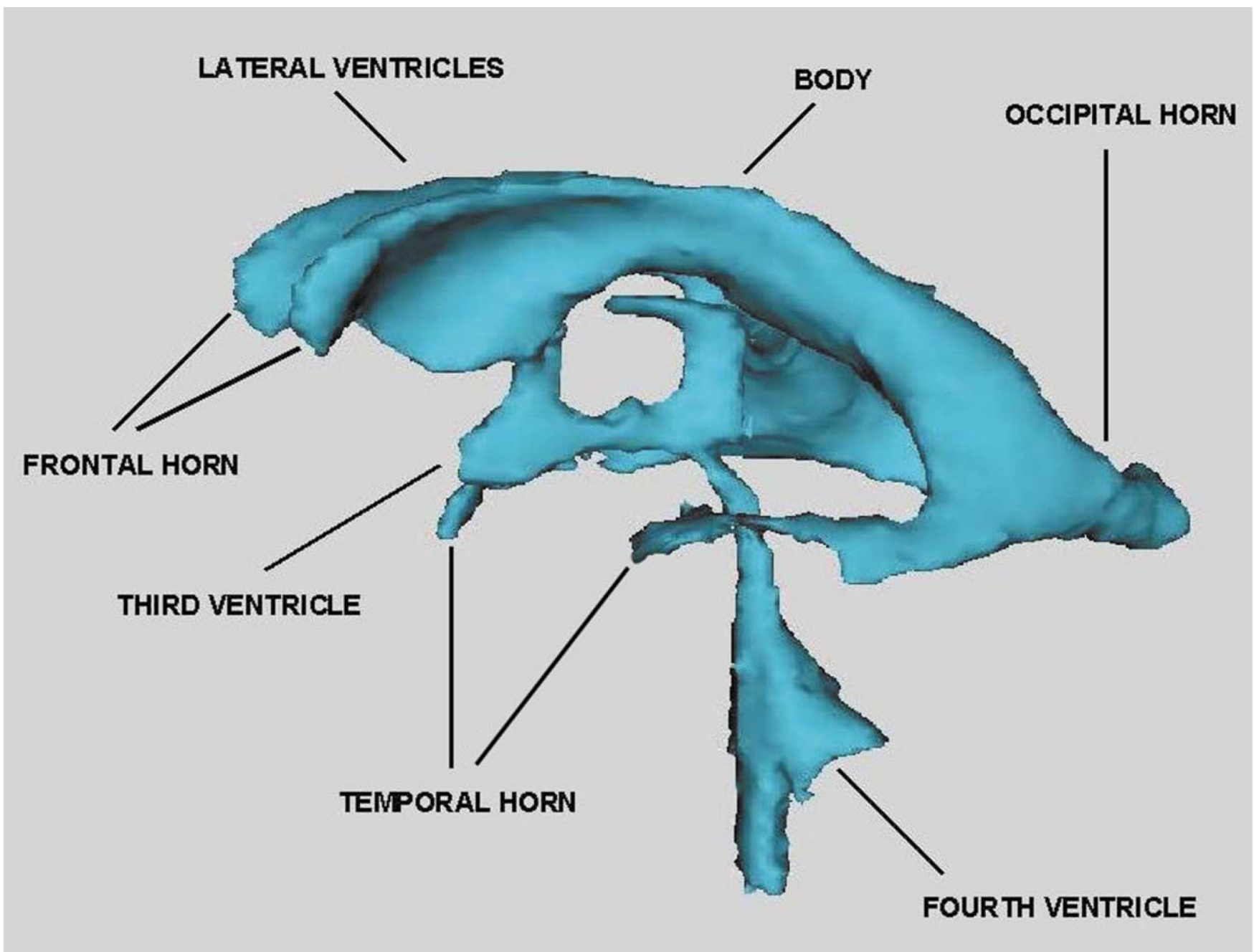

Fig. 1.

This image shows the ventricular system derived from 1.5-mm contiguous MR images which were segmented to delineate the ventricles. A three-dimensional reconstruction surface rendering program was used to visualize the labeled MR data set. The component parts of the ventricular system (see labels) include: the lateral ventricles (body, temporal horns, frontal horns, occipital horns), and third and fourth ventricles. [Courtesy of Aleksandra Ciszewski, B.A., Marianna Jakab, M.S., Marek Kubicki, M.D., PhD, Elizabeth David, A.B., and Michael Halle, PhD Clinical Neuroscience Division, Laboratory of Neuroscience, Department of Psychiatry, and Surgical Planning Laboratory, Department of Radiology, Harvard Medical School.] 


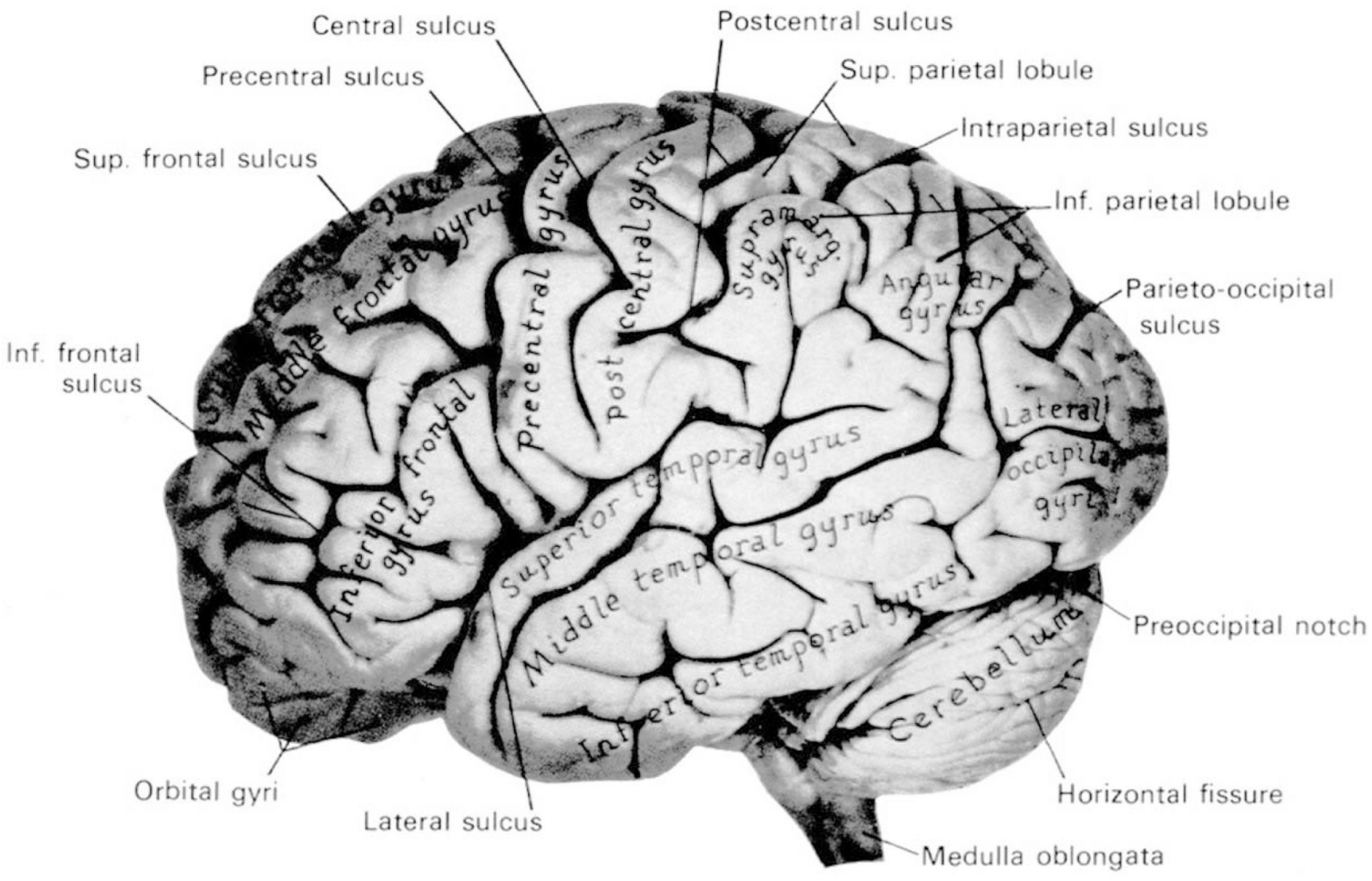

Fig. 2.

Photograph of a lateral view of the human brain. [From Carpenter, Human Neuroanatomy, 1983, reprinted with permission of Williams \& Witkins, New York, New York.] 


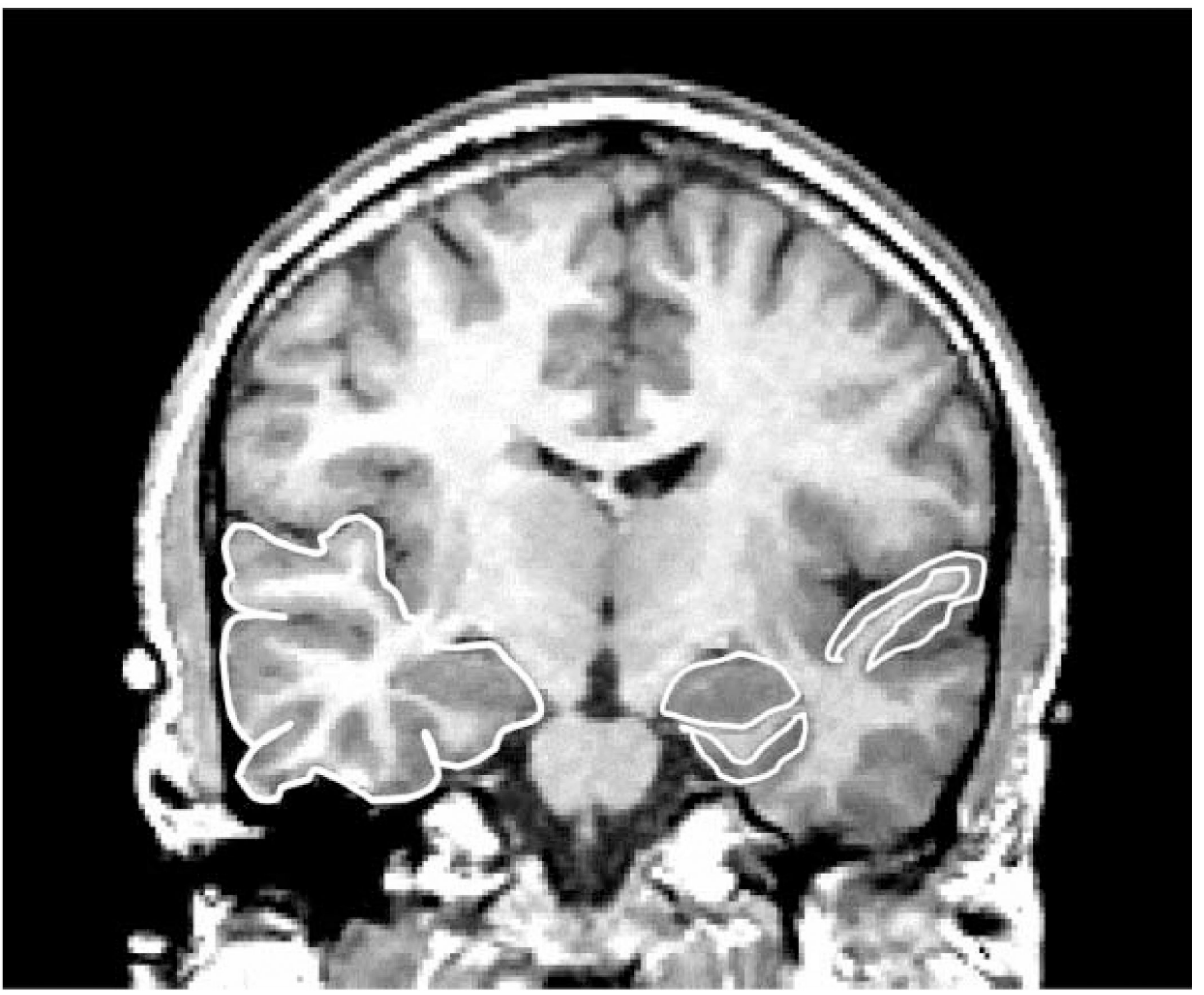

Fig. 3.

Coronal 1.5-mm slice showing medial temporal lobe and neocortical structures. The region delineated in white on the left side of the image (subject's right) is the temporal lobe. The regions delineated in white on the right side of the image (subject's left) include the superior temporal gyrus, which borders the Sylvian fissure, the amygdala (almond shaped region in the medial temporal lobe), and the parahippocampal gyrus, delineated beneath the amygdala. [Reprinted with permission of The New England Journal of Medicine, Shenton ME, Kikinis R, Jolesz FA, Pollak SD, LeMay M, Wible CG, Hokama H, Martin J, Metcalf D, Coleman M, McCarley RW, 327, 602, 1992, Copyright (1992), Massachusetts Medical Society.] 

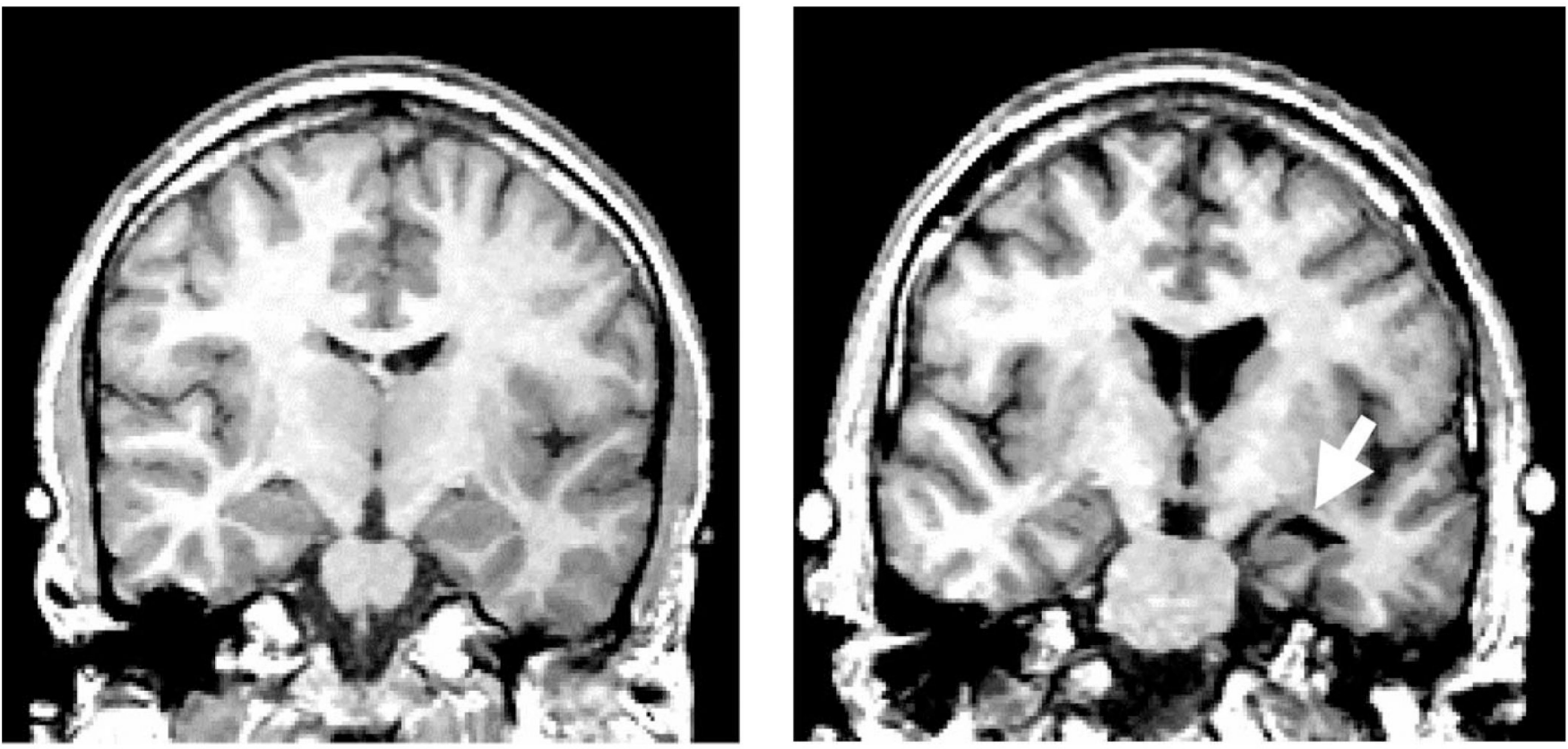

Fig. 4.

Coronal 1.5-mm slice of a normal control (left panel) and a schizophrenic patient (right panel). Note the increased CSF (black) in the left Sylvian fissure in the patient image (right panel, viewer's right), as well as the increased CSF in the left temporal horn which surrounds the amygdala (see white arrow), and tissue reduction in the left superior temporal gyrus. The lateral ventricles are also enlarged in the patient image as can be seen by the black CSF regions in the center of the image. Contrast this with the slice at approximately the same neuroanatomical level for the normal control (left panel). [Reprinted with permission of The New England Journal of Medicine, Shenton ME, Kikinis R, Jolesz FA, Pollak SD, LeMay M, Wible CG, Hokama H, Martin J, Metcalf D, Coleman M, McCarley RW, 327, 602, 1992, Copyright (1992), Massachusetts Medical Society.] 


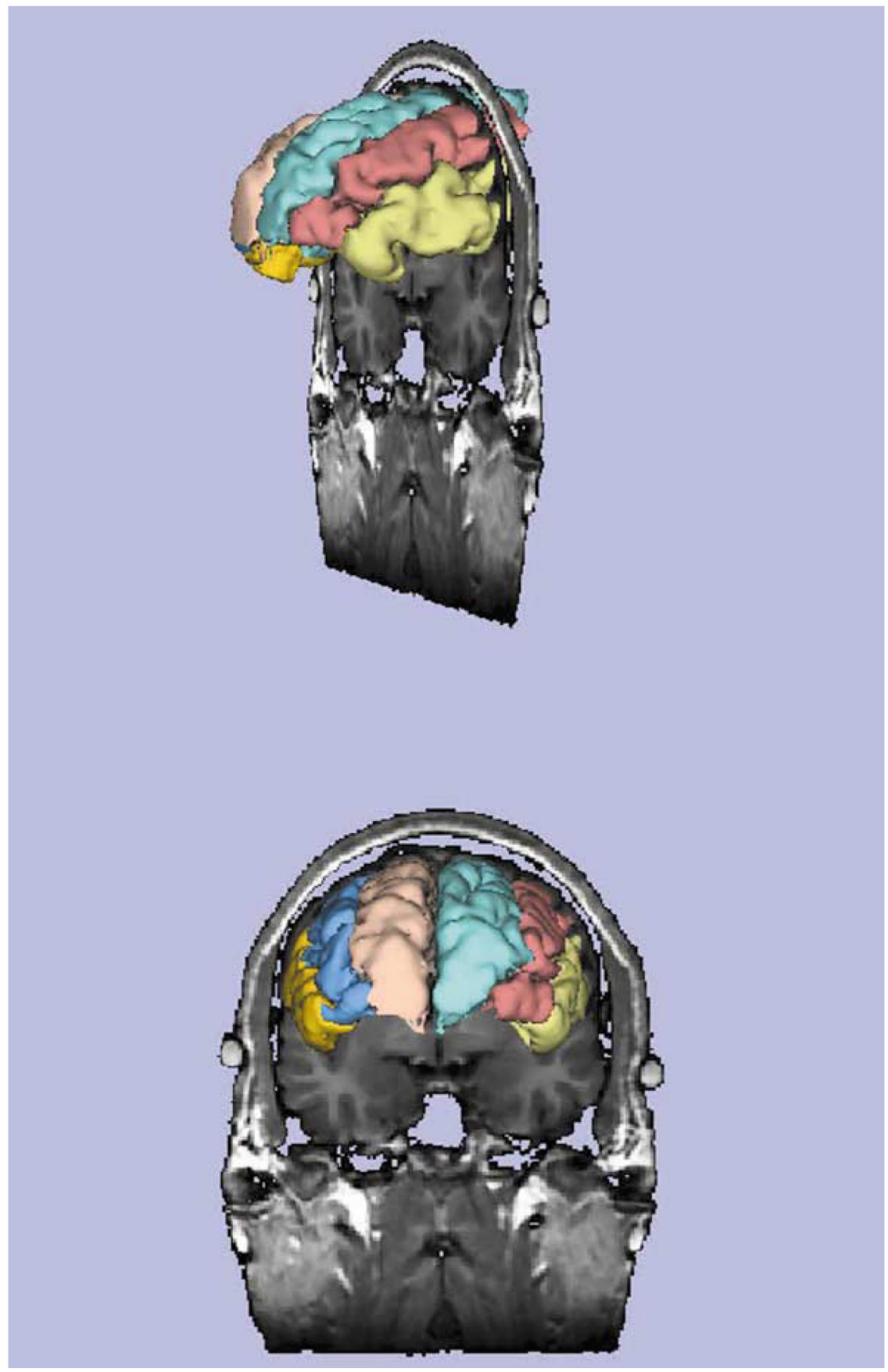

Fig. 5.

3D surface rendering of the superior, middle and frontal lobe gyri is shown along with a coronal $1.5-\mathrm{mm}$ slice that illustrates the relationship of the gyri to the coronal slice. The side view depicts the gyri just at the beginning of the amygdala (top), and the front view (bottom) shows the same slice and 3D reconstruction but in a different orientation. Superior frontal (flesh/aqua color), middle frontal (blue/peach color), and inferior frontal (gold/yellow) gyri are depicted. [Courtesy of Aleksandra Ciszewski, B.A. and Marianna Jakab, M.S., Clinical Neuroscience Division, Laboratory of Neuroscience, Department of Psychiatry, and Surgical Planning Laboratory, Department of Radiology, Harvard Medical School.] 


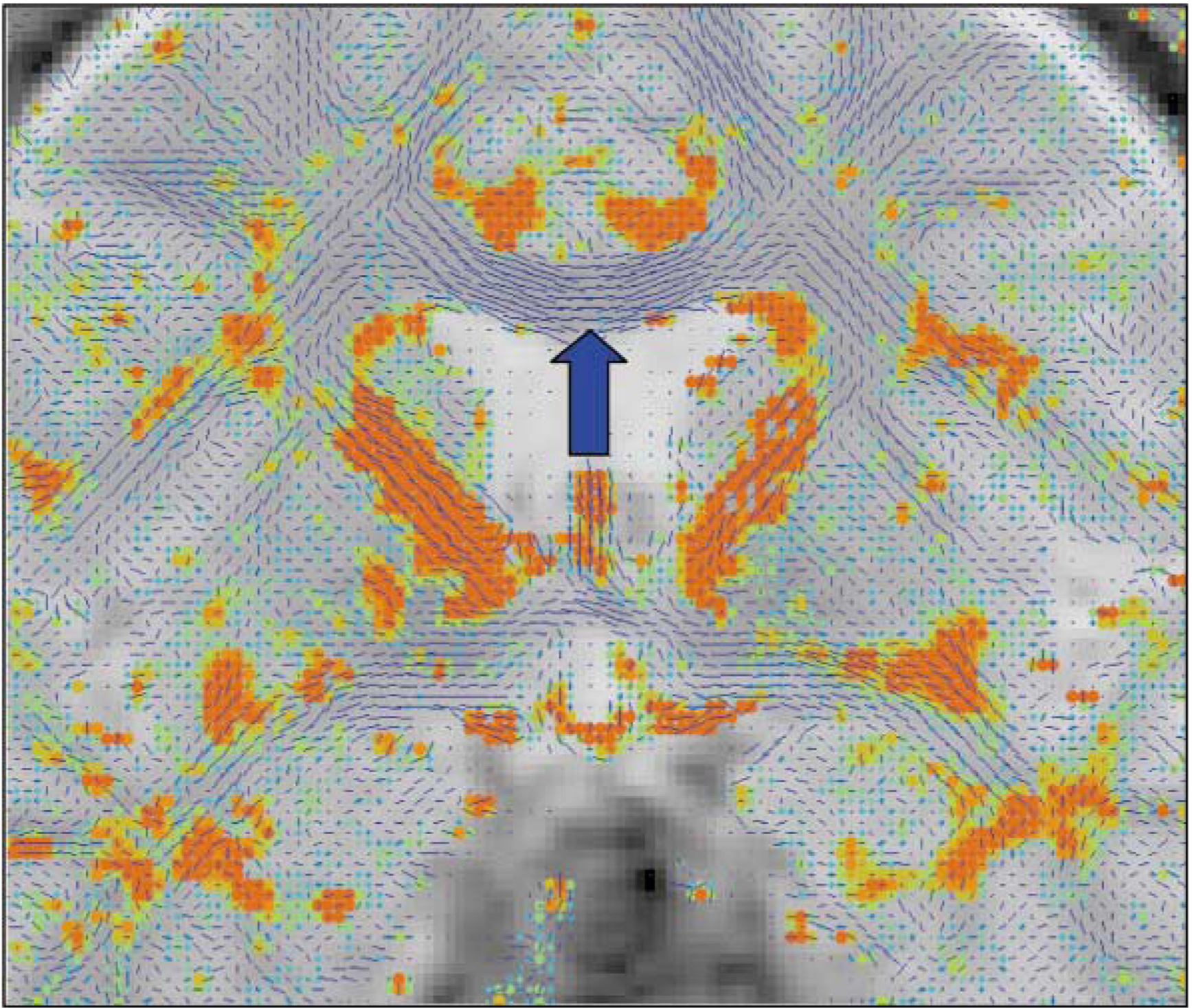

Fig. 6.

MR brain diffusion tensor image map of a normal control subject. The diffusion tensor map is displayed as eigenvectors with the blue lines representing the direction of the in-plane components of each eigenvector which correspond to the largest eigenvalue. Note the orientation of the fibers in the corpus callosum which can be readily appreciated. In gray matter, where spherical diffusion is predominant, the eigenvectors points in a random direction. The displayed lines corresponding to the largest eigenvectors are also very short. Harder to visualize are the green and orange colored dots, where the in- and out-of-plane components of the largest eigenvector barely exceed threshold. This figure demonstrates the possibilities that this new technology affords. We call particular attention to the white matter fiber tracts of the corpus callosum, because we think they strongly illustrate the power of this technique in visualizing heretofore unseen fiber tracts in vivo. [Courtesy of Marek Kubicki, M.D., PhD, Clinical Neuroscience Division, Laboratory of Neuroscience, Department of Psychiatry, and Surgical Planning Laboratory, Department of Radiology, Harvard Medical School.] 


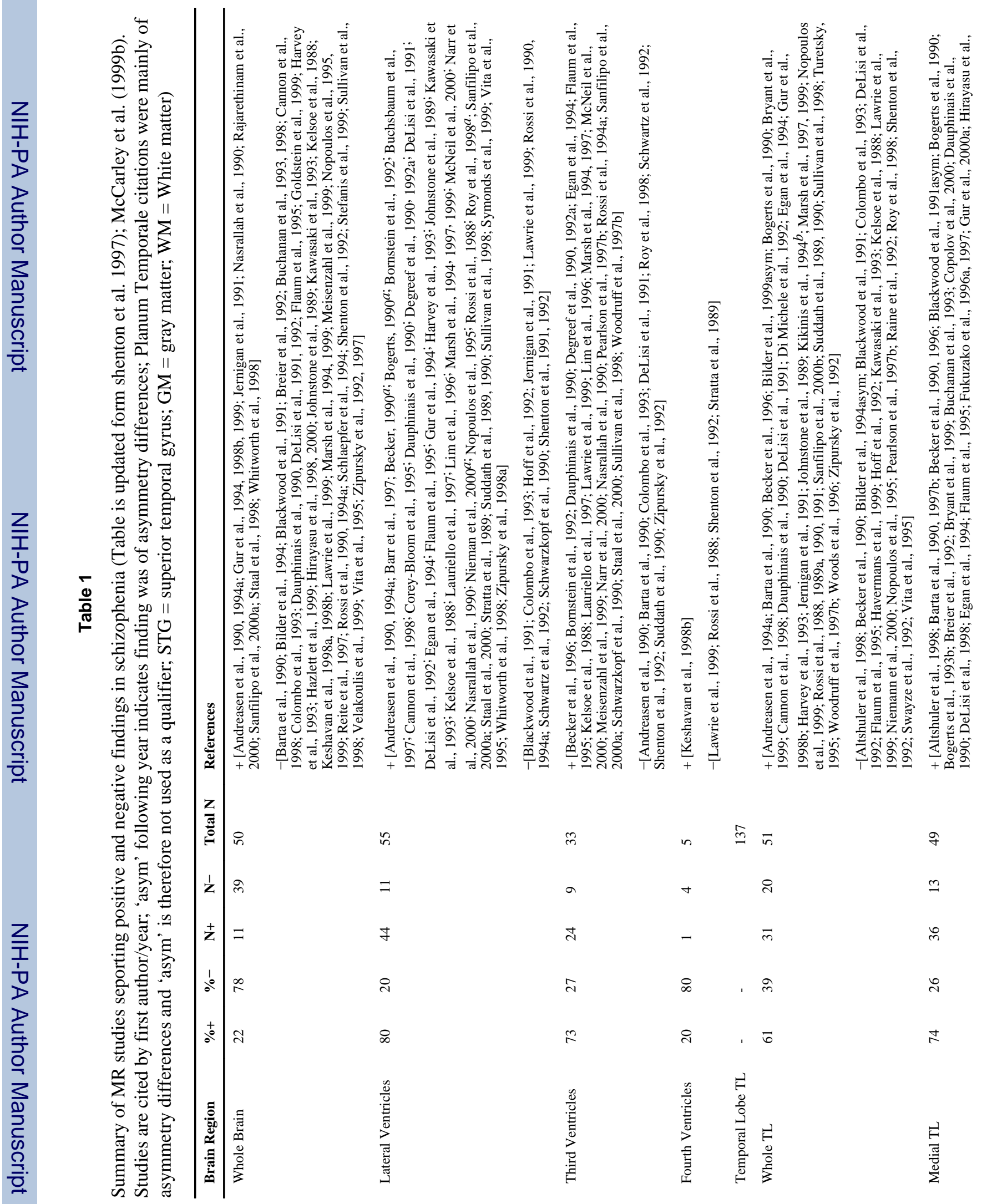




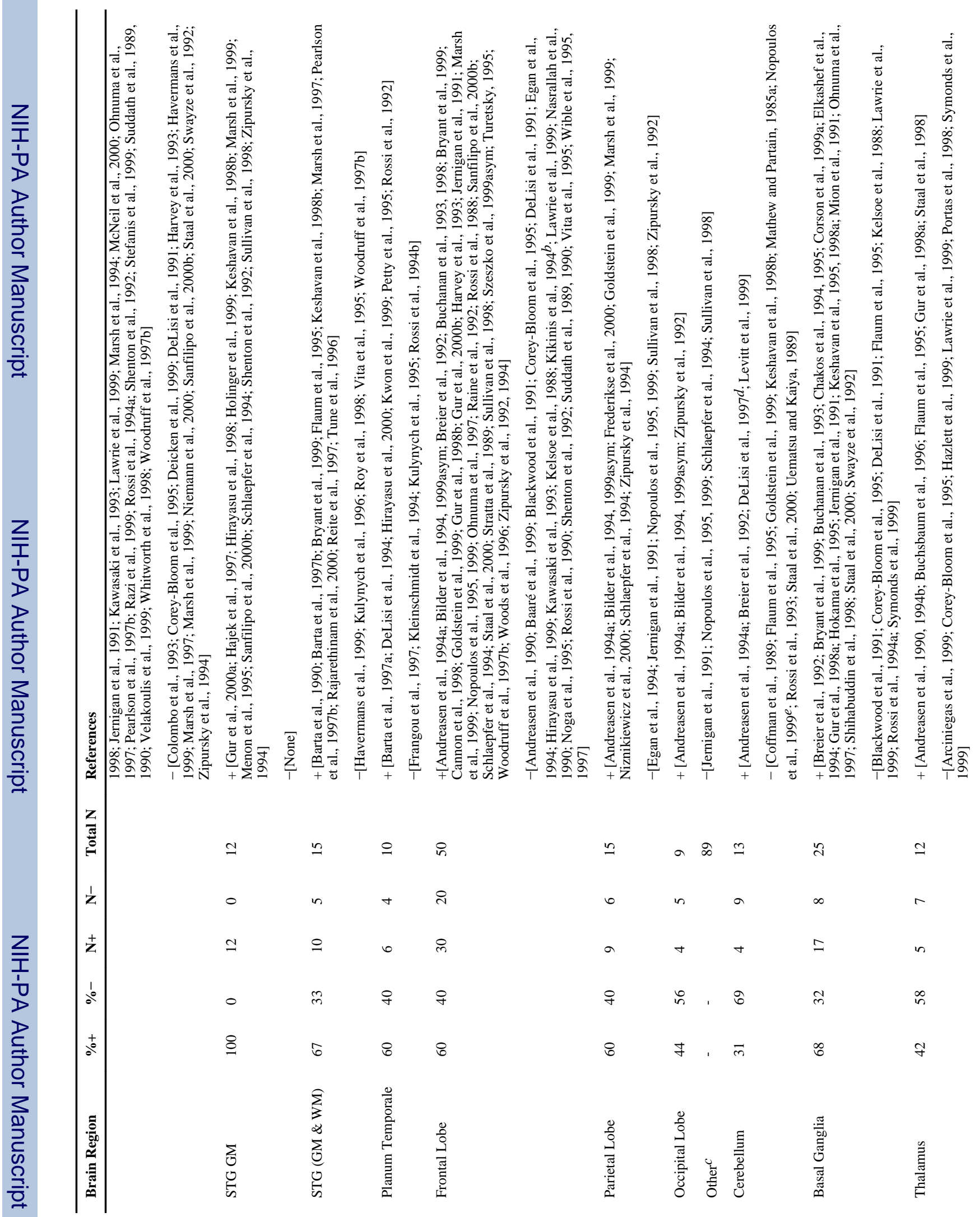




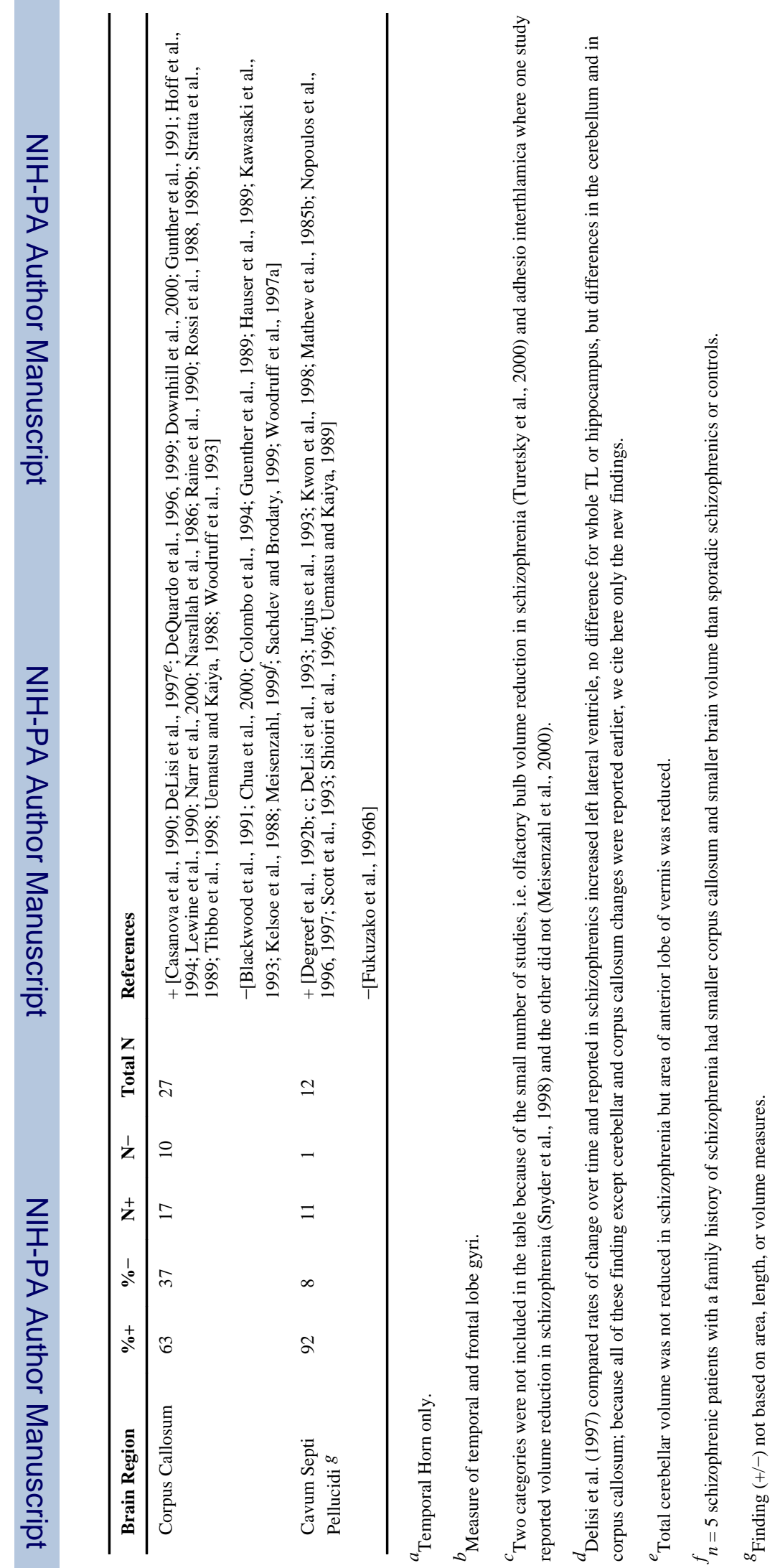




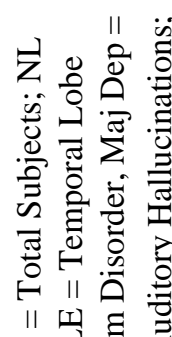

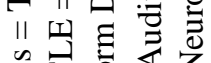

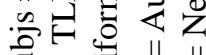

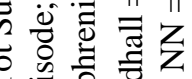

商 总完:

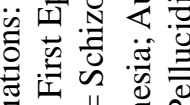

II II

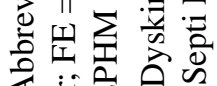

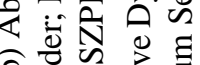

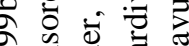

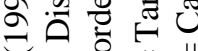

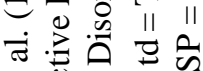

屯 可记

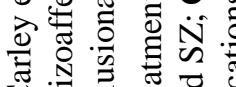

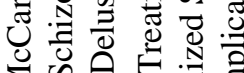

$\sum$ य $\|$ ॥ี

๙

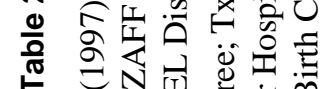

院

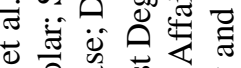

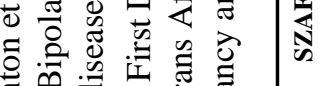

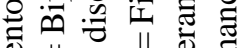

¿

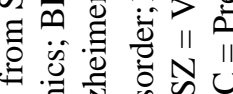

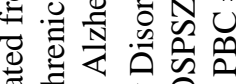

帘

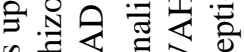

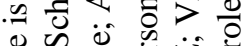

थ

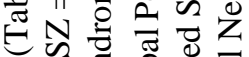

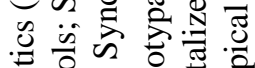

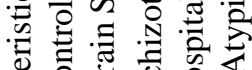

过司卷

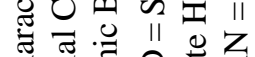

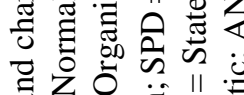

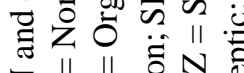

Z $\|$ ".

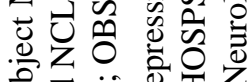

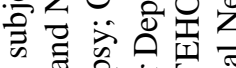

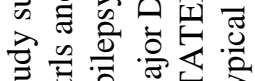

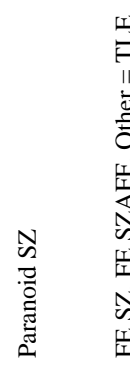

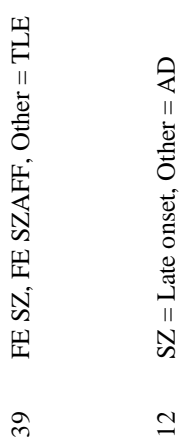

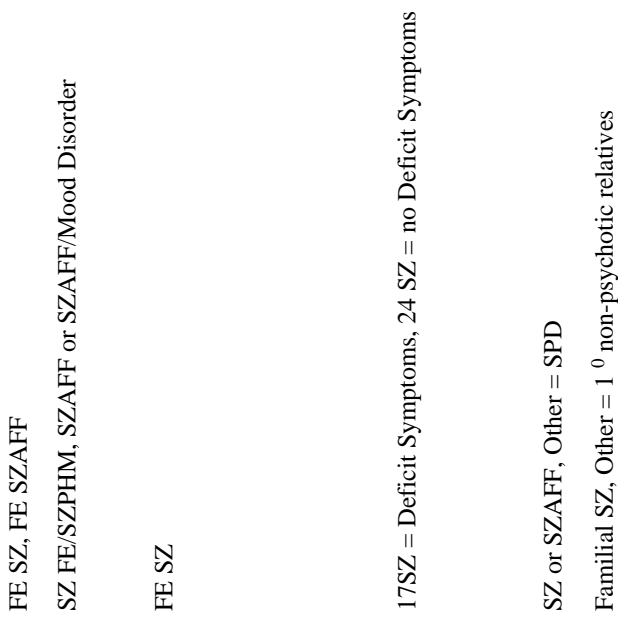

$\simeq 8$

$\simeq \bar{\infty}$

$\simeq$

I

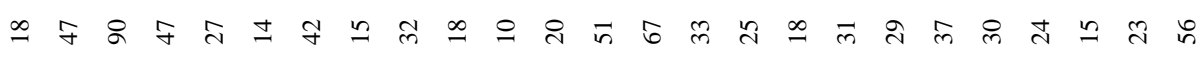

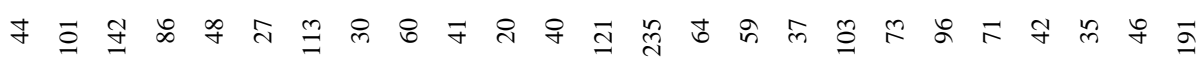

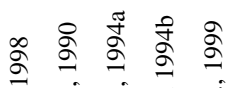

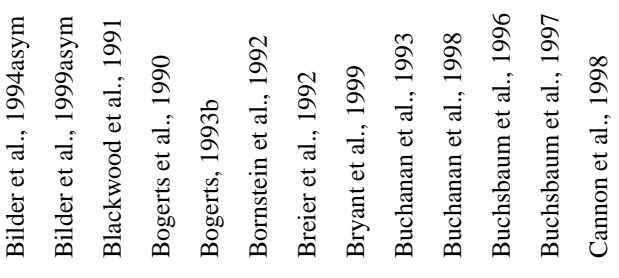




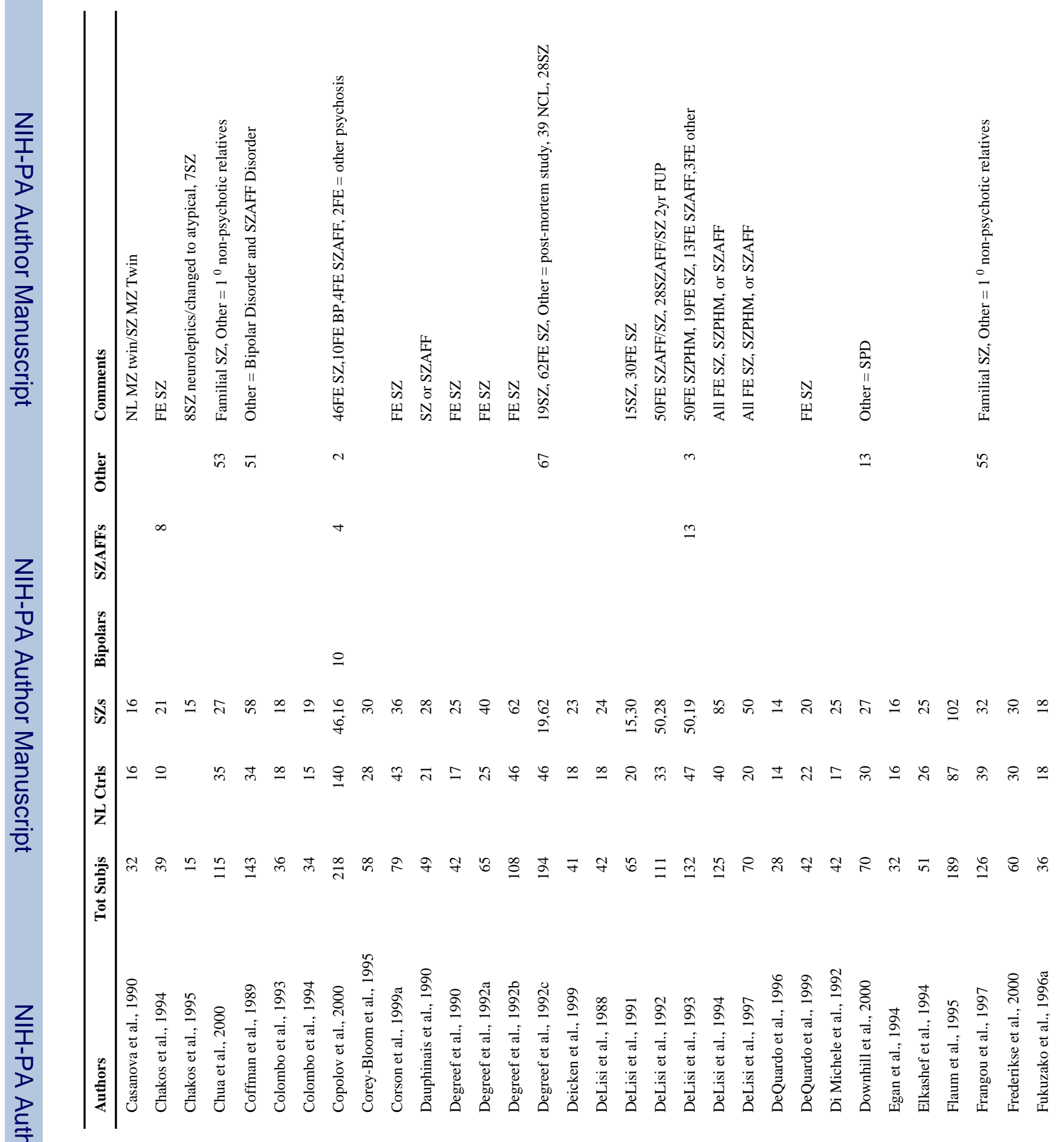




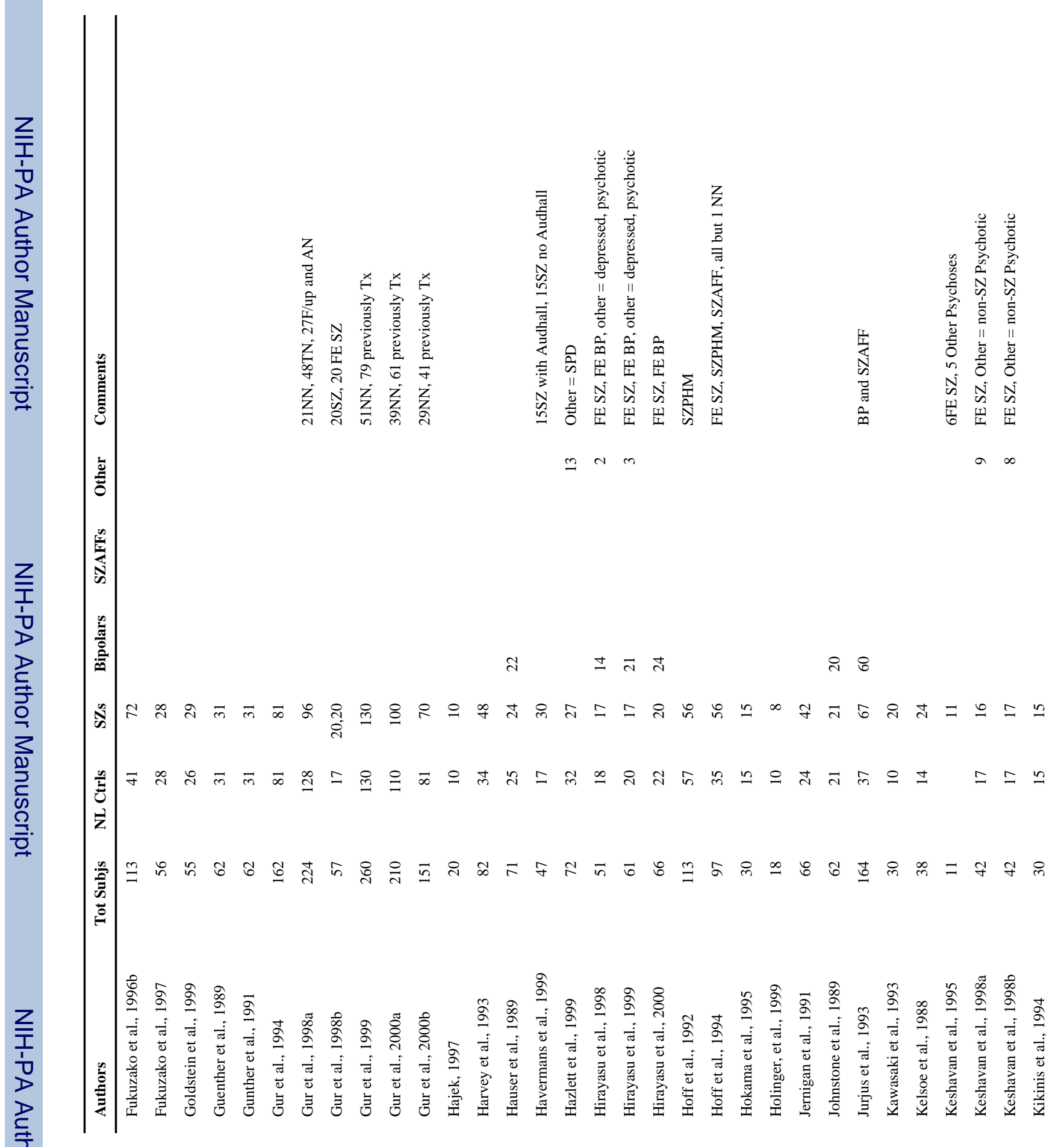




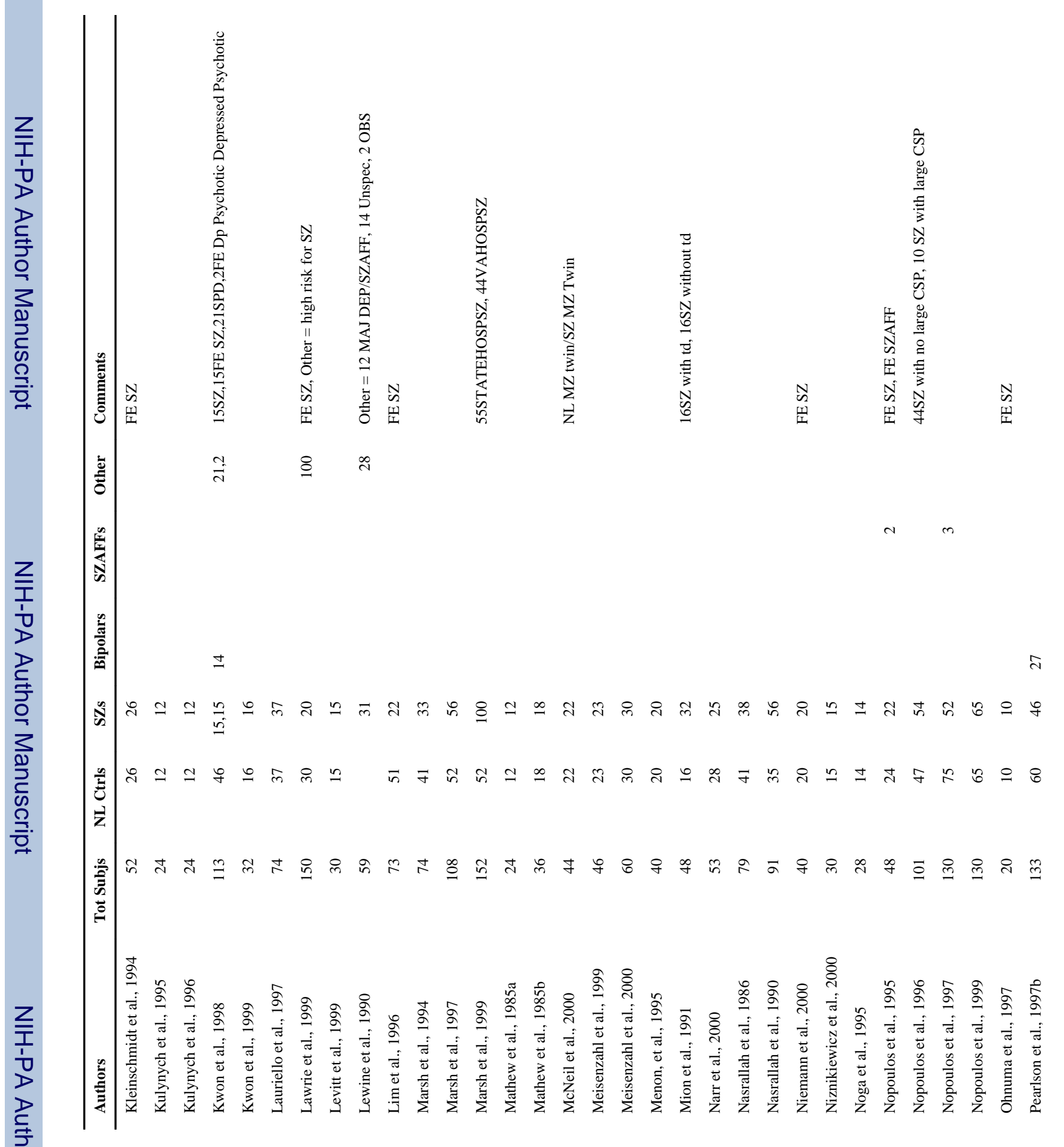




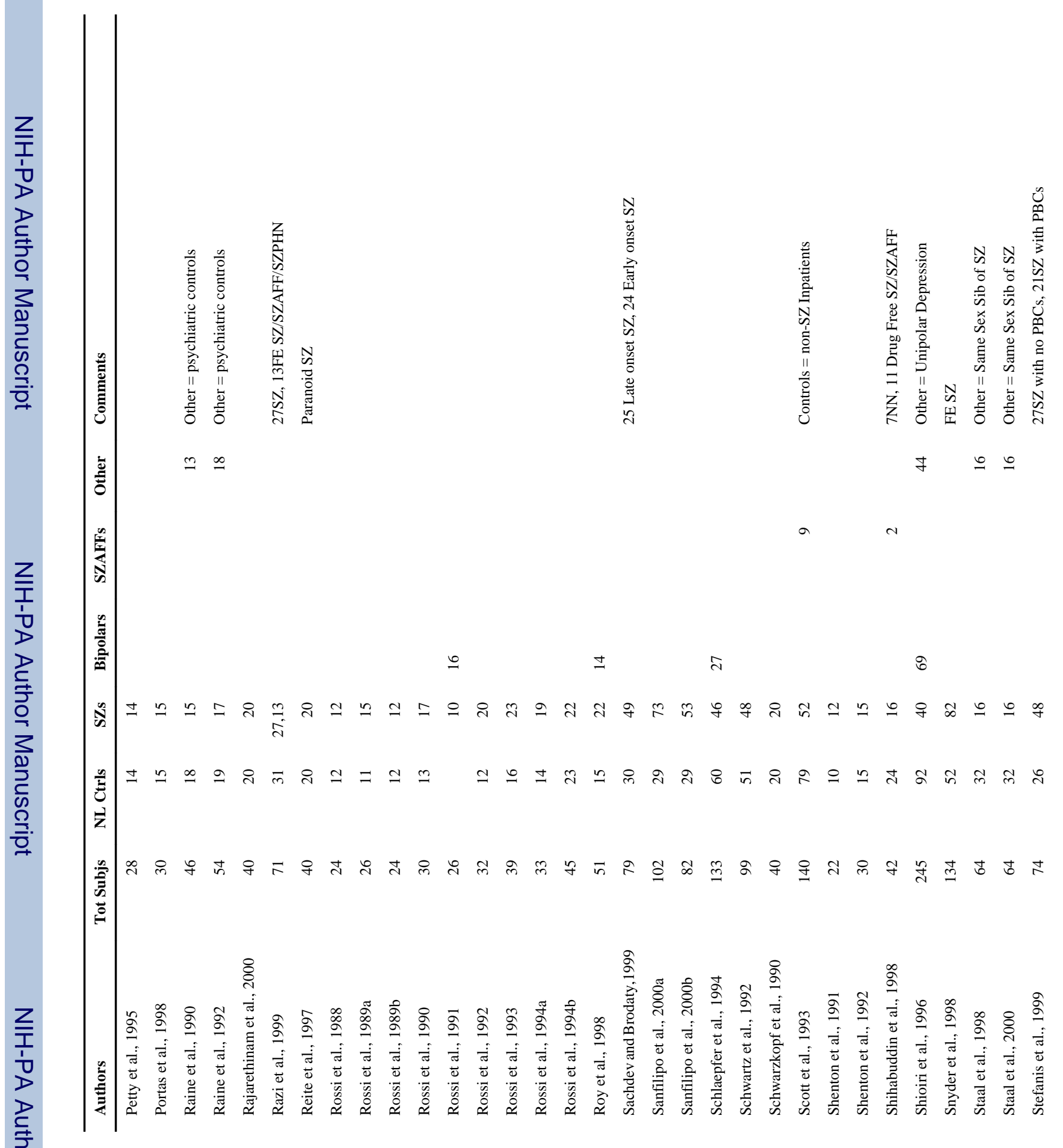




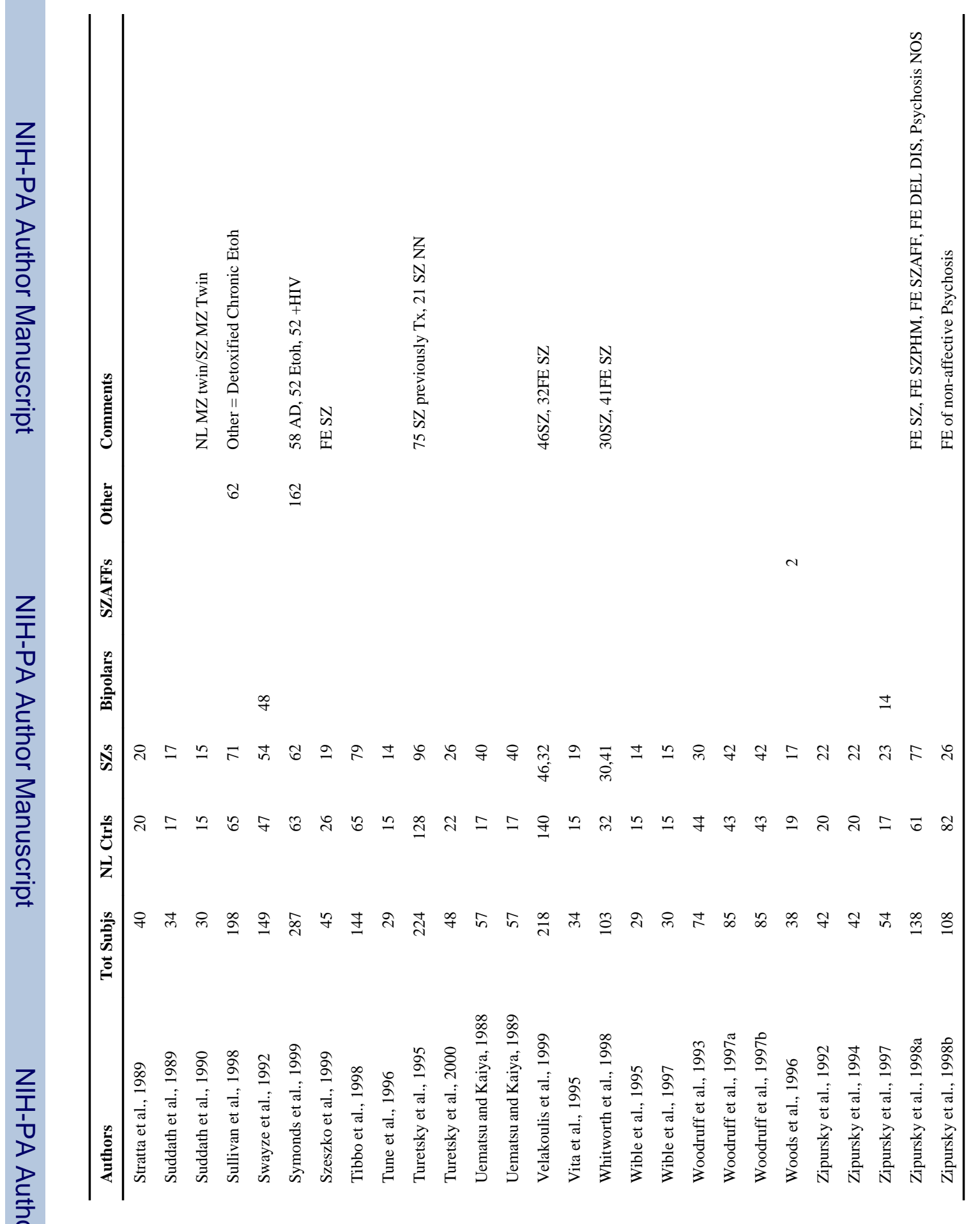


Table 3

Medial temporal lobe findings in schizophrenia. SZ = Schizophrenia; $\mathrm{PHG}=$ Parahippocampal Gyrus; AMYGHIPP = Amygdala-Hippocampal Complex; PBC = Pregnancy and Birth Complications

\begin{tabular}{|c|c|}
\hline Author(s) & Findings \\
\hline Altshuler et al., 1998 & $\downarrow$ HIPP volume in SZ, but AMYG $\uparrow$ in Bipolar Disorder \\
\hline Barta et al., 1990 & $\downarrow$ Left AMYG (did not measure HIPP) \\
\hline Barta et al., 1997b & $\downarrow$ Left AMYG (did not measure HIPP) \\
\hline Becker et al., 1990 & $\downarrow$ HIPP and PHG \\
\hline Becker et al., 1996 & $\downarrow$ HIPP \\
\hline Blackwood et al., 1991 & $\begin{array}{l}\text { Left }<\text { Right AMYG in controls, no such asymmetry noted in SZs, also asymmetry } \\
\text { differences in PHG between groups }\end{array}$ \\
\hline Bogerts et al., 1990 & $\downarrow$ Left Posterior HIPP; $\downarrow$ Total Left AMYG-HIPP Complex (Male FE SZ) \\
\hline Bogerts et al., 1993b & $\downarrow$ Posterior Portion of AMYG-HIPP (20\% Left; 15\% Right) (Chronic SZ) \\
\hline Brier et al., 1992 & $\downarrow$ AMYG Bilaterally; $\downarrow$ Left HIPP \\
\hline Bryant et al., 1999 & $\downarrow$ AMYG-HIPP Complex \\
\hline Buchanan et al., 1993 & $\downarrow$ AMYG-HIPP Complex \\
\hline Colombo et al., 1993 & No differences in the HIPP \\
\hline Copolov et al., 2000 & $\downarrow$ HIPP in FE SZ \\
\hline Corey-Bloom et al., 1995 & $\begin{array}{l}\text { No difference in mesial temporal lobe gray matter (included AMYG-HIPP Complex } \\
\text { and PHG) }\end{array}$ \\
\hline Dauphinais et al., 1990 & $\downarrow$ Right AMYG-HIPP Complex and $\downarrow$ Right PHG \\
\hline Deicken et al., 1999 & No difference in HIPP but $\downarrow$ NAA in HIPP bilaterally \\
\hline DeLisi et al., 1988 & $\downarrow$ AMYG-HIPP Complex and PHG bilaterally; trend $\downarrow$ Left AMYG-HIPP Complex \\
\hline DeLisi et al., 1991 & No difference in AMYG-HIPP Complex or PHG \\
\hline Egan et al., 1994 & $\downarrow$ AMYG-HIPP Complex, especially on the Left \\
\hline Flaum et al., 1995 & $\downarrow$ HIPP \\
\hline Fukuzako et al., 1996a & $\downarrow$ HIPP \\
\hline Fukuzako et al., 1997 & $\downarrow$ HIPP \\
\hline Gur et al., 2000a & $\downarrow$ HIPP gray matter in men and women; $\downarrow$ AMYG in men, but $\uparrow$ in women \\
\hline Harvey et al., 1993 & No Difference AMYG-HIPP Complex \\
\hline Havermans et al., 1999 & No difference in Anterior AMYG-HIPP or in PHG \\
\hline Hirayasu et al., 1998 & $\downarrow$ Left Posterior AMYG-HIPP in both FE schizophrenics and in FE Bipolar patients \\
\hline Jernigan et al., 1991 & $\downarrow$ AMYG, HIPP, and PHG \\
\hline Kawasaki et al., 1993 & $\downarrow$ Left PHG but no difference in AMYG-HIPP Complex \\
\hline Lawrie et al., 1999 & $\downarrow$ AMYG-HIPP Complex in FE SZ \\
\hline Marsh et al., 1994 & $\downarrow$ Bilaterally in AMYG, HIPP, and AMYG-HIPP Complex \\
\hline Marsh et al., 1997 & No Difference HIPP \\
\hline Marsh et al., 1999 & No Difference HIPP \\
\hline McNeil et al., 2000 & $\begin{array}{l}\downarrow \text { HIPP bilaterally in patients with PBCs, and Left HIPP } \downarrow \text { correlated with longer } \\
\text { labor }\end{array}$ \\
\hline Niemann et al., 2000 & No Difference in AMYG or in HIPP \\
\hline Ohnuma et al., 1997 & $\downarrow$ Left HIPP and Left PHG \\
\hline Pearlson et al., 1997b & $\downarrow$ Right AMYG and $\downarrow$ Entorhinal Cortex in SZ and $\downarrow$ Left AMYG in Bipolar patients \\
\hline Razi et al., 1999 & $\downarrow$ PHG, particularly on the Left \\
\hline
\end{tabular}




\begin{tabular}{ll}
\hline Author(s) & Findings \\
\hline Rossi et al., 1994a & $\downarrow$ AMYG-HIPP Complex, particularly on the Left \\
Sanfilipo et al., 2000b & No Difference in HIPP or PHG (Prefrontal GM correlated with (-) Symptoms) \\
Shenton et al., 1992 & $\begin{array}{l}\downarrow \text { Left Anterior portion of the AMYG-HIPP Complex, } \downarrow \text { PHG bilaterally, but more } \\
\text { on the Left }\end{array}$ \\
Staal et al., 2000 & No Difference in AMYG, HIPP, or PHG \\
Stefanis et al., 1999 & $\begin{array}{l}\downarrow \text { Left HIPP in SZ with severe PBCs and no family history of SZ, but not in familial } \\
\text { cases of SZ; } \downarrow \text { HIPP correlated with earlier age of onset }\end{array}$ \\
Suddath et al., 1989 & $\begin{array}{l}\downarrow \text { Temporal Lobe Gray matter in central sections corresponding anatomically to } \\
\text { portions of the temporal lobe that contain the AMYG-HIPP Complex }\end{array}$ \\
Suddath et al., 1990 & $\downarrow$ HIPP \\
Swayze et al., 1992 & No Difference AMYG or HIPP \\
Velakoulis et al., 1999 & $\begin{array}{l}\downarrow \text { HIPP in Chronic and FE SZ; } \downarrow \text { Left HIPP in both FE SZs and FE Affective Psychotic } \\
\text { patients ( } \downarrow \text { Right HIPP correlated with age and illness duration in Chronic SZ) }\end{array}$ \\
Whitworth et al., 1998 & $\downarrow$ Posterior portion of the AMYG-HIPP Complex in Chronic and FE SZ \\
Woodruff et al., 1997b & $\downarrow$ Left HIPP \\
Zipursky et al., 1994 & No Difference HIPP \\
\hline
\end{tabular}


Table 4

First episode MRI studies listed by brain region of interest, author (year), and positive or negative findings (Abbreviations: asym = Asymmetry; $\mathrm{Chr} \mathrm{SZ} \mathrm{=} \mathrm{Chronic} \mathrm{Schizophrenic;} \mathrm{LAT} \mathrm{=} \mathrm{Lateral} \mathrm{Ventricle;} \mathrm{PHG} \mathrm{=}$ Parahippocampal Gyrus; Neurol.= Neuroleptic; Tx = Treatment)

\begin{tabular}{|c|c|c|}
\hline Brain Region & References & \\
\hline \multirow[t]{8}{*}{ Whole Brain } & +James et al., $1999^{a}$ & -Bilder et al., 1994 (asym) \\
\hline & & -DeLisi et al., 1991, 1992 \\
\hline & & -Hirayasu et al., 1998, 2000 \\
\hline & & -Keshavan et al., 1998a, ${ }^{\text {b }}$ \\
\hline & & -Lawrie et al., 1999 \\
\hline & & -Nopoulos et al., 1995 \\
\hline & & -Velakoulis et al., 1999 \\
\hline & & $\begin{array}{l}\text {-Whitworth et al., } 1998 \text { ( } \downarrow \\
\text { Chr SZ) }\end{array}$ \\
\hline \multirow[t]{5}{*}{ Gray Matter } & +Gur et al., 1999 & \\
\hline & +Lim et al., 1996 & \\
\hline & +Ohnuma et al., 1997 (Cortical Gray Matter) & \\
\hline & $\begin{array}{l}\text { +Zipursky et al., 1998a (Gray Matter, includes } \\
\text { Basal Ganglia) }\end{array}$ & \\
\hline & +Zipursky et al., 1998b (Cortical Gray Matter) & \\
\hline \multirow[t]{14}{*}{ Ventricles } & +Barr et al., 1997 & -DeLisi et al., 1992 \\
\hline & +Bogerts et al., $1990^{b}$ & $\begin{array}{l}\text {-Lawrie et al., } 1999 \text { (LAT } \\
\text { and 4th) }\end{array}$ \\
\hline & +Degreef et al., 1990, 1992a & -Niemann et al., 2000 \\
\hline & +DeLisi et al., 1991, 1998 & -Ohnuma et al., 1997 \\
\hline & +Hoff et al., 1992 & \\
\hline & +James et al., 1999 & \\
\hline & +Keshavan et al., 1998b & \\
\hline & +Lawrie et al., 1999 (3rd ventricle) & \\
\hline & +Lieberman et al., $1993^{c}$ & \\
\hline & +Lim et al., 1996 & \\
\hline & +Nopoulos et al., 1995 & \\
\hline & +Snyder et al., 1998 & \\
\hline & +Whitworth et al., 1998 & \\
\hline & +Zipursky et al., 1998a & \\
\hline \multirow[t]{6}{*}{ Temporal Lobe (Whole) } & +Bilder et al., 1999 (asym) & -Bilder et al., 1994 (asym) \\
\hline & +Bogerts et al., 1990 & -Hoff et al., 1992 \\
\hline & +DeLisi et al., 1991 & -Lawrie et al., 1999 \\
\hline & +Gur et al., 1998b & -Niemann et al., 2000 \\
\hline & +Gur et al., 2000a (Temporal Pole) & -Nopoulos et al., 1995 \\
\hline & & -Ohnuma et al., 1997 \\
\hline $\begin{array}{l}\text { Medial Temporal Lobe } \\
\text { Structures }\end{array}$ & +Bogerts et al., 1990 & -DeLisi et al., 1991 \\
\hline
\end{tabular}




\begin{tabular}{|c|c|c|}
\hline Brain Region & References & \\
\hline \multirow{4}{*}{$\begin{array}{l}\text { (Amygdala-hippocampal } \\
\text { Complex measured together) }\end{array}$} & +Hirayasu et al., 1998 & \\
\hline & +Lawrie et al., 1999 & \\
\hline & +Lieberman et al., $1993^{c}$ & \\
\hline & +Whitworth et al., 1998 & \\
\hline \multirow[t]{3}{*}{ Superior Temporal Gyrus } & +Gur et al., 2000a (males only) & \\
\hline & +Hirayasu et al., 1998 & \\
\hline & +Keshavan et al., 1998b & \\
\hline \multirow[t]{4}{*}{ Planum Temporale } & +DeLisi et al., 1994 & -Kleinschmidt et al., 1994 \\
\hline & +Hirayasu et al., 2000 & \\
\hline & $\begin{array}{l}\text { +Hoff et al., } 1992 \text { (abnormal asymmetry, } \\
\text { lateral sulcus in females) }\end{array}$ & \\
\hline & +Kwon et al., 1999 & \\
\hline \multirow[t]{8}{*}{ Hippocampus } & +Bilder et al., 1995 & -DeLisi et al., 1991 \\
\hline & +Bogerts et al., 1990 (males only) & -Niemann et al., 2000 \\
\hline & +Copolov et al., 2000 & \\
\hline & +Gur et al., 2000a & \\
\hline & +Hirayasu et al., 1998 & \\
\hline & +Ohnuma et al., 1997 & \\
\hline & +Velakoulis et al., 1999 & \\
\hline & +Whitworth et al., 1998 & \\
\hline \multirow[t]{4}{*}{ Amygdala } & +Gur et al., 2000a ( $\uparrow$ females, $\downarrow$ males) & -Bilder et al., 1995 \\
\hline & & -DeLisi et al., 1991 \\
\hline & & -Niemann et al., 2000 \\
\hline & & -Ohnuma et al., 1997 \\
\hline \multirow[t]{2}{*}{ Parahippocampus } & +Bogerts et al., 1990 & \\
\hline & +Ohnuma et al., 1997 & $\begin{array}{l}\text {-Razi et al., } 1999 \text { (PHG } \downarrow \text { Chr } \\
\text { SZ) }\end{array}$ \\
\hline \multirow[t]{5}{*}{ Frontal Lobe (Whole) } & +Bilder et al., 1994, 1999 (asym) & -DeLisi et al., 1991 \\
\hline & + Gur et al., 1998b, 2000b ${ }^{d}$ & -Hirayasu et al., 1999 \\
\hline & +Ohnuma et al., 1997 & -Lawrie et al., 1999 \\
\hline & +Nopoulos et al., 1995 & \\
\hline & +Szeszko et al., 1999 & \\
\hline Premotor & +Bilder et al., 1994 (asym) & -Bilder et al., 1999 (asym) \\
\hline Prefrontal & +Bilder et al., 1994, 1999 (asym) & \\
\hline Cingulate & +Ohnuma et al., 1997 & -Hirayasu et al., 1999 \\
\hline Sensorimotor & & -Bilder et al., 1999 (asym) \\
\hline Parietal Lobe & & -Nopoulos et al., 1995 \\
\hline Occipital Lobe & & -Nopoulos et al., 1995 \\
\hline Occipitoparietal & +Bilder et al., 1994, 1999 (asym) & \\
\hline \multirow[t]{3}{*}{ Corpus Callosum } & +DeLisi et al., 1997 & -Ohnuma et al., 1997 \\
\hline & +DeQuardo et al., 1999 & \\
\hline & +Hoff et al., 1994 (females only) & \\
\hline
\end{tabular}




\begin{tabular}{lll}
\hline Brain Region & References & \\
\hline Cavum Septi Pellucidi & + Degreef et al., 1992b, c & \\
& + DeLisi et al., 1993 & \\
& + Kwon et al., 1998 & -DeLisi et al., 1991 \\
Basal Ganglia & + Chakos et al., 1994 & -Gur et al., 1998a (neurol. \\
& + naive) \\
& + Gur et al., 1998a (previously Tx) & -Lawrie et al., 1999 \\
& + Keshavan et al., 1995, 1998a & \\
& + Ohnuma et al., 1997 & \\
& + Shihabuddin et al., 1998e & -Lawrie et al., 1999 \\
Thalamus & + Gur et al., 1998a & \\
Adhesio Interthalamica & + Snyder et al., 1998 & -Keshavan et al., 1998b \\
Cerebellum & + DeLisi et al., 1997
\end{tabular}

${ }^{a}$ Study of childhood schizophrenia.

${ }^{b}$ Only temporal horn portion of lateral ventricle increased.

${ }^{c}$ Qualitative measures used.

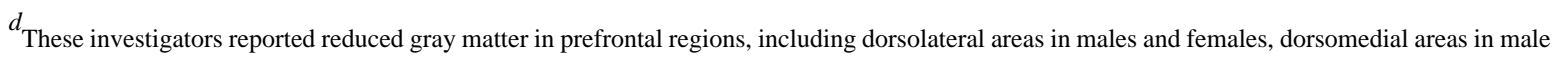
patients, and orbital regions in female patients.

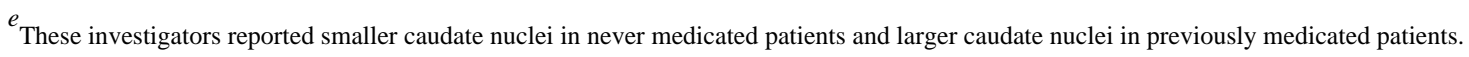




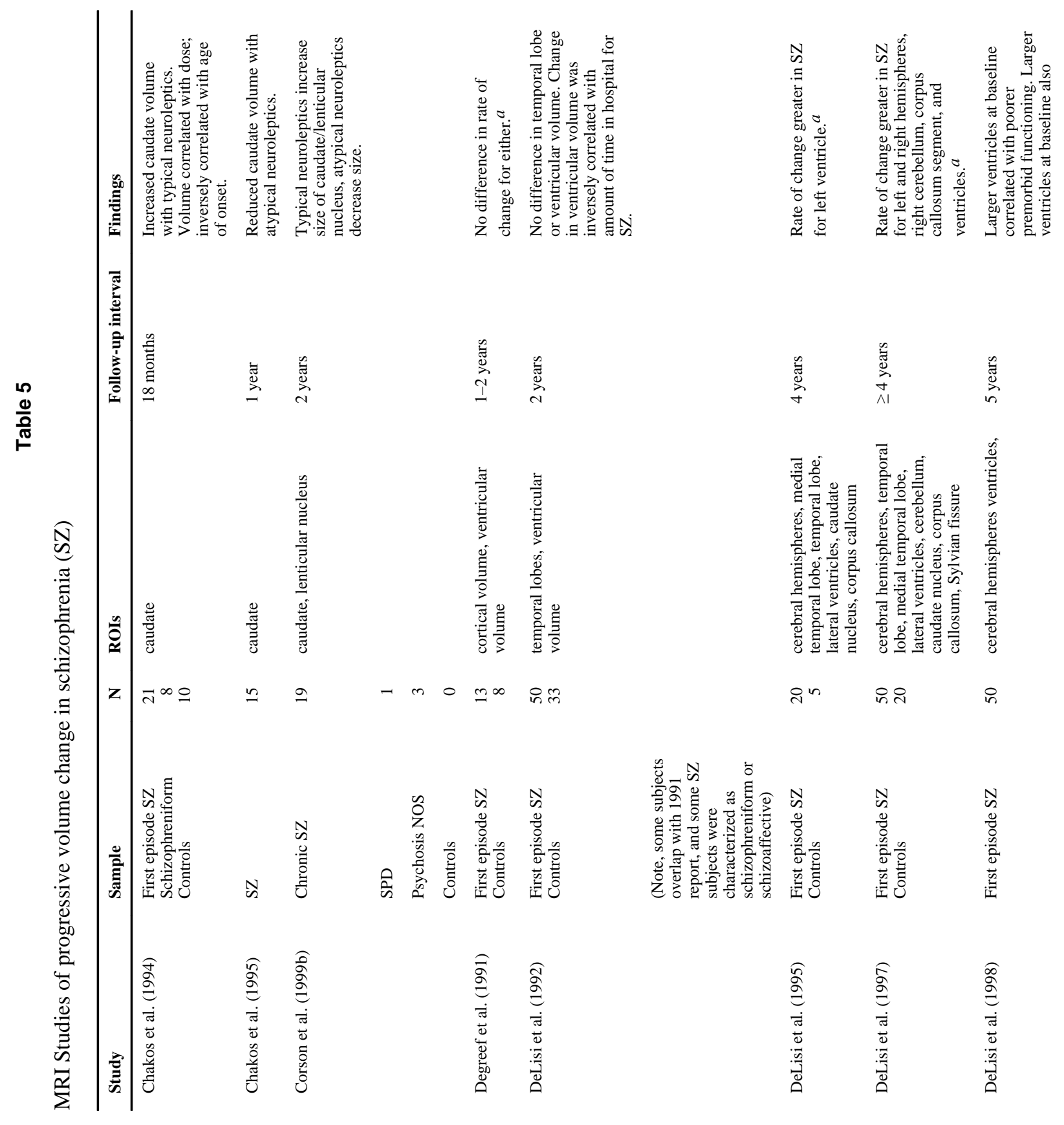


은

ชิ $\mathcal{7}$
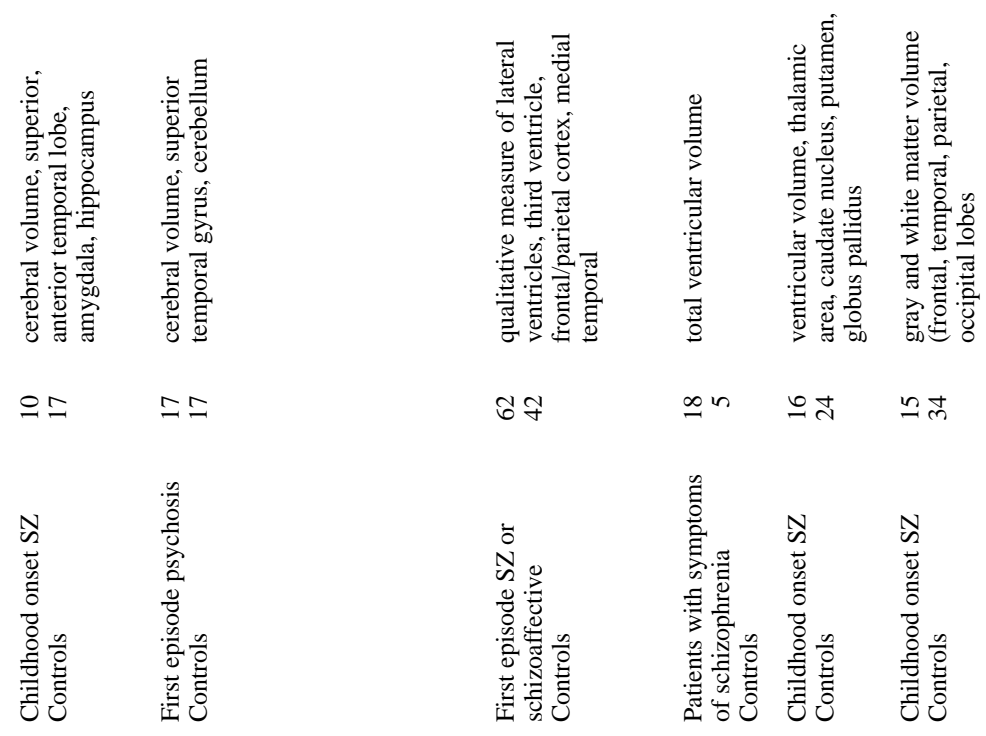

舟 눈
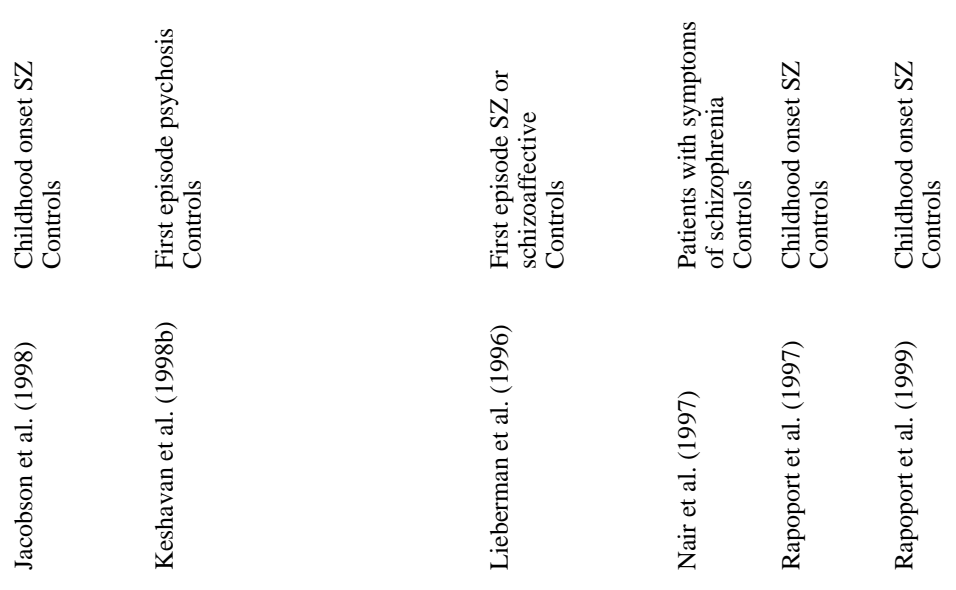

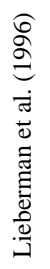

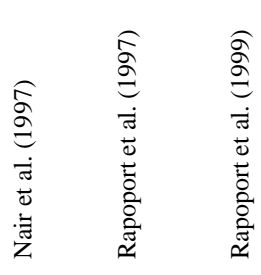

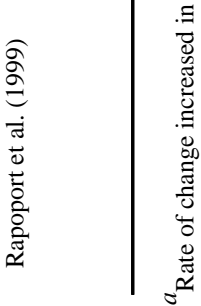

